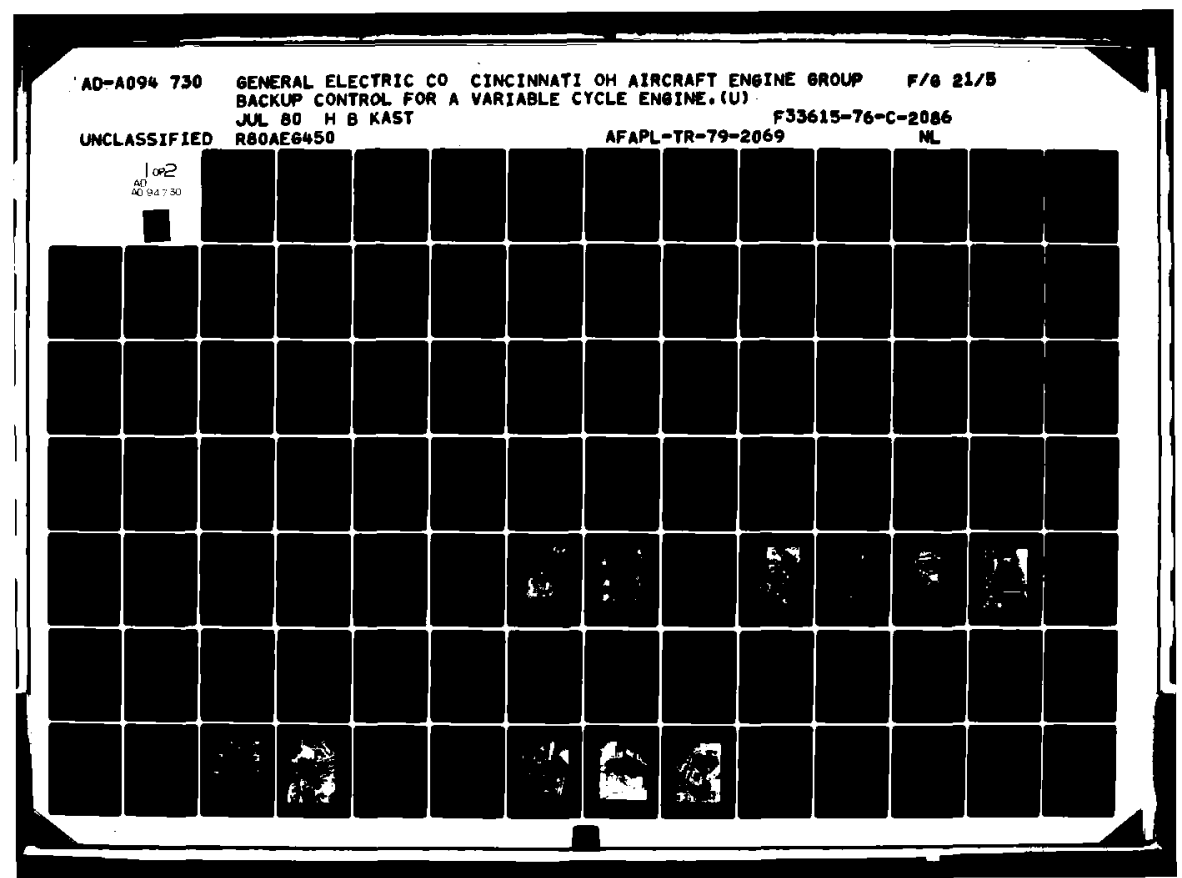


AFAPL-TR-79-2069
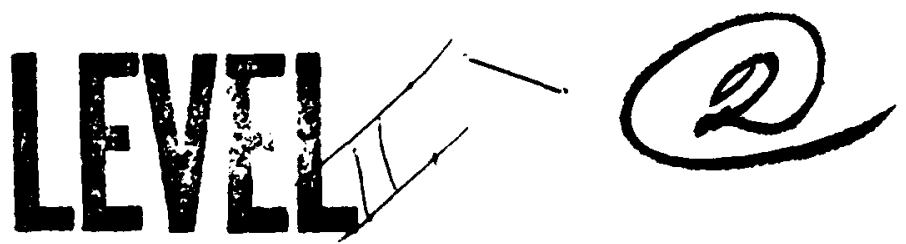

BACKUP CONTROL FOR A

VARIABLE CYCLE ENGINE

\section{Phase II Final Report}

N

$\nabla$ Howard B. Kast

O) General Electric Company

Aircraft Engine Group

Cincinnati, Ohio 45215

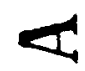

JULY 1980

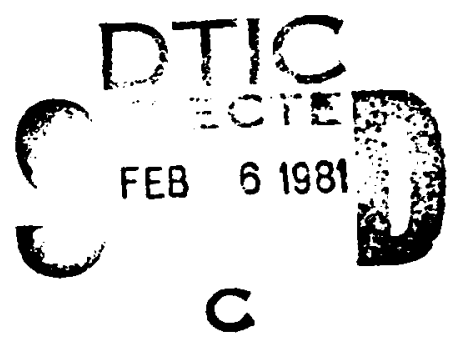

TECHNICAL REPORT AFAPL-TR-79-2069

Final Report For Period 1 September 1977 - 16 April 1979

Approved for Public Release; Distribution Unlimited

Aero Propulsion Laboratory

Air Force Wright Aeronautical Laboratories

Air Foree Systems Command

Wright-Patterson Air Force Base, Ohio 45433

:

Base, Ohio 45433 
When Government drawings, specifications. or other data are used for any purpose other than in connection with a definitely related Government procurement operation, the United States Government thereby incurs no responsibility nor any obligation whatsoever; and the fact that the government may have formulated, furnished, or in any way supplied the said drawings, specifications, or other data, is not to be regarded by iuplication or otherwise as in any manner licensing the holder or any other person or corporation, or conveying any rights or permission to manufacture use, or sell any patented invention that may in any way be related thereto.

This report has been reviewed by the office of Public Affairs (ASD/PA) and is releasable to the National Technical Information Service (NTIS). At NTIS, it will be available to the general public, including foreign nations.

This technical report has been reviewed and is approved for publication.

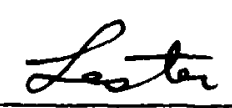

LESTER L. SMALL

Project Engineer

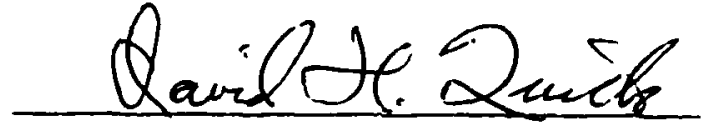

DAVID H. QUICK, Lt Co1, USAF Chief, Components Branch

FOR THE COMMANDER

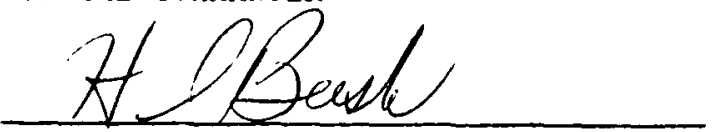

H. I. BUSH

Deputy Director

Turbine Engine Division

\footnotetext{
"If your address has changed, if you wish to be removed from our mailing list, or if the addressee is no longer employed by your organization please notify AFWAL/POTC, W-PAFB, OH 45433 to help us maintain a current mailing list".
}

Copies of this report should not be returned unless return is required by security considerations, contractual obligations, or notice on a specific document. 


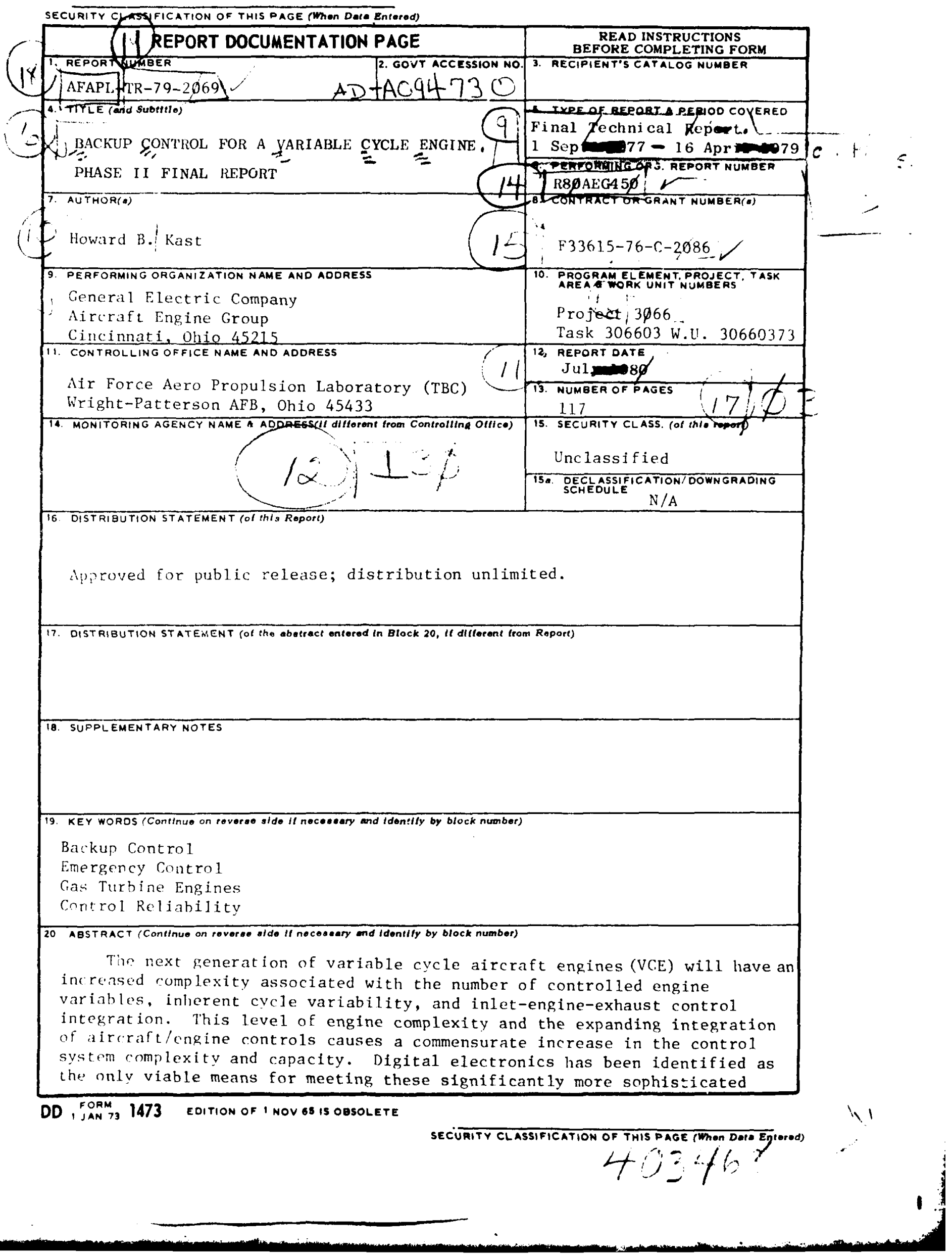


requirements of the future VCF. Although recent digital electronic advances promise new levels of reliability, this improvement is offset by the increased circuitry of the more complex control. Especially in the case of the single-engine aircraft, it is recognized that such variable cycle engines should be equipped with a Backup Control for emergency use.

The results of Phase I, the trade studies, of the Backup Control for a Variable Cycle Engine program were reported earlier in AFAPL-TR-77-92. The trade studies were based on a single-engine aircraft, the JTDE-23 engine, anc a full authority digital electronic primary control system. A minimum get-home capability was defined which included completing a takeoff, a minimum climb rate, deceleration from supersonic flight, windmill air start, minimum cruise range, wave-off, landing, and safe runway roll. Backup control requirements were determined using the YF-17 aircraft data for ihrust, the JTDE-23 engine computer model for the variables to be controlled, and the Fl01 engine and control model for transient performance. Seven backup control approaches were selected for consideration from a 1 ist of 48 possibilities. These approaches included hydromechanical, electrical, fluidic, and a combination of electrical/hyd:omechanical technologies. Reliability estimates were made on six controls, and estimated performance, volume, weight, cost analyses and preliminary design studies were made in more detail on three of these approaches. A recommended approach was selected, namely the hydromechanical backup control using speed demand and fuel flow scheduling. This selection was based on the above analyses and studies, together with a comparison of the technologies, a comparison of parallelversus series-type backup/primary control interface, and a tabulated evaluation of each backup control's advantages and disadvantages.

The recommended hydromechanical approach has been constructed, calibrated and evaluated in a test cell. These evaluations included transient operation and transfer from the primary control to the backup control and back to primary operation. Successful operation was achieved, providing test hardware which is intended for further validation through on-engine testing. 
This report describes a design effort conducted by the General Electric Company and sponsored by the Air Force Aero Propulsion Laboratory, Air Force Systems Command, Wright-Patterson AFB, Ohio, under Project 3066, Task 03 and Work Unjt 73 with Lester L. Small, APAPL/TBC, as Project Engineer.

The work reported herein was performed during the report period of September 1, 1977 to April 16, 1979. R. F. Anderson was the General Electric Program Manager; the technical work was performed under the direction of Howard B. Kast, Engineering Manager. The Engineering Manager was assisted by James E. Hurtle, Eugene T. Hill, and Fobert P. Wanger.

This report covers Phase II of the Backup Control for a Variable Cycle Engine Program. Phase II involved the design, fabrication and bench testing of the selected backup control. Phase I was completed in August 1977 and covered the system trade studies and backup control selection. For the technical results of Phase 1, refer to report No. AFAPL-TR-77-92, "Backup Control for a Variable Cycle Engine, Phase I Interim Technical Report."

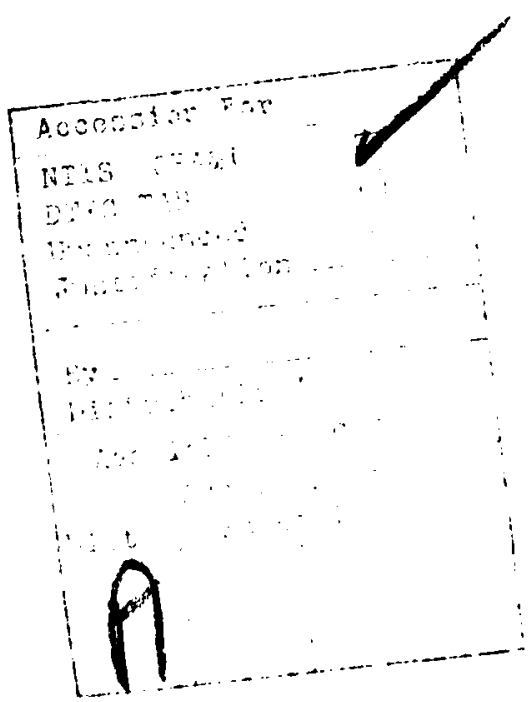


I I HARDWARE DESIGN $\quad 3$

1. Approach

2. Hydromechanical Backup Control Computer

3. Compressor Inlet Temperature Sensor 13

4. Fuel Valve 16

a. General $\quad 16$

b. Main Metering Valve 19

c. Flow Divider Valve 21

d. Cutoff Valve 21

(. Throtting Valve 21

f. Head Sensor 21

S. Servo Wash Screen 21

h. Start Pressurizing Valve 22

i. Hot $y_{i} n_{i}$, Valve Position Transducer 22

i. Summa: 24

5. Meteing Valvo Mechanical Position Feedback 21

6. Transfer Luric $\quad 28$

7. Transer Valve 30

$\begin{array}{lr}\text { 8. Ovorepoed Switch and Valve } & 30\end{array}$

9. Dive and Mounting Adapter

10. Pressure Divider $\quad 39$

11. Off-Eugine Unit $\quad 39$

12. Test Console $\quad 39$

13. Production Hardware Design 39

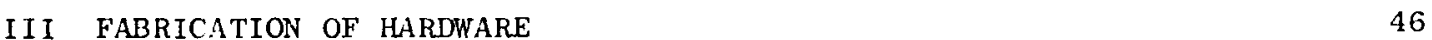

i. Hyclomechanical Computer and Compressor Inlet Temperature Sensor

2. Fuel Valve Assembly

3. Transfer Valve Assembly

4. Drive Adapter, Mechanical Position Feedback and Overspeed Assemblies

5. Off-Engine Unit and Backup Control Test Console 49

IV TEST PLANNING

1. Acceleration Schedule 54

2. Engine Model $\quad 54$

3. Expected Transient Response $\quad 54$

4. Expected Transfer Characteristics 
V TEST RESULTS

$\frac{\text { Page }}{68}$
68
70
74
80
97
99
100
101
103
108

1. Preliminary Calibration

2. Calibration

3. Backup Control Transient Response

4. Transfer to Backup Mode

5. Cyclic Endurance

6. Summary

\section{Concluded)}

VI CONCLUSIONS

REFERENCES

117 


\begin{tabular}{|c|c|c|}
\hline Figure & & Page \\
\hline 1 & Functional Block Diagram of the Backup Control & 4 \\
\hline 2 & Hydromechanical Backup Control Schematic & 5 \\
\hline 3 & Backup Control Computer Schematic & 7 \\
\hline 4 & Partial Section Showing the Speed Sensor & 9 \\
\hline 5 & Partial Section Showing the Metering Valve Servo & 11 \\
\hline 6 & Partial Section Showing the PLA Cam and Several Levers & 14 \\
\hline 7 & $T_{2.5}$ Sensor & 15 \\
\hline 8 & Partial Section Showing the $\mathrm{T}_{2.5}$ Servo & 17 \\
\hline 9 & Fucl Valve Functional Block Diagram & 18 \\
\hline 10 & Maia Futel Valve Schematic & 20 \\
\hline 11 & LVPT Position Transducer Schematic & 23 \\
\hline 12 & $\begin{array}{l}\text { Metering Valve Position Feedback Mechanism at the Fuel } \\
\text { Valve }\end{array}$ & 25 \\
\hline 13 & Metering Valve Position Feedback Mechanism at the Computer & 26 \\
\hline 14 & Feedback Cam and Follower & 27 \\
\hline 15 & Primary/Backup Control Electrical Interface Block Diagram & 29 \\
\hline 16 & Transfer Valve Schematic & 31 \\
\hline 17 & Latching Solenoid Valve Drawing & 32 \\
\hline 18 & Section of Transfer Valve Showing Switches & 33 \\
\hline 19 & Overspeed Switch and Valve & 35 \\
\hline 20 & Partial Section - Backup Control Drive & 36 \\
\hline 21 & Sketch Showing Drive and Mounting Adapter & 37 \\
\hline 22 & $\mathrm{P}_{\mathrm{S3}}$ Pressure Divider & 38 \\
\hline 23 & $\mathrm{~W}_{\mathrm{f}} / \mathrm{P}_{\mathrm{S} 3}$ Versus $\% \mathrm{~N}_{\mathrm{G}}$ at Various Levels of $\mathrm{T}_{2.5}$ (Cam 2108) & 40 \\
\hline 24 & Schematic of the Backup Control Off-Engine Unit & 41 \\
\hline & vil & \\
\hline
\end{tabular}


25 Test Console Block Diagram 43

26 Test Console Metering Valve Circuit 44

27 Test Console Stator Circuit 45

28 Backup Control Computer and $T_{2} .5$ Sensor Assembly 47

29 Detail Parts of the Fuel Valve 48

$\begin{array}{ll}30 & \text { Transfer Valve Assembly }\end{array}$

31 Drive Adapter, Mechanical Position Feedback Mechanism
and Overspeed Switch Detail Parts

32 Hydromechanical Portion of the Backup Control 52

33 Backup Control Test Console and Off-Engine Unit 53

34 Comparison of Accel Schedules 55

35 GE23/J1A3 Engine Model 56

36 GE23/J1A3 Loop Closure Functions $\quad 57$

37 GE23/J1A3 Loop Closure Partials 58

38 Backup Control Governor, Nutcracker, and Metering VaIve Servo Mechanization $\quad 59$

39 Linearized Block Diagram - Backup Control 60

40 Linearized Block Diagram - Backup Control, Takeoff Conditions $\left(P_{S}-P_{O}=1050 \mathrm{psi}\right)$

41 Backup Control Calculated Governor Frequency Response 65

42 Fuel Flow Transient Upon Transfer 66

43 VCE Backup Control Preliminary Calibration Test Setup, Left side View

44 VCE Backup Control Preliminary Calibration Test Setup, Right Side View 


\section{LIST OF ILLUSTRATIONS (Continued)}

Figure

Page

46 Setup Used For Testing The Backup Control

47 View Showing The Computer Section of The Backup

control

48 Flol Augmentor Fuel Pump and Filter Mounted To

Test Stind

49 Sctup for Transient Testing of Backup Control 78

50 Trace of Backup Control at Steady State $\quad 79$

51) Open-Loop Trace of Backup Control Acceleration and
Deceleration, 600 Control rom/sec

52 Open-Loop Trace of Backup Control Acceleration and 82

53 Closed-Loop Throttle Burst and Chop, Full Throtile

Excursion

54 Closed-Lop Throttle Burst and Cnop, Part Throttle Excursion

84

55 Open-Lonp Governor Characteristics, Low Speeds, Showing the Governor Hysteresis

56 Open-Loop Governor Characteristics, Mid Speeds, Showing the Governor Hysteresis

57 Open-Loop Governor Characteristics, High Speeds, Showing the Governor Hysteresis

5r. Typical Frequency Response Traces $\quad 88$

59 Backup Control Governor Frequency Response 89

60 Backup Control Variable stator Frequency Response 90

61 Primary-to-Backup Transfer During Accel, Small Transient off set Error, $\sim 70^{\circ}$ PLA 
6. Primary-to-Backup Transfer During Accel, Ramp Transient (1) 5\% Speed/Sec, $\sim 60^{\circ} \mathrm{PLA}$ 
1 Temperature Sensor Calibration

2 Accel Schedule Data Taken Before and After the Endurance Tes $t$

A-1 Backup Control Subsystem Safety Aralysis 


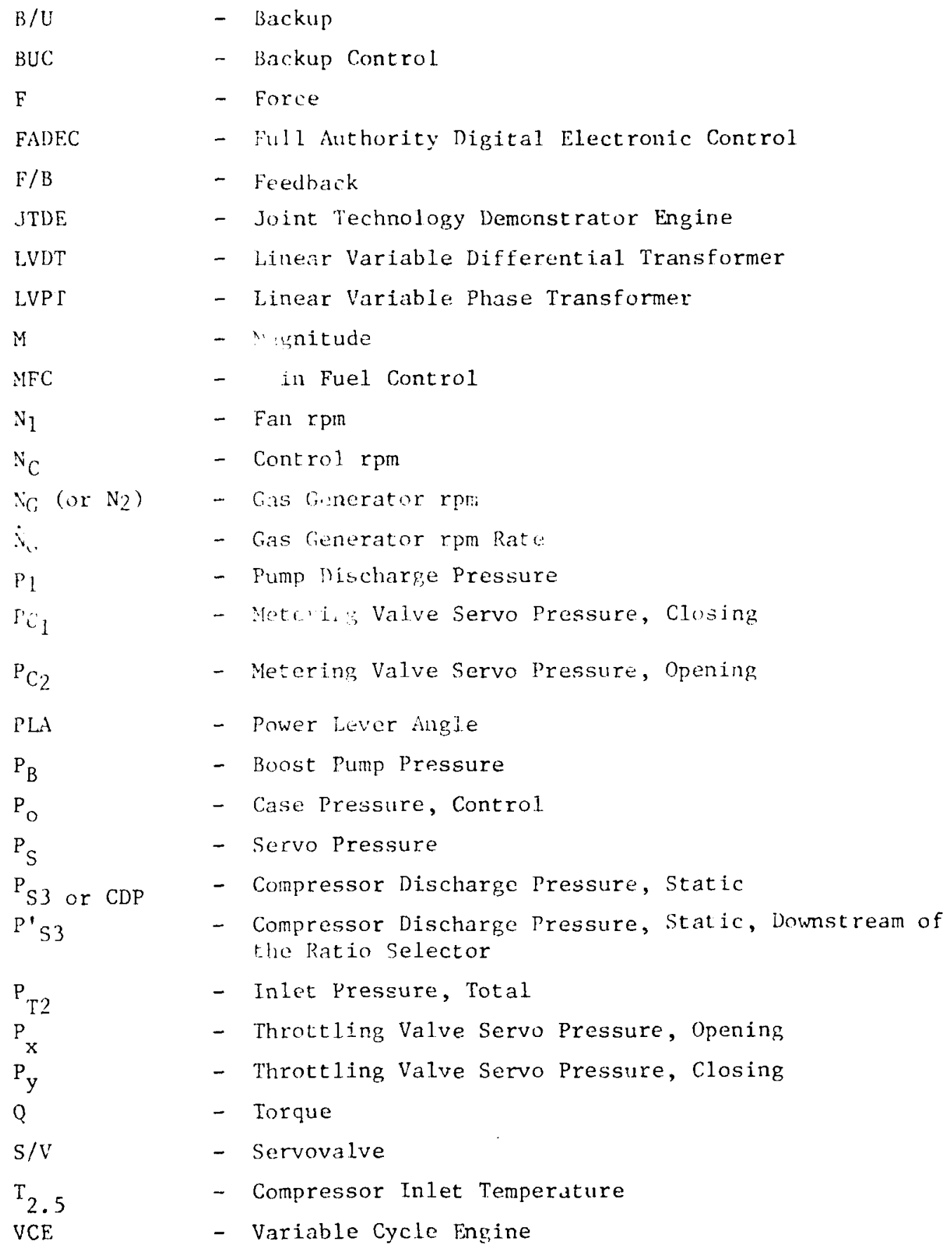




\section{LIST OF SYMBOLS (Concluded)}

$w_{f}$
$\dot{w}_{f}$
$X$ or $x_{M V}$
$w_{f m}$
$\beta_{C}$
$B_{F}$
$\triangle P$
$\theta 2.5$
$\rho$
$\downarrow$

- Fuel flow

- Fuel flow Rate

- Metering Valve Stroke

- Fuel Flow, Main

- Core Stator Angle

- Fan Stator Angle

- Metering Head

- T2.5/518. $7^{\circ} \mathrm{R}$

- Specific Gravity

- Phase 


\section{SECTION $\because$}

\section{INTRODUCTION}

Today's military aircraft developments are addressing mission scenarios and application needs which place a wide range of different operating conditing:s on the propulsion system. The propulsion system requirements result in conflicting demands for optimizing the engine cycle selected for the aircraft gas turbine. To meet this need, aircraft engine designers are moving toward the use of gas turbines having an increased number of parameters that are variable in flight. Ultimately this leads to the variable cycle engine (VCE).

This program covered the design, fabrication, and testing of a Backup Control for a Variable Cycle Engine. This development effort is in support of the evolving full-authority digital electronic control technology. The backup control will provide the aircraft with an emergency get-home capability in the event that the primary electronic control systern is inoperative due to a iailure or loss of electrical power.

Minimum get-home capability was defined as those functions which the aircraft/engine systun should be capable of performing while transferring to, and while operating on, backup control. This capability included completing a takeoff, a minimum climb rate, deceleration from supersonic flight, windmill air start, minimum cruise range, wave-off, landing, and safe runway roil. Operational constraints were determined; these included pilot action to (1) adjust for tolerable but undesirable overspeed or overtemperature, (2) decelerate from supersonic speeds, and (3) execute windmill air starting. There will be no PLA restrictions at subsonic conditions. The control environmental requirements are those of an aircraft engine for Mach number 2.5 operation.

The need for the electronic engine control arises from the increased complexity - i.e., increased number of controlled engine variables, inierent cycle variability, inlet-engine-exhaust control integration - of the next generation of sophisticated variable cycle engines. This increased engine complexity, together with the expanding need for more complete aircraft/engine control integration, demands a commensurate increase in the complexity of the control system, whose capabilities must expand if it is to provide stable, responsive, safe, and, precise engine control.

Digital electronics represents the only viable means of meeting the significantly more sophisticated requirements of the variable cycle engine of the future. With its inherent ability to time-share in the computational section of the control, increasing requirement complexity yields a much smaller increase in hardware compared to present control system mechanizations. Digital electronics also lends itself to "hardening" to the alrcraft engine environment through hybrid construction, packaging, and environinental conditioning techniques. 
As good as digital electronics are today, significant improvements are being developed for apliction to gas turbine engine controls in order to achieve the higher lwels of control raliability desired in 1985-1990. It is recopnized that the iuli-authority digital electronic control for VCL is vet to be avluated under field conditions and compared to the reliability record demonstrated by nydromechanical computer/controllers. This prograra was pirsued in consideration of the significantly increased complexity of a VCE control system, and the current development status of the digital electronic approach. Since VCF propulsion systems are rapidy becoming a reality, conducting this program to develop VCE backup control technolugy was most timely.

The progran consistad of two primary phases. The Phase I objectives were to conduct compreinenive reliability, cost and performance evaluations on a variety of iydromechanical, tectronic and fluidic barkup control approaches for variable cycle entines havjng a primary electronic control systen and then to select a single approich for subsequent design, fabrication and testing. The objectives of Phase I were to conduct the detailed design of the selected backup control, fabricate the control, and conduct bench testing in conjunction with a specifically designed backup control test console.

Based on the results of the above analyses and comparisons, the parallel hydromechanical backup control, which demands $N_{G}$ and schedules $W_{f}$, was recommended for design fabrication and test in Phase II of this program. This selection was nade because it has the reduced unscheduled shutdown associated with parallel systems and because the analyses showed this to be a lightweight economical aproach. It has the further advantage of representing a construction technclogy inherently different from the primary electronic control, thus assuring a reduction in common-mode, single-cause failures.

The hydronechanical backup cuntrol, which is of the parallel or standby type, demands $i_{c}$ and schedules $W_{f}$ for the transient 1 imit. The ${ }_{f}$ and $B_{c}$ schedules are computed based on ${ }_{G}, T_{2}, 5$, and compressor discharge. pressure $\left(P_{S 3}\right)$. This computer is very similar to those used on many prior hydromechanical main fuel controls. A transfer valve is used to switch $W_{f}$

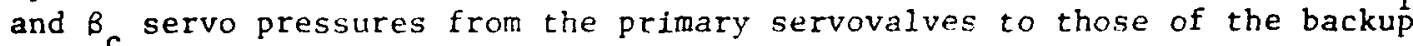
servovalves.

This report covers Phase II of the Backup Control development for a Variable Cycle Engine. The material which follow's includes hardware design and design drawings, a fabrfcation sumary, the test plans and the test results, followed by conclusions and recommendations. 


\section{SECTION II}

HARDWARE DES IGN

\section{APPROACH}

The backup control approach recommended for design, fabrication, and testing is shown by a functional block diagram in Figure 1 and schematically by Figure 2. This $N_{G}$ - deminding and $W_{f}$ - scheduling hydromechanical backup control was recommended based on the trade study conducted during Phase I of this program.

The computation section and $\mathrm{T}_{2} .5$ sensor are based on the equivalent portion of the J85-CE-2l Main Fuel Control. In the backup mode, $N_{C}$ is the Jemanded parameter and closed-loop speed control is maintained by the hydromechanical governor. Accel/decel $\mathrm{W}_{\mathrm{f}}$ limits are computed based on $\mathrm{N}_{\mathrm{G}}$, $\mathrm{T}_{2.5}$, and $\mathrm{P}_{\mathrm{S} 3}$. The $\mathrm{P}_{\mathrm{C}}$ schedule is computed based on $\mathrm{N}_{\mathrm{G}}$ and $\mathrm{T}_{2} .5$.

In the primary mode the backup control fuel valve and $P$ c servo flows are blocked by a transfer valve. This approach minimizes interference and the possible resulting backup control failures which could cause power juss. The bakup control is continuously computing the $W_{f}$ and $\beta_{c}$ limits, thus tracking the engine. This is necessary to prevent stall, which could be caused by a jump in $W_{f}$ during transfer.

Transter can be initiated (1) by pilot action, (2) by loss of primary control power, (3) by loss of primary control "good health" signal, or (4) by an overspeed condition as sensed by the backup control speed sensor. Transfer is accomplished by a current signal to the latching solenoid valve, which ports servo pressure to the piston driving the transfer valve spool. The latching solenoid was selected because it is compatible with (1) aircraft electrical power and its possible interruptions, (2) the types of electrical signals preferred for pilot action, (3) loss of primary control power, and (4) loss of the primary control "good health." Direct-acting hydromechanical overspeed protection is provided to guard against a stuck-open metering valve. In the backup mode, the primary metering valve and $\beta_{c}$ servo flows are blocked and the backup control has sole authority to control these variables.

The fuel valve is based on the design used for the Light Weight Fuel Delivery System program conducted by GE for the U.S. Navy. This valve was designed to operate on fuel contaminated per Mil-E-5007C. The flow-dividing function for the vortex valves is also provided.

Some modifications to the above components were required to provide the added functions needed by the backup control. A switch was added to the computer to initiate transfer to backup upon $\mathrm{N}_{G}$ overspeed as sensed by the hydromechanical control. An overspeed valve was also added. This valve 


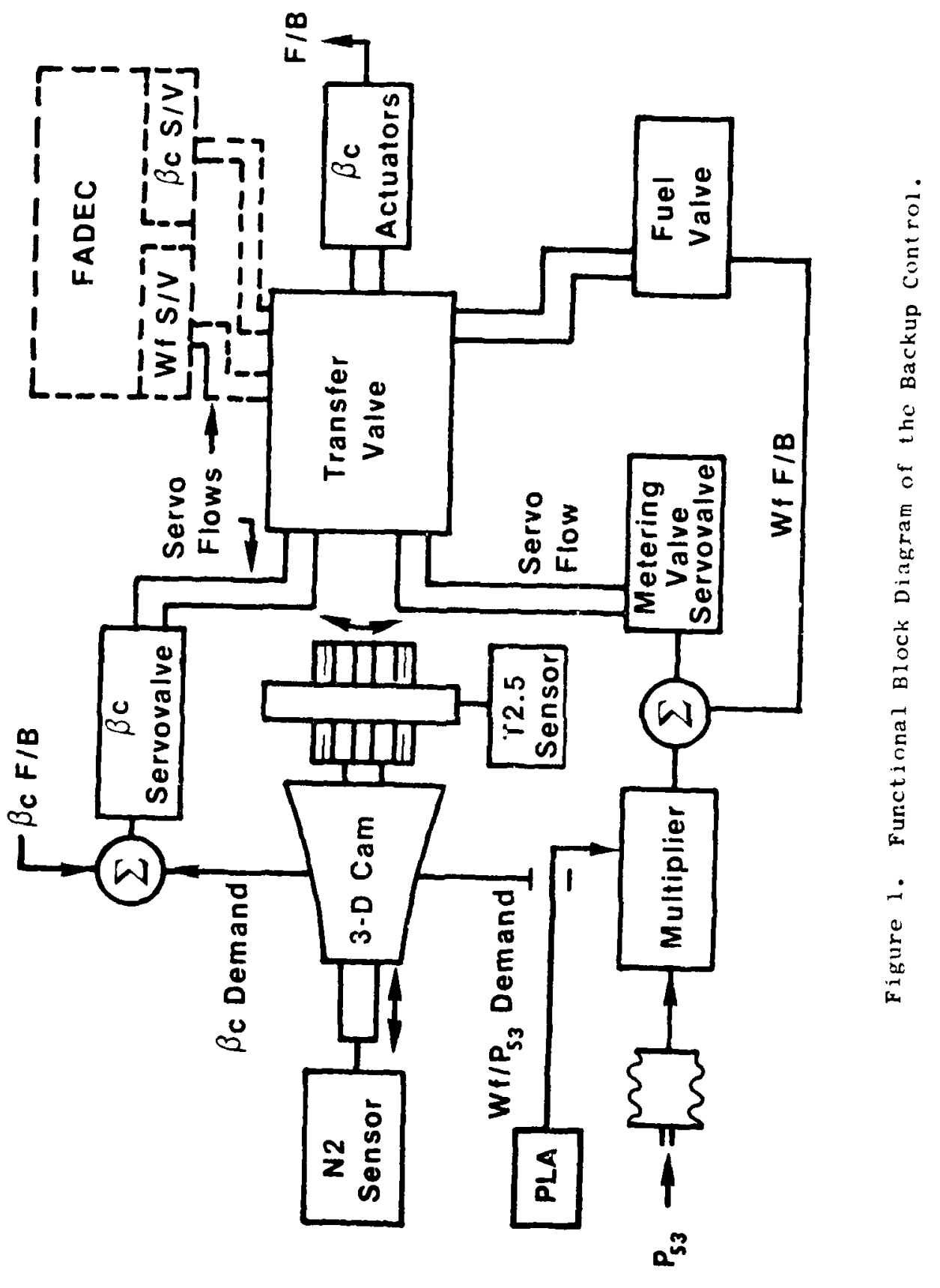




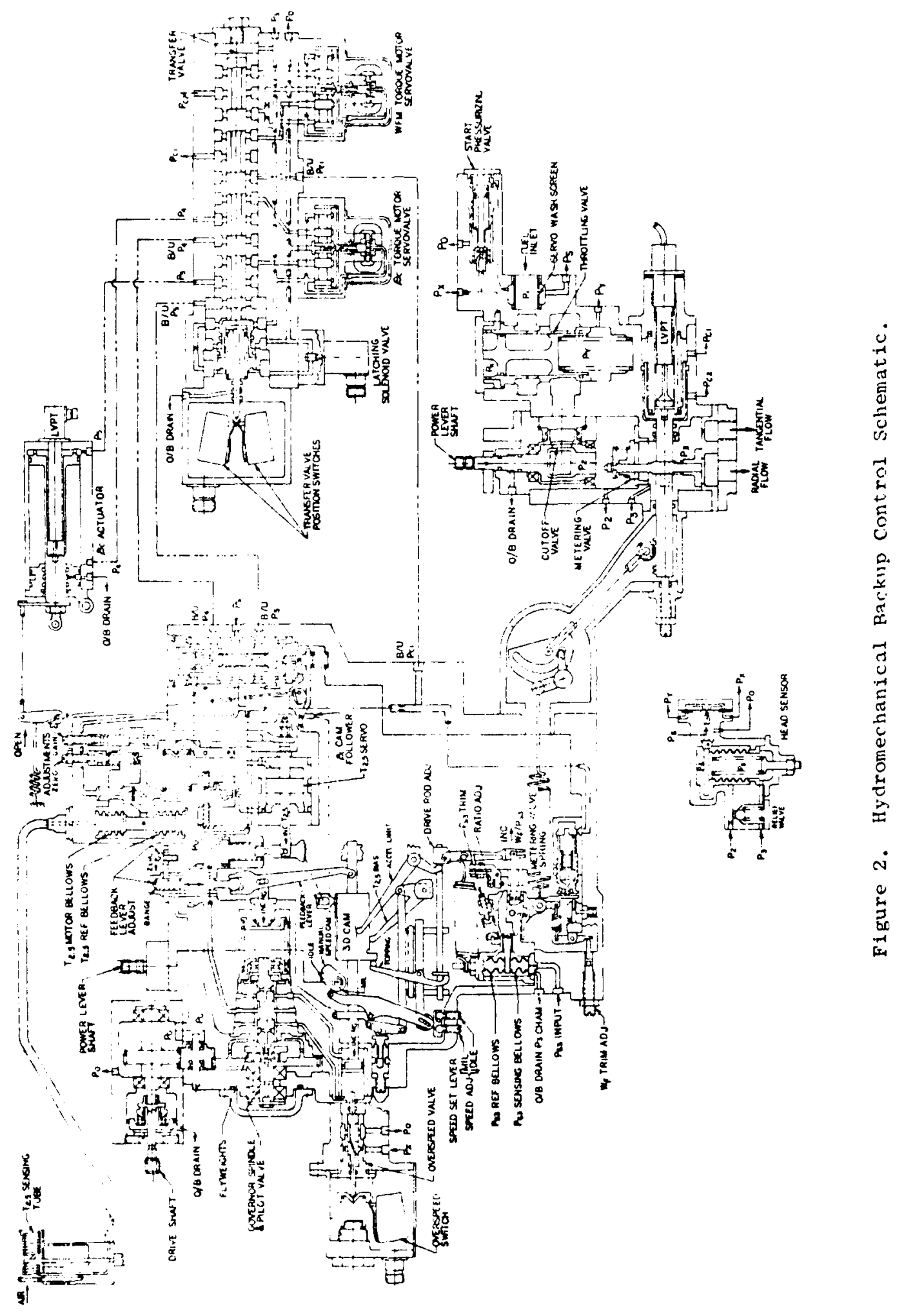




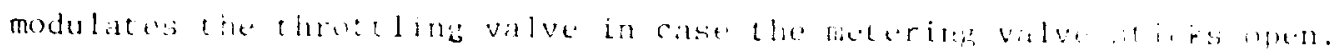

The transfer valve was designed speciflcally for this program. As indicated above, this vilve determines whether the primary or backur servo pressures conciol the metering, valve and $B_{c}$ actuators. The transfer valve has two switches. The first provides feedback to the primary control, notifying it that the transfer valve spool is in the backup position; the second curns on the cockpit indicator light.

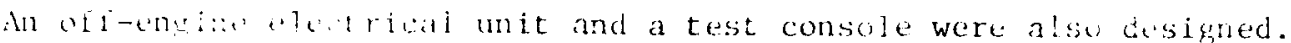

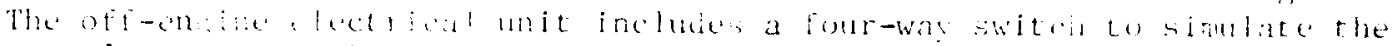
pilot's switch(ts). The test console simulated the primary control during bench testing of the backup control.

The various subassemblies involved are discussed in detafl in the paragraphsi thit follow.

\section{HYDROMECHANICAL BACKLP CONTROL COMFLTER}

The hackup control computer is shown schematically bu Firure 3 . In the backup mode, this contrul computes a metering valve position for each engine operatiar, condition. Steady-state conditions art maintained in conjunction with limiting and biasing functions, sucl: as cut niximu RPM, accel/decel linits, minimum $W f$ and $T$ ? s t,ias, which are intwertal su that a single

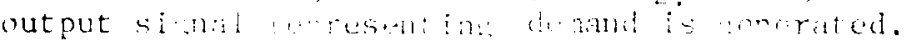

Motion of the $\mathrm{W}$, luer occurs wh uer na unalance exists in the moments of force aling an it. The posilion of the rollers represerts the

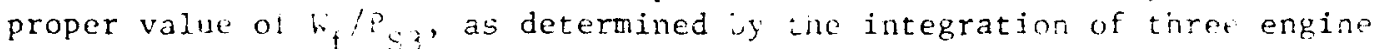
operating parameters: $N_{0}, P L A$, and $T_{2} 5^{\circ}$ A multiplying, force acts on the rollers througn a lever and is a function of $P_{S 3}$ absolute. The lever system is arranged as a multiplier surli this the load, $P_{53}$, times the point of load application, $W_{f} / P_{s}$, equils tuel flow. In equation form, it is:

$$
P_{S 3} \times W_{f} / P_{S 3}=W_{f}
$$

$P_{S 3}$ is sensed by a bellows. The pressure times the bellows area produces a force. The multiplying force is transmit ed to the rollers by a lever attached to the sersing bellows. An evacuated bellows of equal effective area is mounted upposite the sensing bellows to serve as a reference. This second bullows also provide:s compensation for undesired sensing bellows movement that results from changes of temperature and pressure in the bellows chamber. The bellows chamber is sealfd off from the control casing and vented to the atmosphere through a small orifice. A rupluici consing bellows would fill the chamber with compressor discharge air, the scis and orifice maintaining a level of $\mathrm{P}_{\mathrm{S}_{3}}$. $\mathrm{P}_{\mathrm{S}_{3}}$ acting on the outside of the reference beilows generates a force on the ${ }^{3}{ }_{S 3}$ lever to prevent complete loss of the $\mathrm{P}_{\mathrm{S} 3}$ signal if the sensing bellows fails. 


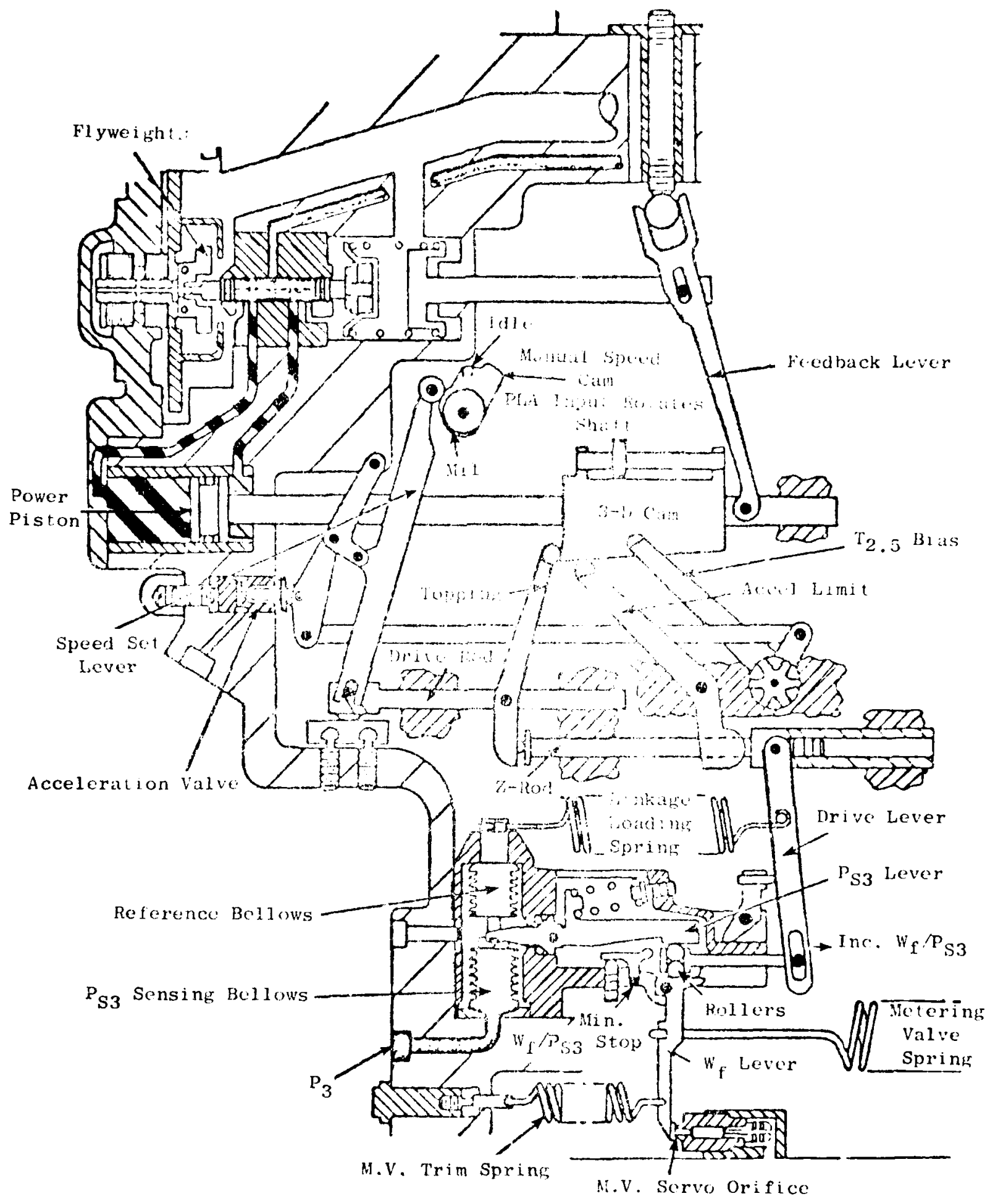

Figure 3. Backup conteol Computer schematic. 


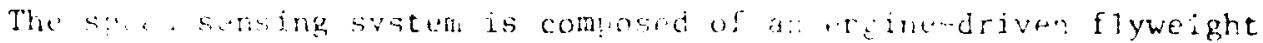

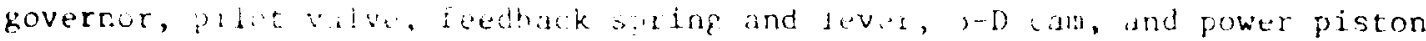

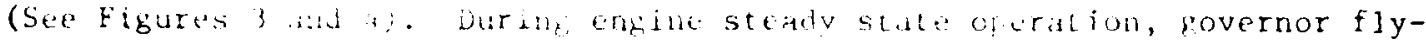

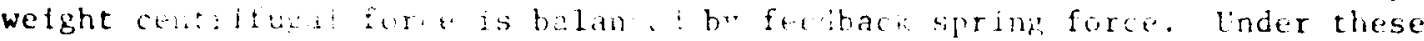
conditions, tir plot vilve is he d in null fosition. Assume an increase in fuel fin tr ranntit to a control leve advance. Adujtional fuel flow produces fincedse anjire speed In response th which the governor flywe ights move outward, lisplailig the pllot valve to the right. High-pressure fuel,

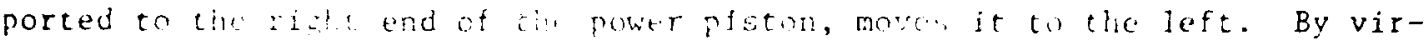

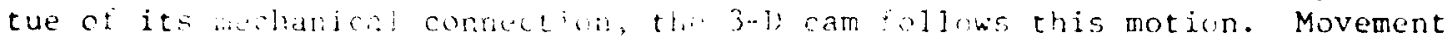

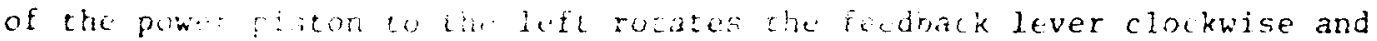
around its i vot aint. This detion composses the spring intil the spring

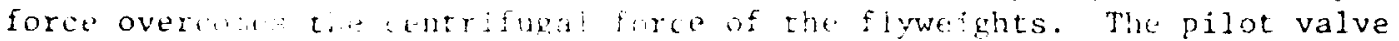
moves back toward the whl position and the flvwe ights move toward their steady state position. When spring force is biancer by flywejght centrifugal force, the rilo: "alve is in a null position. The speci sensing system

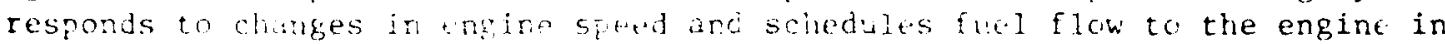

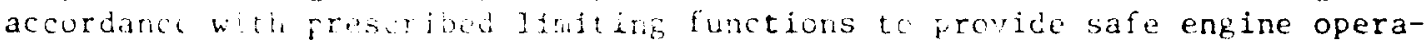
tion.

The incorjoration of a 3-1 cam minimios controj size and weight by employing a single cat to pe form a number of functions. Translation of the cani, a furction oi engine speed, is provided by the speed sensing system. Rotaton of the ram, a function of compessor inlet cemperature,

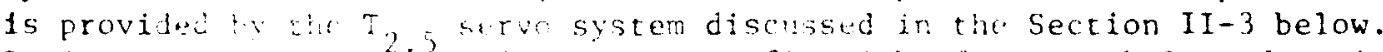
Durting stwady-state perat in, goveznor Jyweight force is halanced against

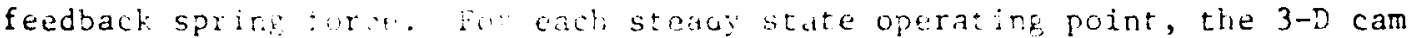
has a corresponding rquabrium position.

The contcured surface of the 3-D cam provides for signals to initiate the limting and scheduling functions of the control. Four contcurs are

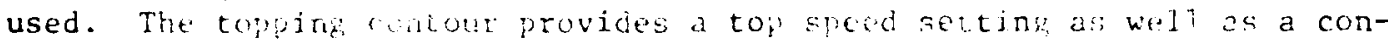

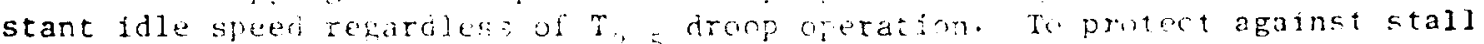
and over-temperature, the acoletatjon contour provides a $h_{f} / p$ sersus $N_{2}$

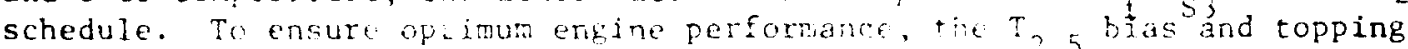

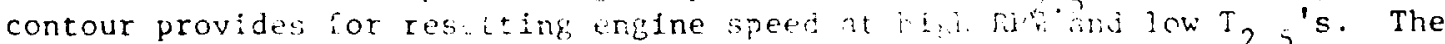
variable geometry contour provides for scheduling position of the variable stator vanes as a function of compressor injet temperature and engine rotor speed.

The metaring valve pusitioning servo is iss luk between the computing section and the meterine valve. Hydraulio torce on the metering valve pis-

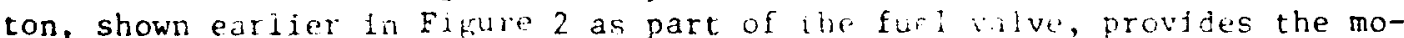
tion necessary for changing the flow area. The ragnitude and direction of the force ar provided by a hydraulic servo which consists of the metering valve piston, A flxed supply or:fice, a flapper ilve with a pressurc balancing pistor, a metering valve feedback sprias, ant the $w_{\text {f }}$ lever. Servo supply pressure $\left(P_{S}\right)$, essentially pump discharg, 1. takon from the back side of a wash screer in the fuel value. In the batkup ride, one side of the servo pitin sees a fraction of scrvo pressut, while the spring side sees 


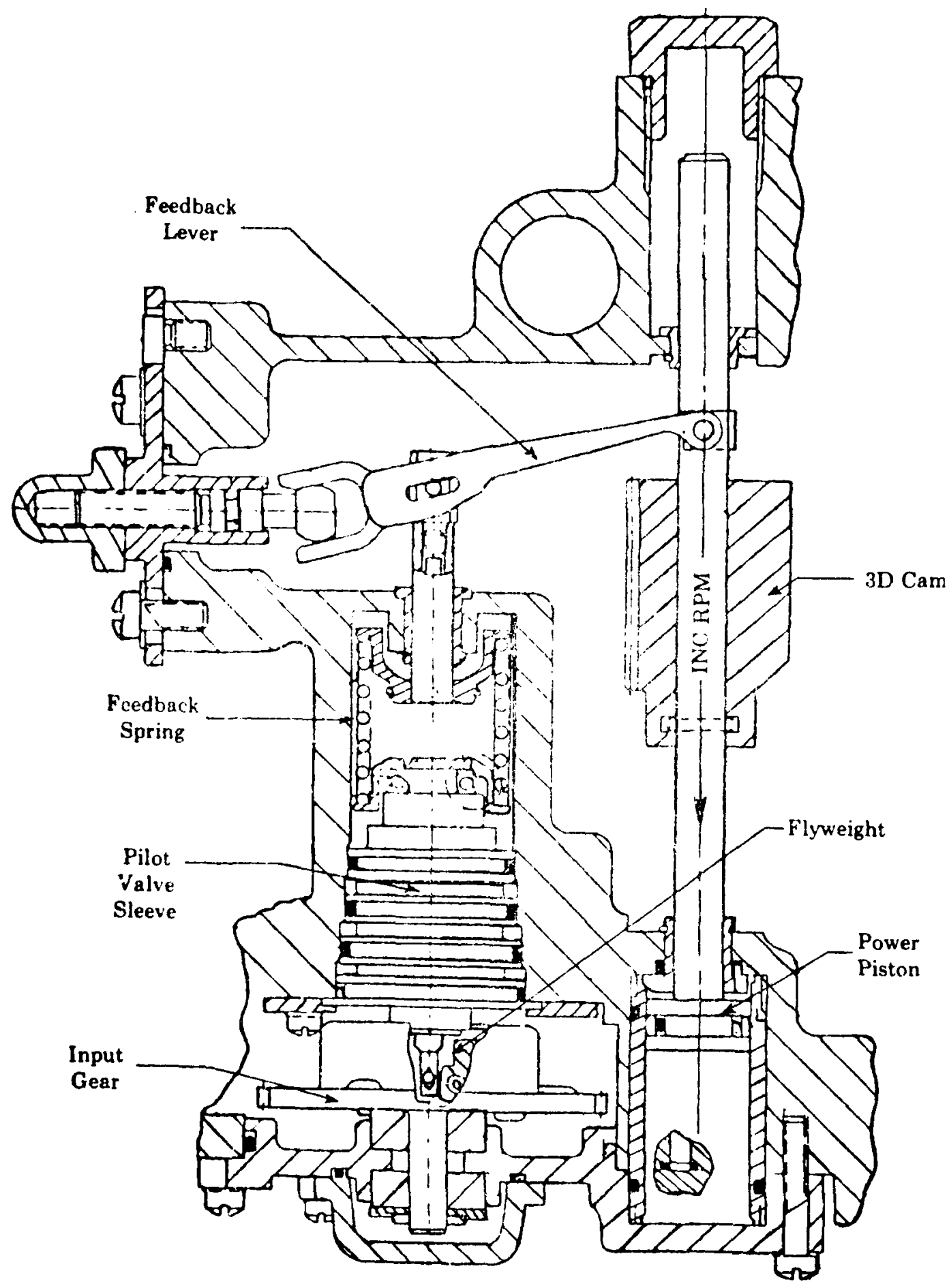

Figure 1. Partial Section Showing the Speed Sensor. 


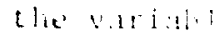

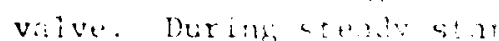

piston are bilaned and i

the $w_{f}$ lever "rtonas"

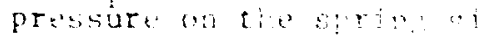

metering val ve are i! t

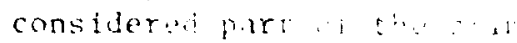

interface witi i is

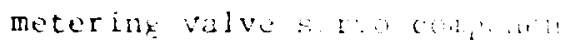

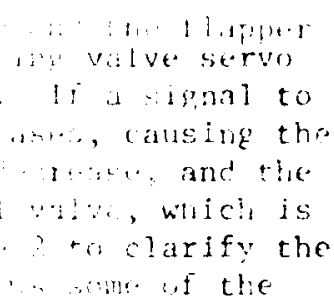

Operat ion :

i. heduled as

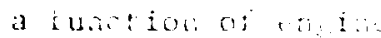

lic force arpel:

try netur? ri.

the fuel passons tingos

ton. The fuel dis?nars

casine. The rat. Wi

servo disehoren at !

gap siza, as dat in the

both sides oi tar , a : ! !

the bom move whing i

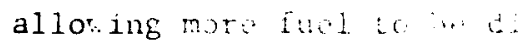

of the piston decons

downward. The riston

fuel to flon ir in

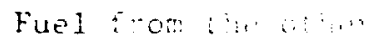

uoper port

is fed bar

to the bean, so bas :

creasos, illy :

it upward. $\because \cdots$ an $\quad$ it

sition and the $a, \cdots, \ldots$

lic forces

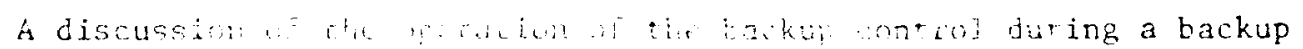

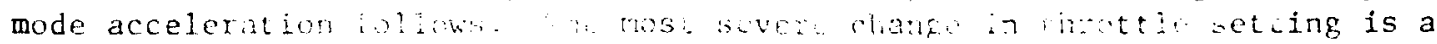

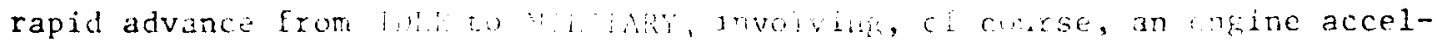

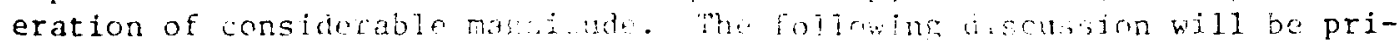
marily concerned witl an aceslout lon of this rye but wij also cover vari-

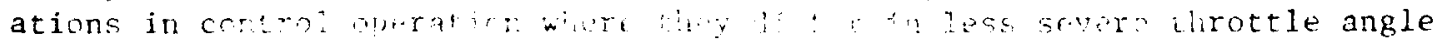
changes.

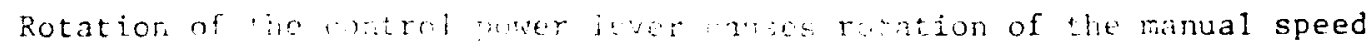

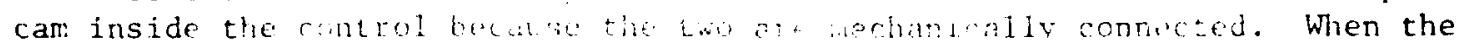

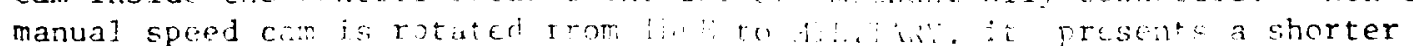

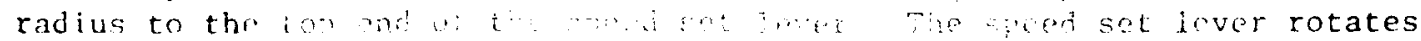

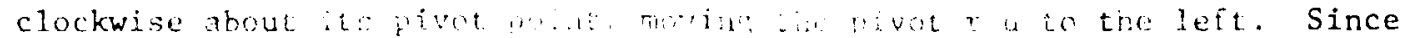
the topping lewer $:$ : a point, it wili a

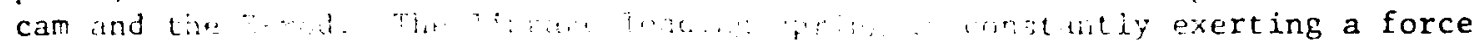




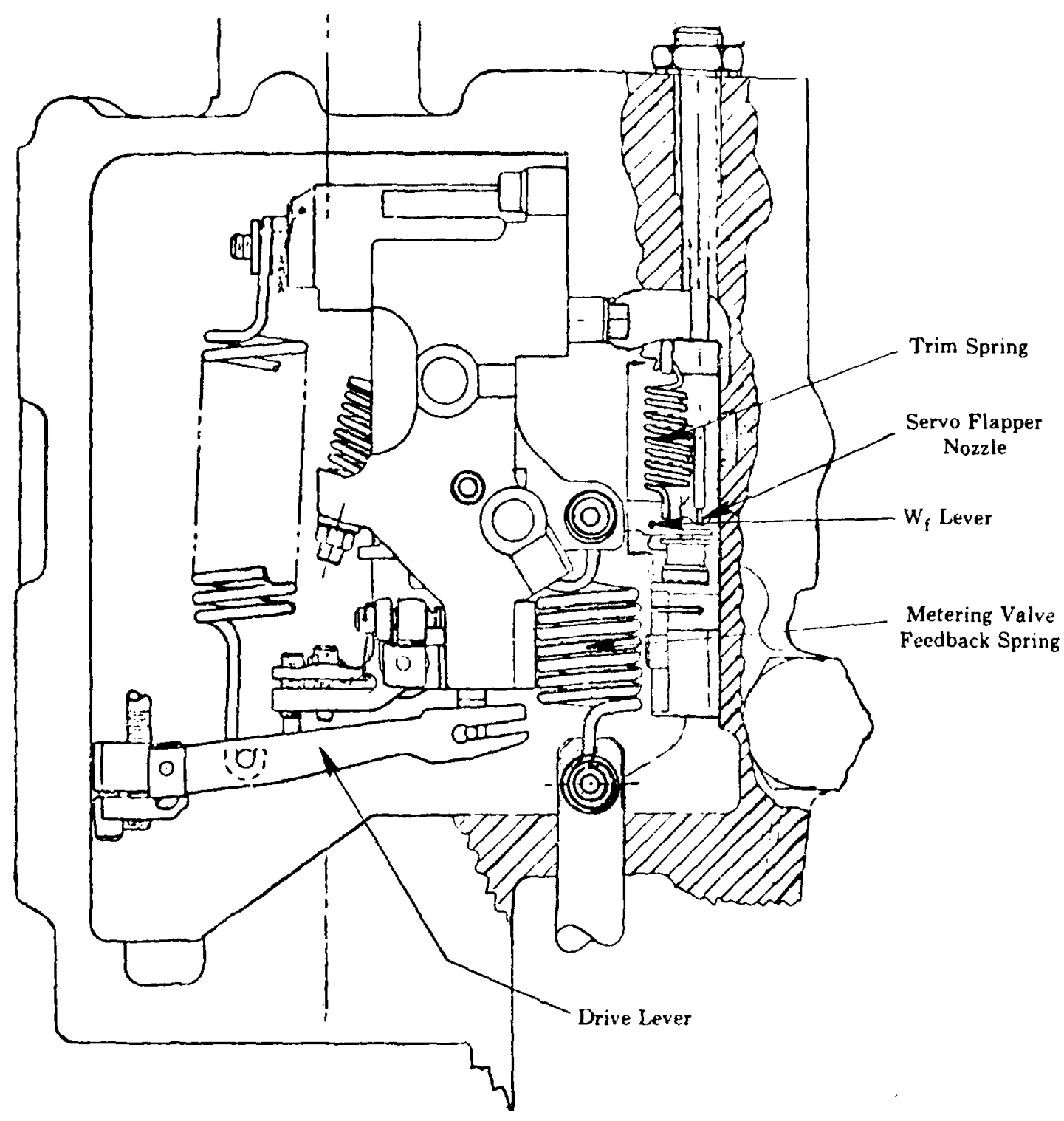

Figure 5. Partial Section Showing the Metering Valve Servo. 


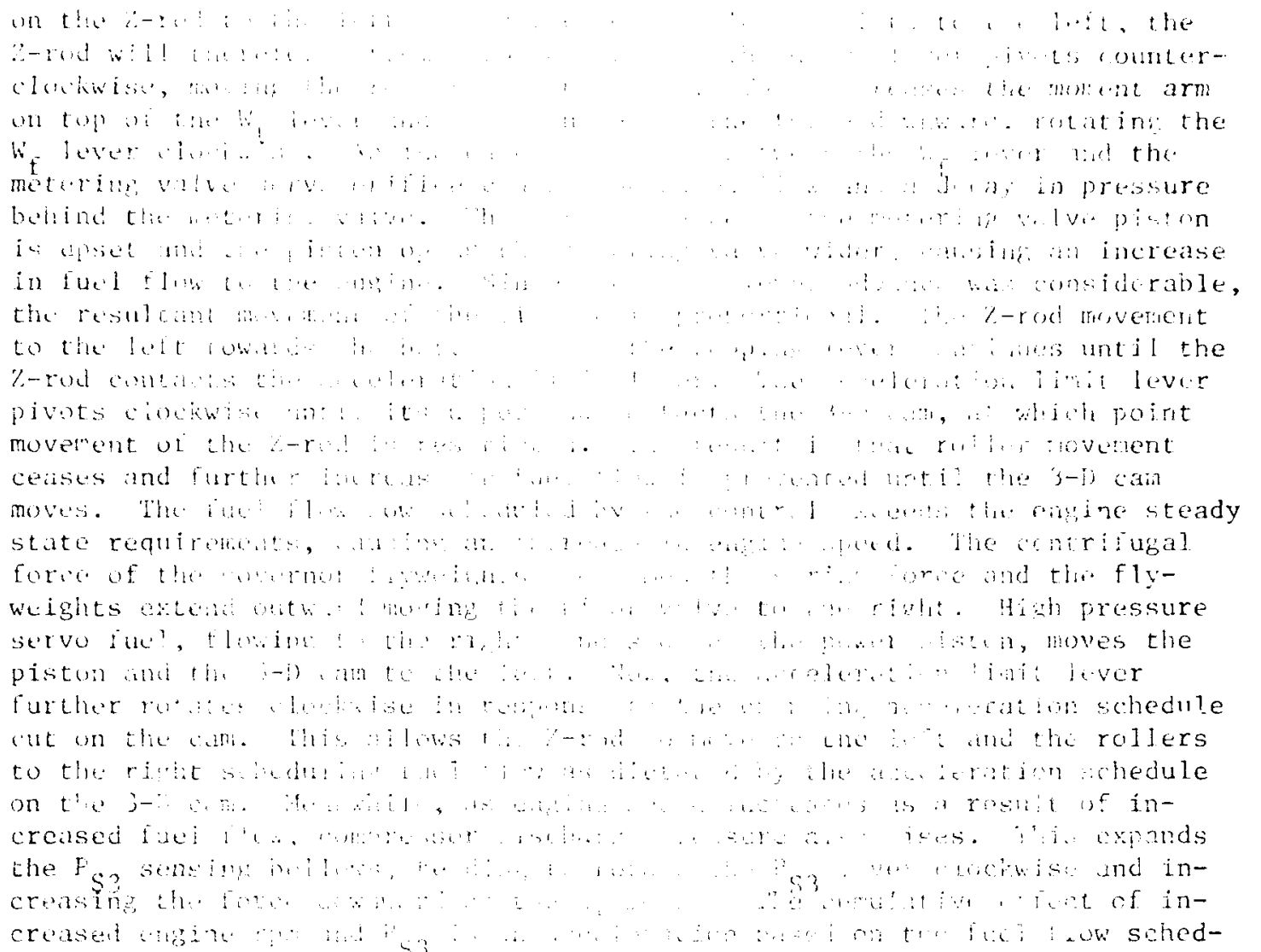

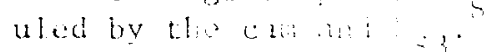

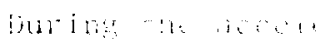

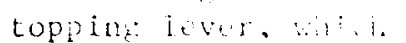

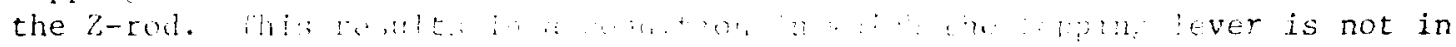

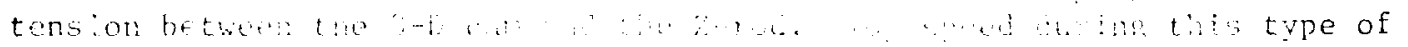

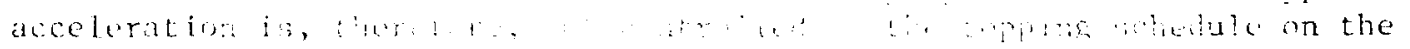
end of the $j-11 \quad \therefore \cdots, \cdots, \because, \because$,

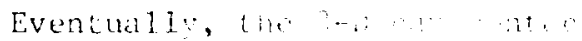

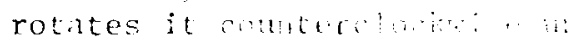
this point. the sit. : t. to on the corte berist movement at rit, i- is Z-rod to thr ristit ant should bar noteci til.ti i, is a difforunt a! : l : : ahanged whe ll : ?., i ferent onstari + iir: Elow at tisc tias litit tis

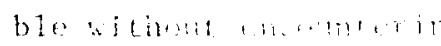

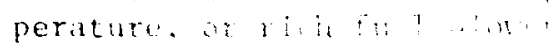

at: sis of the cam. 'vink lever and $\therefore:$ L-rud. At Titicin schedule ish:. continued low to push the :ng t tol flow. It $\because$ t:riperat tre there

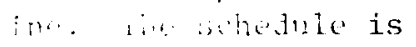
. $\because \pi, a^{*}$ proviting a dif$\because \because i_{i} \div \quad$ antolling fuel i. l.1. $\therefore$ in tai ia lischarge tem$\therefore$ : $\ldots, \quad$. $c .$, rapid 
throttle movements of considerable magnitude, will follow the same pattern. These may be initiated at any point along the steady state line and, if great enough, will involve the employment of the acceleration schedule on the 3-D cam.

A power lever movement of only a few degrees does not follow the above pattern. This slight movement rotales the manual speed cam slightly, presenting a shorter radius to the speed set lever. The speed set lever pivots clockwise and moves the drive rod and, therefore, the topping lever, to the left. The linkage luading spring causes the $Z$-rod to lollow the lower end of the topping lever to the left and the rollers to move to the right, thus increasing fuel flow. However, in contrast with an acceleration of considerable magnitude, the $z$-rod does not travel far enough to contact the acceleration limit lever before it catches up with the topping lever. The Incroase in fuel flow causes an increase in engine speed which is sensed in the governor. The centrifugal force of the flyweights overcomes the spring force balancing the pilot valve and the pilot valve moves to the right. High pressure fuel moves the power piston and the $3-D$ call to the left rotating the topping lever counterclockwise. Since the $z-$ rod is in contact with the topping lever, it will move to the right and the rollers to the left, decreasing fuel flow. Movement of the 3-D cam pivots the feedback lever clockwise sufficiently to increase the spring force against the pilot valve. The pilot valve moves towards the governor flyueights until the forces on the spring and flyweights are again in balance. The engine is now operating at a steady-state point, the operating condition selected by the power lever. (See Figure 6.)

\section{COMPRESSOR INLET TEMPERATURE SENSOR}

The compressor inlet temperature sensor ( $T 2.5$ ) is shown schematically by Figure 7 . The servoed T2.5 sensor output rotates the 3-D cam.

The $\mathrm{T}_{2} .5$ sensing tube is filled with nitrogen. The spiral tubes in the inlet are shrouded for protection. The gas is very sensitive to minute changes in temperature. This sensitivity causes a motor bellows located within the control to expand or contract with changes in compressor iniet temperature. A reference bellows, also filled with gas but at a lower pressure, is located opposite the motor bellows. The reference bellows compensates for changes in fuel temperature within the control. The $\mathrm{T}_{2} .5$ servo nozzle, connected to the bellows assembly, pivots with expansion and contraction of the bellows, thereby directing servo fuel to the right or left side of the servo piston which moves axially within the chamber. The piston is mounted on a shaft with one end of the shaft attached to a gear sector which in turn mates with a similar gear sector on the 3-D cam. The other end of the shaft is attached to a control arm which, along with a feedback spring, works to establish a force-balance system within the servo. In a null or steady-state position, a force balance positions the servo nozzle, so that servo fuel discharging through the nozzle impinges upon a spikc at the entrance to the servo piston, dividing the flow to create equal or balanced pressure on both sides of the piston. Assume that an increase in $T_{2} .5$ causes the bellows to expand. The servo nozzle, attached 


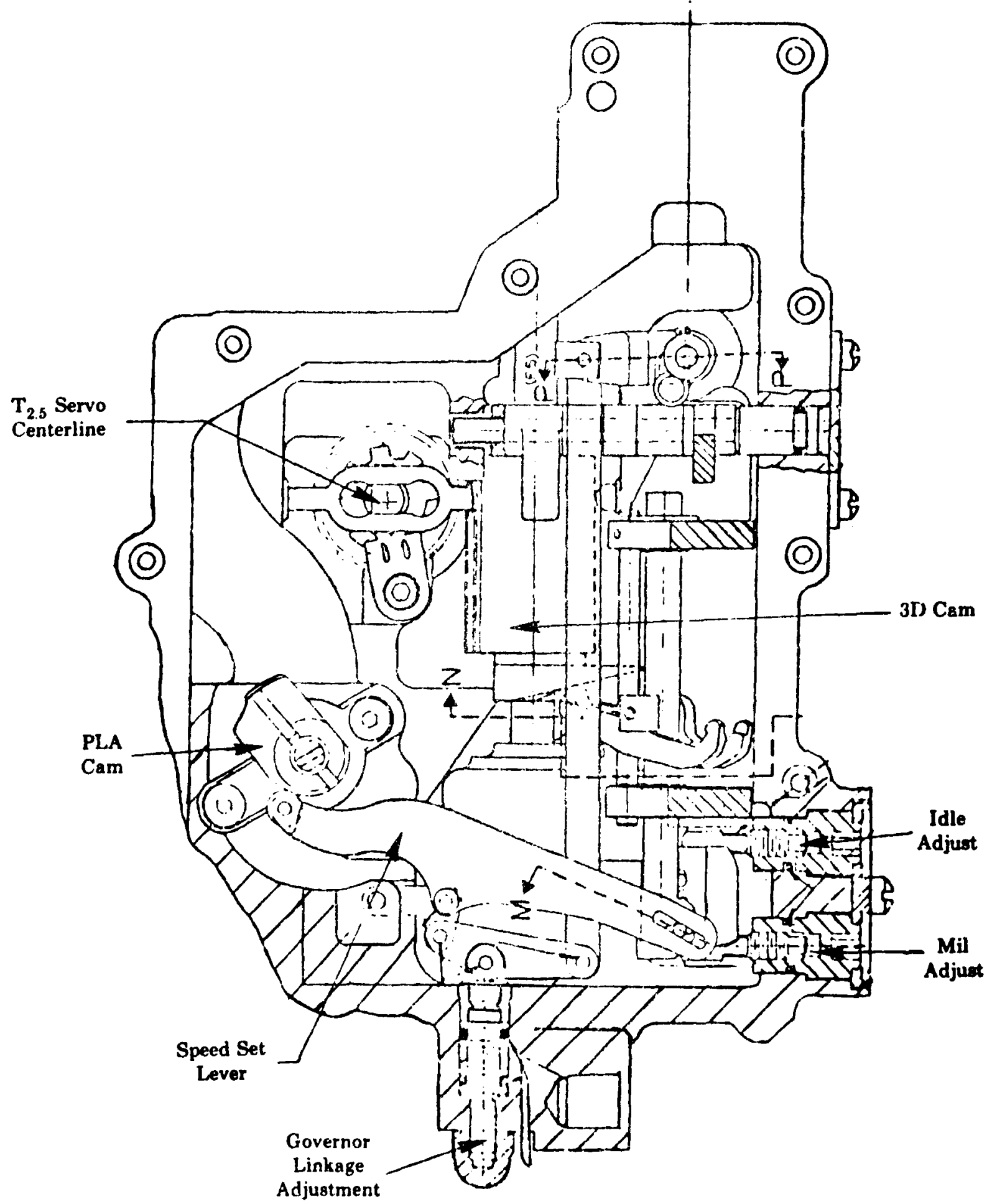

Figure 6. Partial Sretion Showing the PLA Cam and Several lavers. 


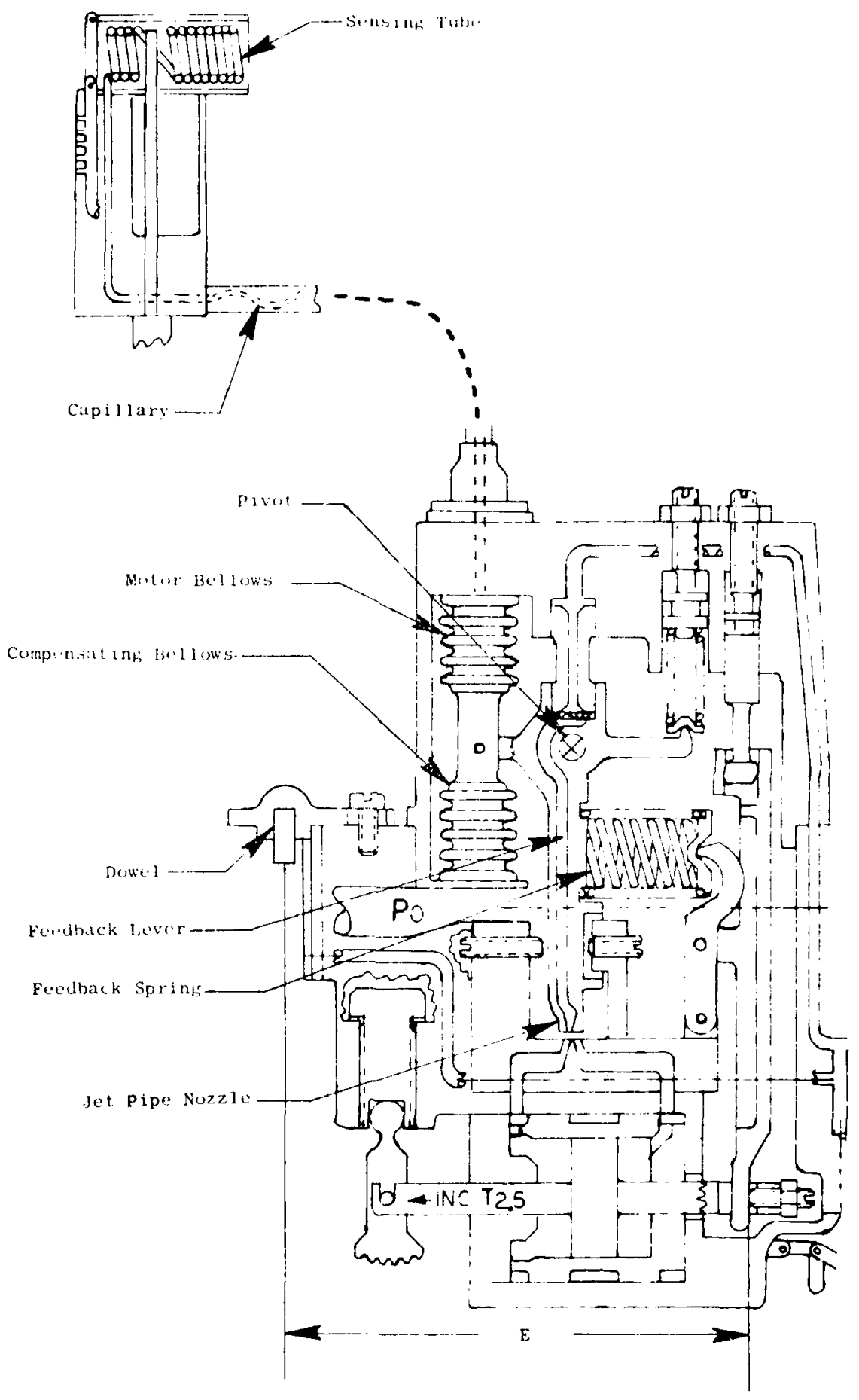

Fifure 7. T2.5 Sunsor. 
to the bellows, will pivot in a coune erelockwise direction, directing high pressure servo tuel to the right ilde ut the spike and to the right side of the servo piston. Besalla. the sreater portion of servo fuel is directed to the right side of lhe sorvo pistorn, a pressure differential now exists, creating a force unhalance aross the piston. With this force unbalance, the servo piston now moves; to the left, rotating the 3-1 cam counterclockwise. In moving to the lit, the servo piston moves the feedback arm in a counterclockwise directim, corpressing, the servo nozzle spring. As the spring force increases, with tho piston moving to the left, it moves the nozzle servo countercloskwise, rradually diresting more flow to the left side of the servo piston. A stcady-state or null position is reached; i.e., forces generated by the expanding, of the bellows are balanced by counteracting spring force. At this point, the servo nozale is located such that servo fuel flow is directed equally to the right- and left-hand sides of the servo piston, maintaining equal pressure on both sides of the servo piston.

Figure 8 is a partial section showing some of the components of the 12. 5 survo. It is integrated with the hyd momechanical computer as shown in Figure 2 .

The charge pressures and the Feedback spring rate and preload were the variables that could be adjusted to allow the use of the J85 T2.5 sensor fur the backup control. Further, the expected test temperature range is $20^{\circ} \mathrm{F}$ to $400^{\circ} \mathrm{F}$ while the present sensor range is $-65^{\circ} \mathrm{F}$ to $275^{\circ}$ F. For this backup control, the pressure was adjusted so that $20^{\circ} \mathrm{F}$ corresponded with the present $-65^{\circ} \mathrm{F}$ cam position. Calibration allows obtaining the best accuracy at a given $\mathrm{T} 2.5$ and fuel temperature. The temperatures selected for this were a $\mathrm{T}_{2} .5$ of $224^{\circ} \mathrm{F}$ and a rue: temperature of $100^{\circ} \mathrm{F}$. These are nominal temperatures for engine testing.

\section{FIIEL VALVE \\ a. Ceneral}

The fuel valve used with the hydromechanical backup control. is based on the one designed, fabricated and tested for the Light weight Fuel Delivery System program under li.S. Navy Contract No. 0140-75-C-0040.

The mechanization of the main fuel components employs shear-type valves and a jet-pipe hydraulic amplifier to provide maximun contamination resistance. The main fuel metering package provides for (1) main fuel metering, including a throttling valve for holding a constant head, (2) main fuel cutoff, (3) positional readout of the metering valve for electrical computation use, and (4) splitting of the flow for the vortex valve distribution system. These functions, appearing as they are required for the backup control, are shown schematically in Figure 9.

The main fuel valve package contains the following elements: 


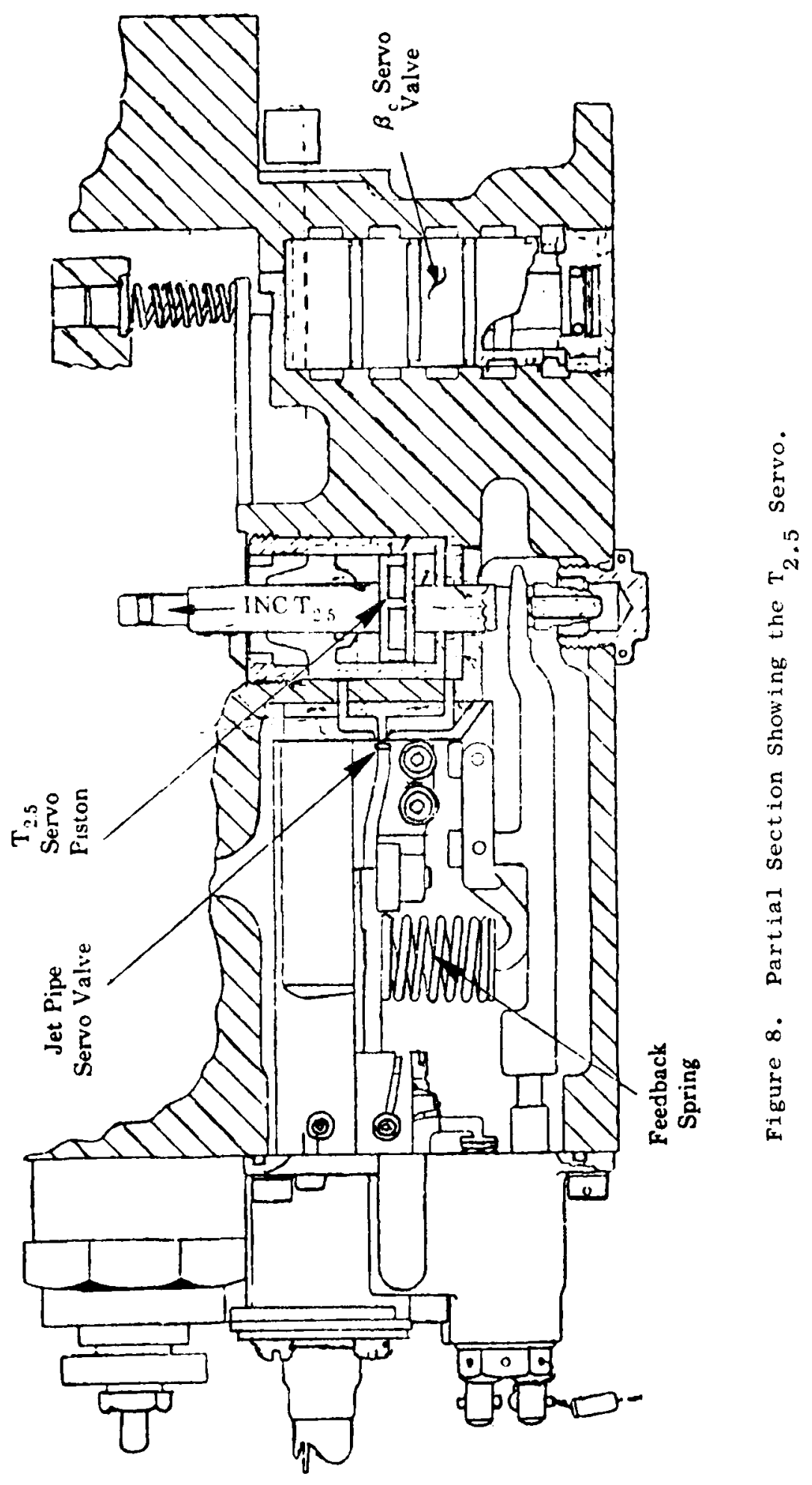




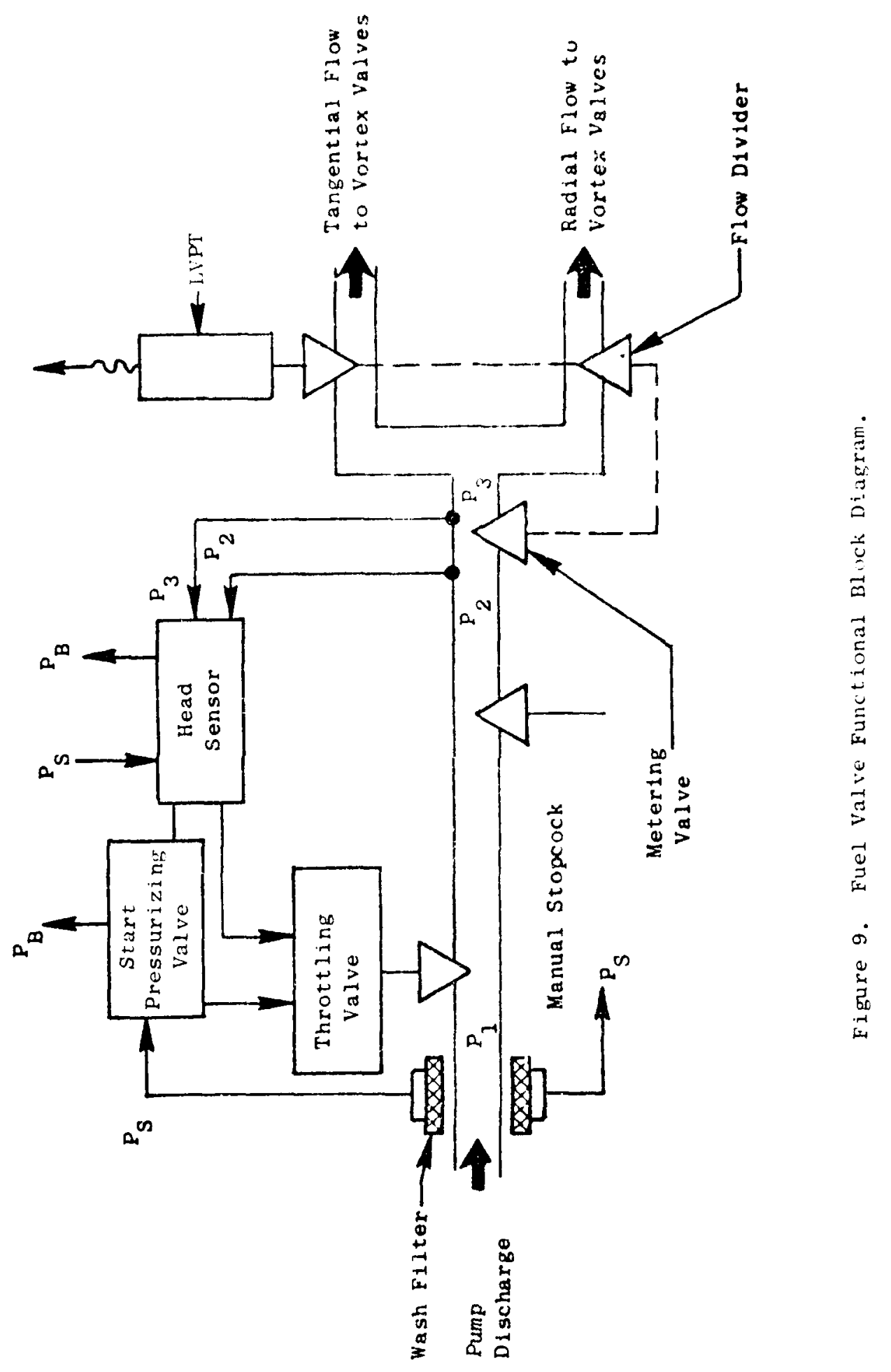


- min fucl metering valve

- flon divider valve

- cutoff valve

- throttling valve

- head sensor

- serro wash sereen

- start pressurizing valve

Firure 10 is a cross section showing the functional relationship "If the vilues and some of their details. The major components of the fuel valle are discussed in detail in the following paragraphs.

\section{b. Main Metering Valve}

The metering valve is a shear-type valve lapped to zero clearance to avoid silting and leakage. The shoe is driven by an actuation piston which is cutrolled by either the primary or backup control servovalve.

Fucl flow feedback is provided by tine LVPT, which is discussed later. The pressure drop across the metering valve is kept constant at approximately 53 psid by the head sensor and throttling valve.

The shoe of the metering valve is loaded by the 53 psi differential pressure but is balanced by pressure grooves machined into the plate to minimize friction. The shoe is also loaded by a light spring (5 lb) to maintain contact during non-operation. The valve port is triangular.

The valve nominal dimensions are as follows:

$\begin{array}{ll}\text { Maximum flow (at } 53 \text { psid) } & 16,670 \mathrm{pph} \\ \text { Valve stroke } & 0.6 \mathrm{in} . \\ \text { Piston area } & 1.0 \mathrm{sq} . \mathrm{in} . \\ \text { Port gain } & 0.5473 \mathrm{X}^{2} \mathrm{sq} . \text { in. } / \text { in. } \\ & (\mathrm{X} \text { is stroke) }\end{array}$

An adjustable minimum flow stop is provided that will set a minimum fuel flow below that which is normally scheduled by the primary or backup controls.

The dynamic seals on the metering valve piston and rod are $V i t$ on TM o-rings with Teflon TM cap seals. A rod scraper is used to protect the rod and seal from contamination carried through the metering valve cavity. The shoe and valve plate are of Type 440 stainless steel with a Dicronite ${ }^{T M}$ (dry film lubricant) coating. The housing bores have a hard anodic coating. 


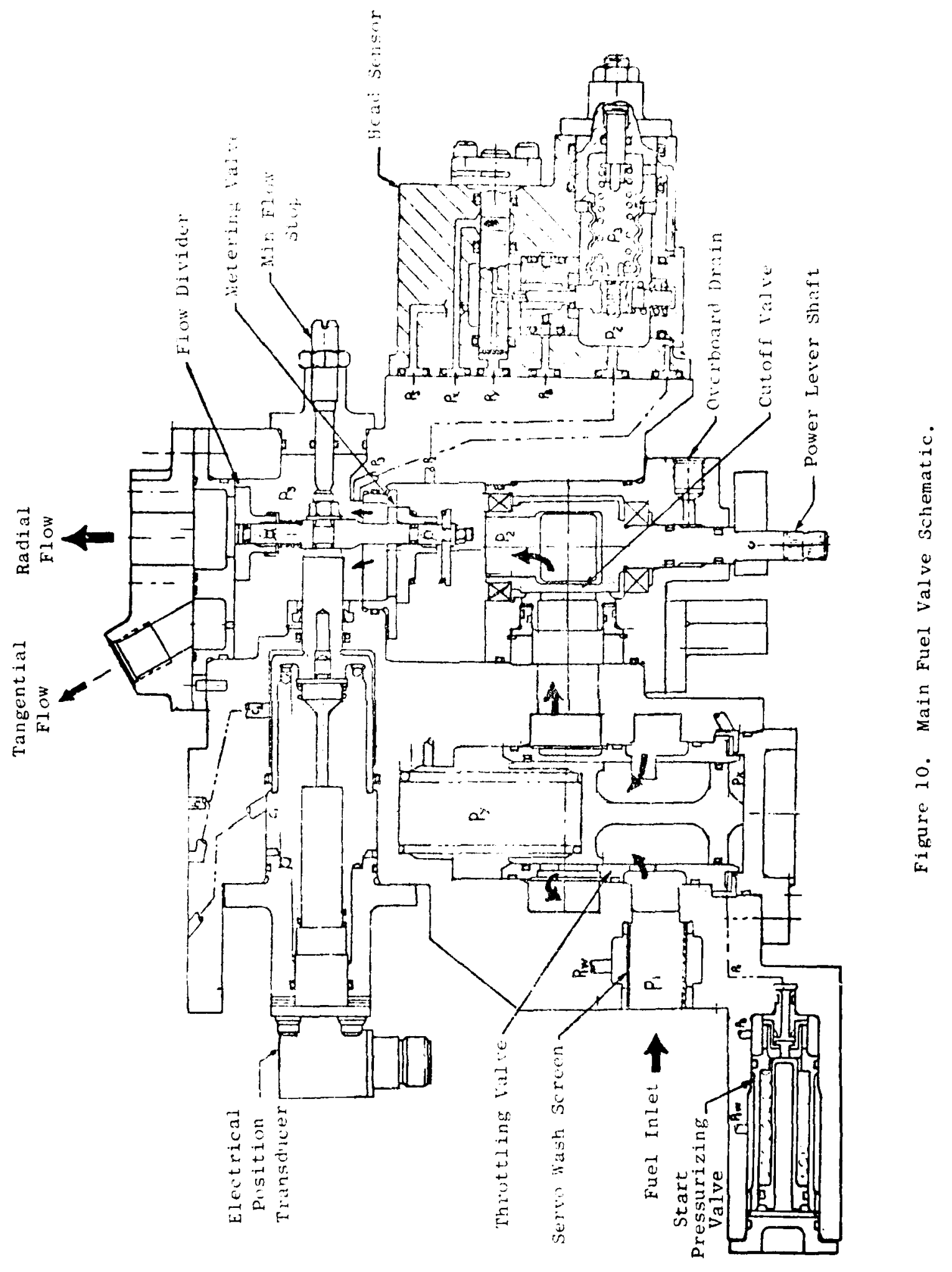




\section{c. Flow Divider Valve}

The flow divider is a shear valves similar to the metering valve and is driven by the same servo piston. Its shoe loading and balancing are similar to those of the metering valve. The shoe and plate use thu same material and coating as were used for the metering valve's shoe and plate.

\section{c. Cut off valve}

The cutoff valve is a rotary shear valve driven by the power lever. The plug and spool are lapped at assembly for near-zero leakage. The plug o-ring diameter and plug contact area have been defined to provide a limited pressure load to maintain sealing. To maintain contact at low pressure drop conditions, a spring preload of about $10 \mathrm{lb}$ is used on the plug.

The plug material is hardened 4406 stainless steel. The spool/ shaft is a braze fabrication of $440 \mathrm{C}$ and 410 stainless steel.

To eliminate bearing internal clearance, the bearings are preloaded with a wave spring. The outboard bearing has been sized to carry the shaft thrust locd at maximum pressures. A double rotary seal with an overboard drain in-between is used to maintain zero external leakage.

\section{e. Throttling valve}

The throttling valve pictured in Figure 10 is an unmodified, F101 augmentor fuel control throttling valve based on an existing design. This valve was selected because of its succes in passing F101 designassurance contamination testing with no degradation. The augmentor fuel control was exposed to MIL-E-5007C contaminant filtered to 74 micron absolute. The test duration was 15 hours.

\section{f. Head Sensor}

The head sensor pictured in Figure 10 is an F101 augmentor fuel control head sensor utilizing a jet pipe driven by a bellows. The assembly uses the existing design with no changes. Past response testing of augmentor controls and the fuel valve has shown that the head sensor gain is adequate to meet the system requirements.

\section{g. Servo Wash Screen}

The servo wash screen provides clean servo flow to the primary $W_{f}$ and $: c$ electrohydraulic servovalves, the head sensor/throttling valve servo and the hydromechanical backup control computer and servos. The filtration level is $40 \mathrm{micron}$ absolute ( $25 \mathrm{micron}$ nominal) and is based on the clean fuel requirements of the metering valve servovalve and the stator servovalve. The screen construction uses a square-weave Type 347 stainless steel wire wash surface mesh backed by coarse RigimeshTM support. 
The wash screan wll be capable of supplying a maximum transient servo flow of 5000 pph at joo"s speed.

\section{h. Start Pressurizing Valve}

To ensure that there would always be sufficient pressure for servo oporation durnt start, a start pressurizing valve was added to the system in case (1) engine motoring would be initiated with the power lever at the ldle (or above) position or (2) the metering valve would inadvertently be in a large-area position. Without the start pressurizing valve, system mpedance wold not be adequat" to pressurize the servos and "hot" - tarts could ocour. The start pressuriaing vilve senses inlet pressure and ports the throtilingr vale opening pressure to boost in order to keep the valve clused. At inlet pressure of 150 psi above boost, control of the throttling valve is returned to the head sensor for normal head rerulation. Thus, sufficient scrvo pressure will be available during engine start regardlas of the initial positions of the metering valve and cutoff value.

\section{Mivering Valve Position Transducer}

The primary electronic control (FADEC) is digital, and there are significant advantages to using digitally compatible sensors. A major advantage is that analog-to-digital converters are not necessary. FADEC Will use linear variable phase transformers (LVPT's) for all position transducers including melering valve position.

The linoar variable phase transformer is an electromechanical device that senses mechanical position and outputs an electrical signal that is directly convertible to digital form. (See Figure 11.) Its construction is very similar to a linear variable differential transformer (LVDT) having three coils (two primary and one secondary) arranged in line on a bobbin through which an iron core is moved. The two primary coils are excited by a constant-amplitude alternacing current with specific phase separation that also is kept constant. The primary currents induce an alternating magnetic flux in the core. This flux is equal to the vector sum of the fluxes that would be induced in the core by the primary windings separately. The secondary coil has an induced potential of constant magnitude which is used to detect the phase of the core flux. The phase of the secondary current is a function of the core position. If the core is centered in the coils such that the number of turns engaged in each primary winding is the same, the secondary windinf phase will be midway between the phase angles of the primary windings. As the core is moved away from the midposition and engages unequal numbers of primary turns of each type, the secondary coil phase angle changes to be more closely aligned with the phase of the higher-coupled primary winding. With linear-wound primary coils, the theoretical phase output of the secondary coil is an arctangent function of core position. If the primary coils are wound in a special pattern, such as exponential, the output signal becomes a nearly linear function of corf position. 


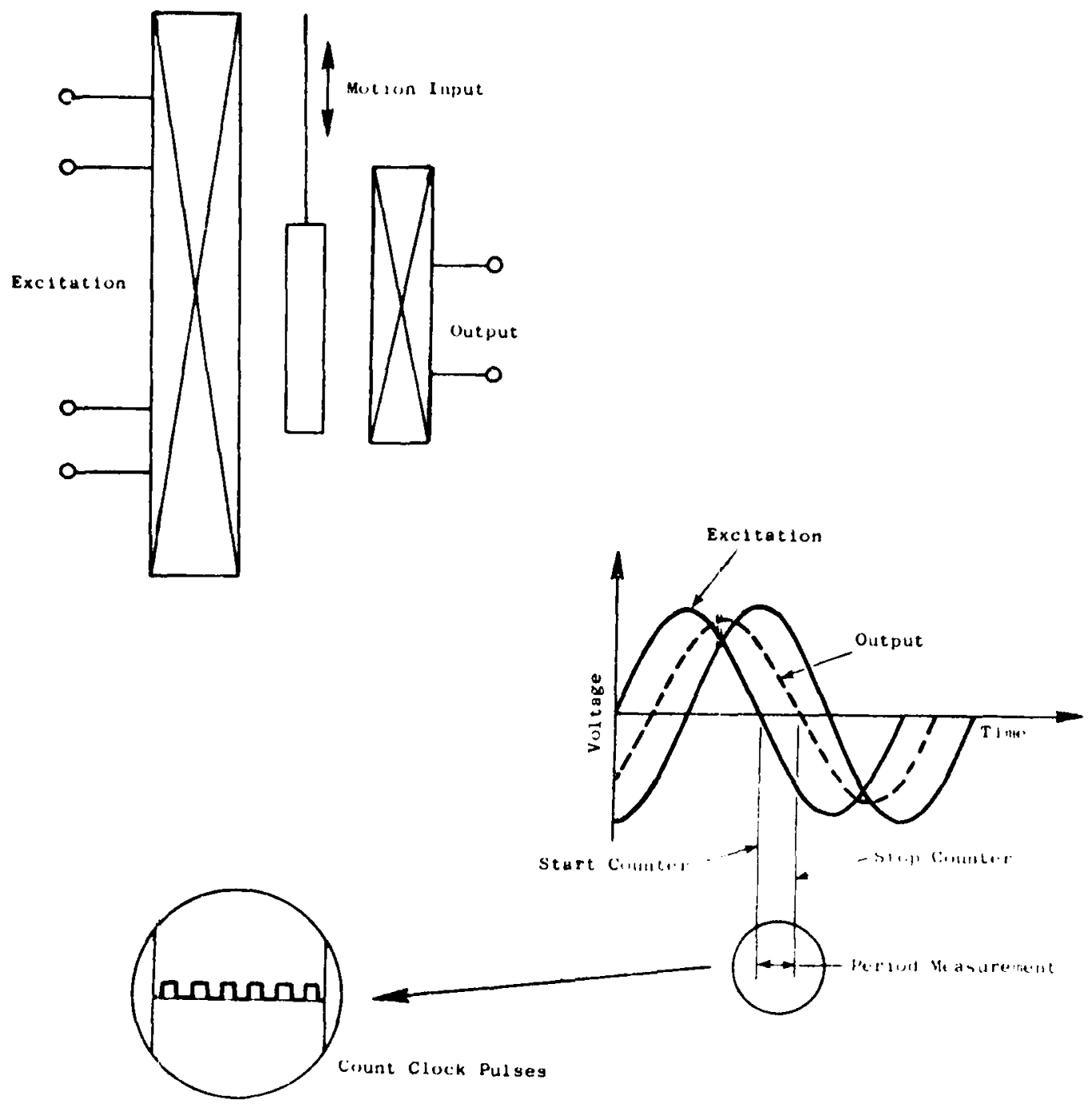

Figure 11. LVPT Position Transducer Schematic. 
With suitable digital electronic elements, the output phase angle shift from a nuld reference position is detected and converted to a binary word that can be used directly in a digital closed-loop system.

Physically, the LVPT is similar to the LVDT in size, shape, construction and materials. Therefure, it has similar very high levels of reliability and identical mounting requirements.

\section{j. Summary}

The fuel valve discussed above was recognized to be a low risk item because cxcept for the LVPT, this valve has been thoroughly tested as a component and as an element in systems tests. This fuel valve design was also used successfully on five GE23 engine tests.

\section{METERING VALVE MECHANICAL POSITION FEENBACK}

The metering valve previously used for the J85-21 Main Fuel Control (MFC) did not have sufficient capacity for the JTDE engine. In addition, this control used a bypass valve while a throttling valve is needed with the intended centrifugal main fuel pump. Therefore, the fuel valve discussed previously was mounted adjacent to the computer on the same mounting adapter.

Metering valve mechanical position feedback is needed to stabilize the fuel metering loop. Figure 12 shows the mechanism at the fuel valve. A guided rod is threaded to the metering valve servo piston rod. A rod seal is used to separate the metered fuel from the cavity containing the rack and pinion. This cavity is at boost pump pressure $\left(P_{B}\right)$. The rack is mounted to a second member, which in turn is threaded to the guided rod. Shims and a backup roller are used in eliminating the backlash between the rack and pinion. The pinion is attached to a rod which transmits the rotation to the computer portion of the backup control. The adjustable minimum fuel flow stop is also shown.

The feedback mechanism at the computer is shown by Figures 13 and 14 . A rotary shaft is used to transmit the inetering valve position from the fuel valve to the computer. This shaft (Figure 13) rotates a slot-type cam. A bellcrank, with a roller at one end and a low-friction pivot by the other, is used to transmit the cam rise to the feedback spring (Figure 14).

The feedback cam rise versus degrees rotation was defined. The following design information was used:

\author{
Pinion Pitch Diameter \\ Pinion Diametral Pitch \\ Maximum Metering Valve Travel (X) \\ Maximum Feedback Spring Stroke \\ Maximum Fuel Flow (at 0.60 in.) \\ Motering Valve Gain \\ Follower Roller Radius
}

$0.50 \mathrm{in.}$ 32 teeth/in.

$0.60 \mathrm{in}$.

$0.575 \mathrm{in}$.

$16,670 \mathrm{Ib} / \mathrm{hr}$

$46,1001 \mathrm{~b} / \mathrm{hr} / \mathrm{in} .2$

0.156 in. 


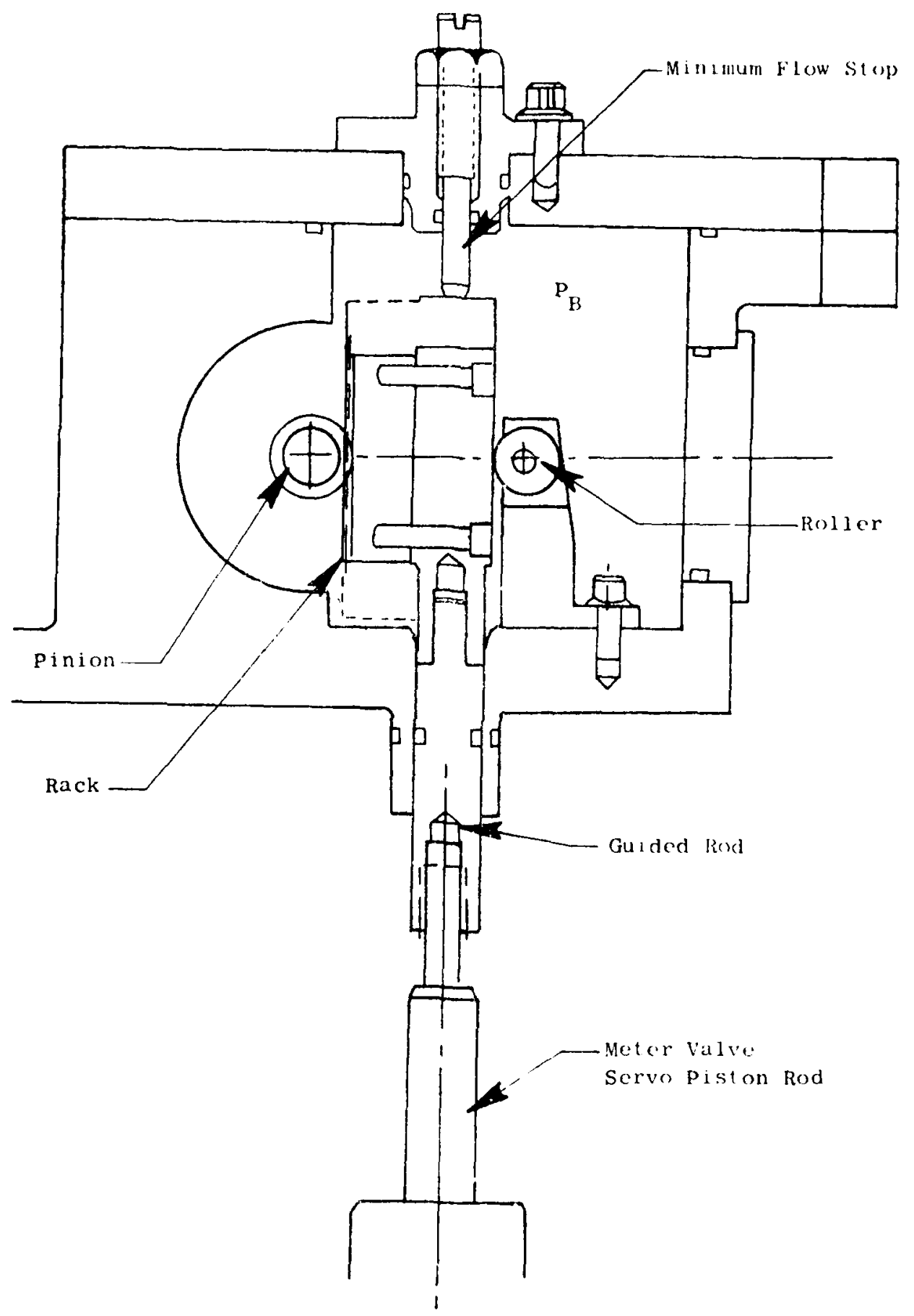

Firure 12. Metering Valve Position Fcedback Mechanism at the Fuel valve. 


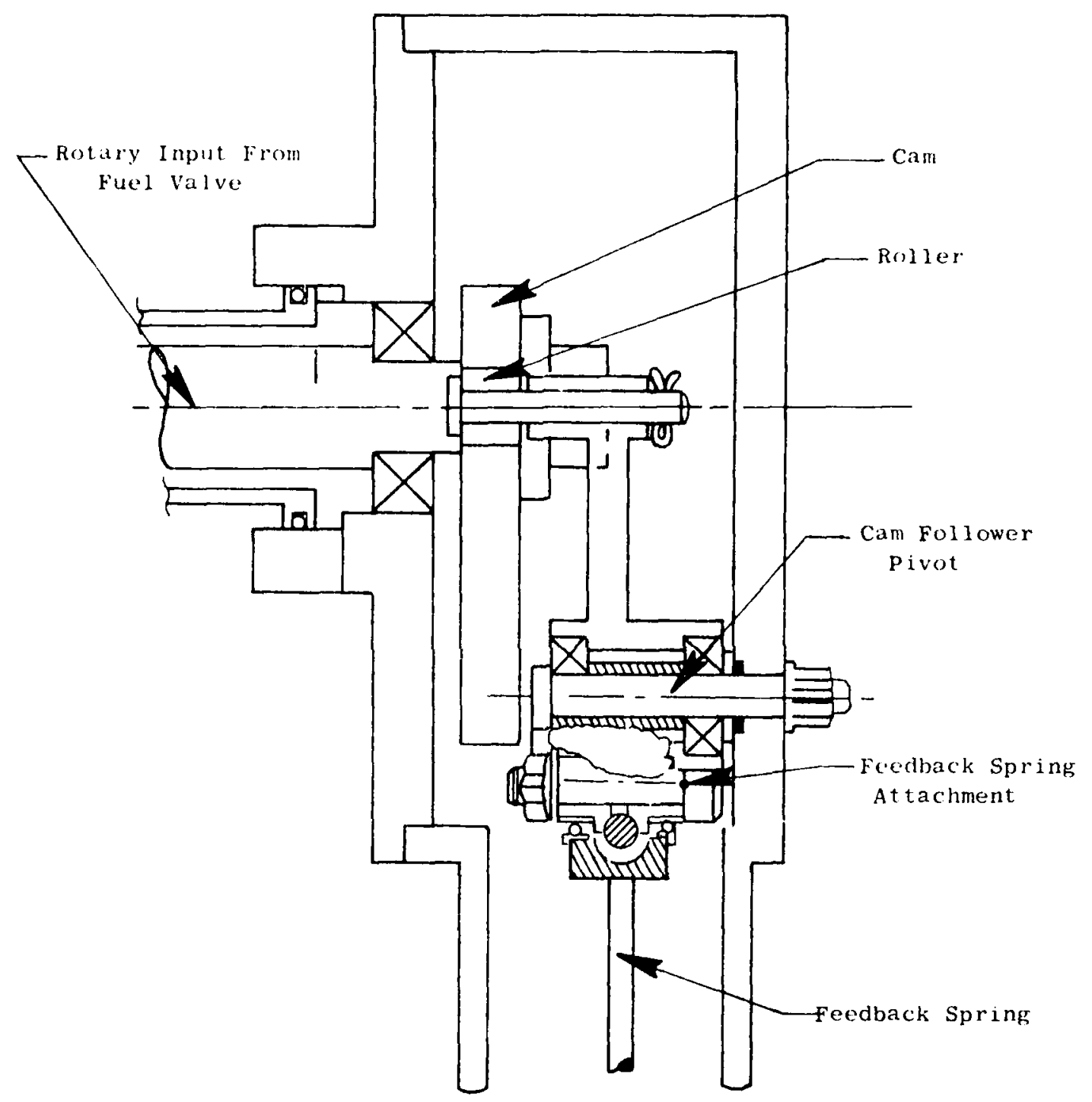

Figure 13. Metering Valve Position Focdback Mechanism at the Computer. 


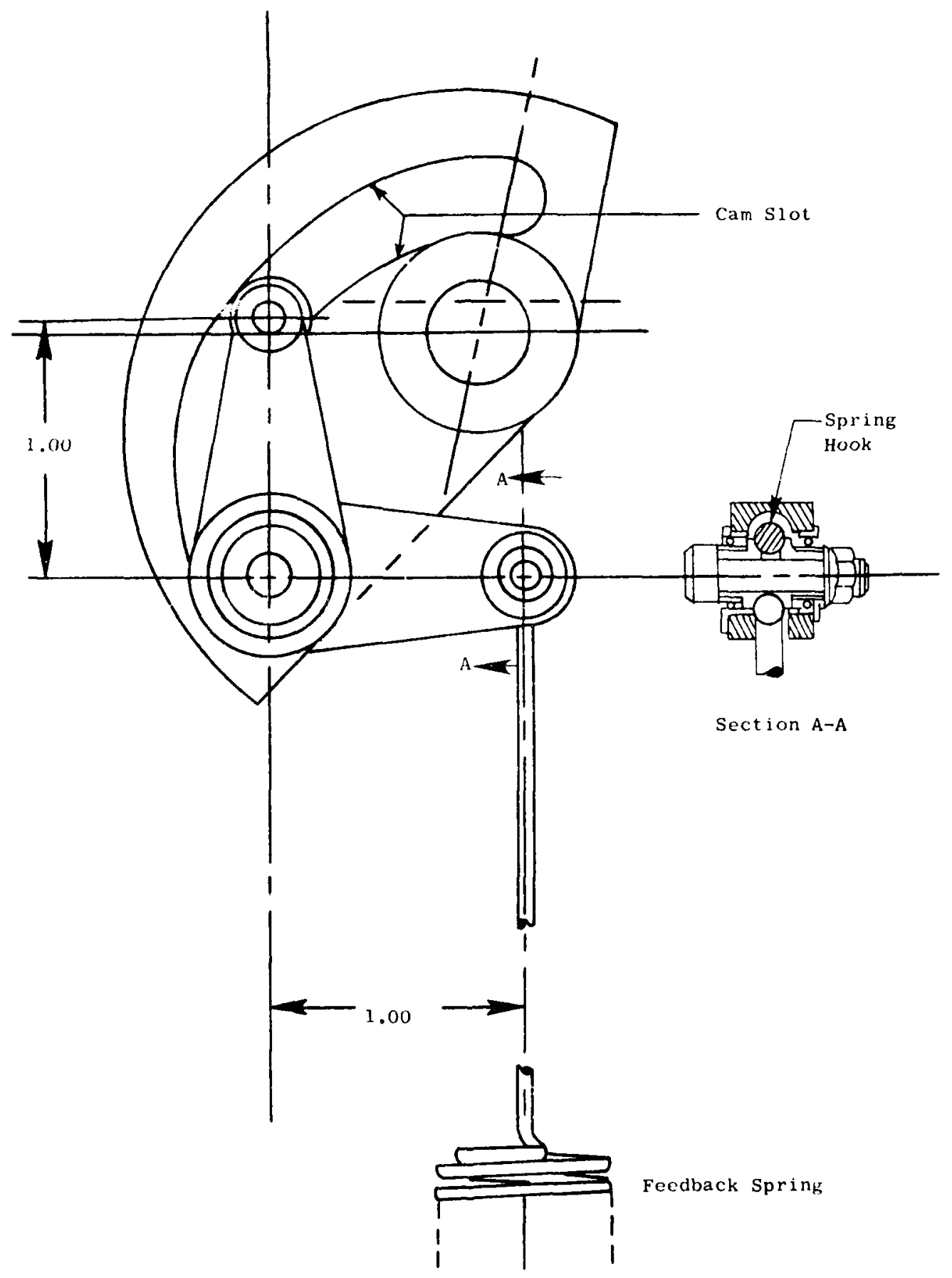

Figure 14. Feedback $\mathrm{Cam}$ and Follower. 
other alculat lons; pertaining to the netering valve position feedback mechanisms were made. solle of the pertinent results are:

\begin{tabular}{|c|c|}
\hline Maximum Spring Purce & $14.81 \mathrm{~b}$ \\
\hline Result in: Cam forpue, Maximull & 9.7 in. $-1 b$ \\
\hline Ciam Contalle St ress & 55,245 psi \\
\hline Pinion ditar fonth laad, maximam & $38.81 \mathrm{~b}$ \\
\hline Pinion Gear lonth st ressi, mas jmum & $19,968 \mathrm{psi}$ \\
\hline Feedback sirring it ress, maxidum & $69,210 \mathrm{psi}$ \\
\hline Faedback sipring llowk stress & $64,000 \mathrm{psi}$ \\
\hline
\end{tabular}

The stresse: given in the above 1 ist are considered to be conservative.

\section{TRANSFER LUGIC}

The following transier criteria were used in the design of the backup control.

- Core overspeed as detected by the hydromechanical backup control computer

- Pilot demand

- Lack of electrical power to the primary control

- Lack of a "good health" signal as determined by the sejf-test feature of the primary control

The selected transfer logic and its implementation are shown by Figure 15. The various means of initiating and completing transfer are discussed below.

When overspeed is detected, the speed sensor in the hydromechanical backup control closes the normally open overspeed switch. This ennects 28 volts (aircraft power) to the backup solenoid no matt whit the mode is for the four-position switch in the of -engine unit. The speed sensor also opens a normally closed switch in the primary solenoid circuit. When overspeed occurs, the opening of this switch prevents applying 28 volts to hoth solenoids when the four-position switch is in the PRTMARY mode. The desirability of the normally closed switch was ideniffied lat in the design phase. Instead of redesigning, this action was demonstrated by using the HOLD position. The backup solenoid actuates a valve that ports pressures in a manner that causes the valve spool to translate to int backup position. When the backup position is reached, two switches are closed. The first sends a signal to the primary control indicalias that transfer of Wf and $B_{C}$ control is comp ete; the primary control then turns off all current going to the remaining servovalies. This causes che remaining servos to drift toward their desired stops. The sucrnd switch turns on the indicator light in the off-engine unit.

The pilut can demand backuj lontrol operation bu selecting the BACKUP position of the four-position switch. This comnects 28 volts to only the backup solenoid. The action thereafter is the same as was discussed above for the case that occurs; when rverspeed is detected. 


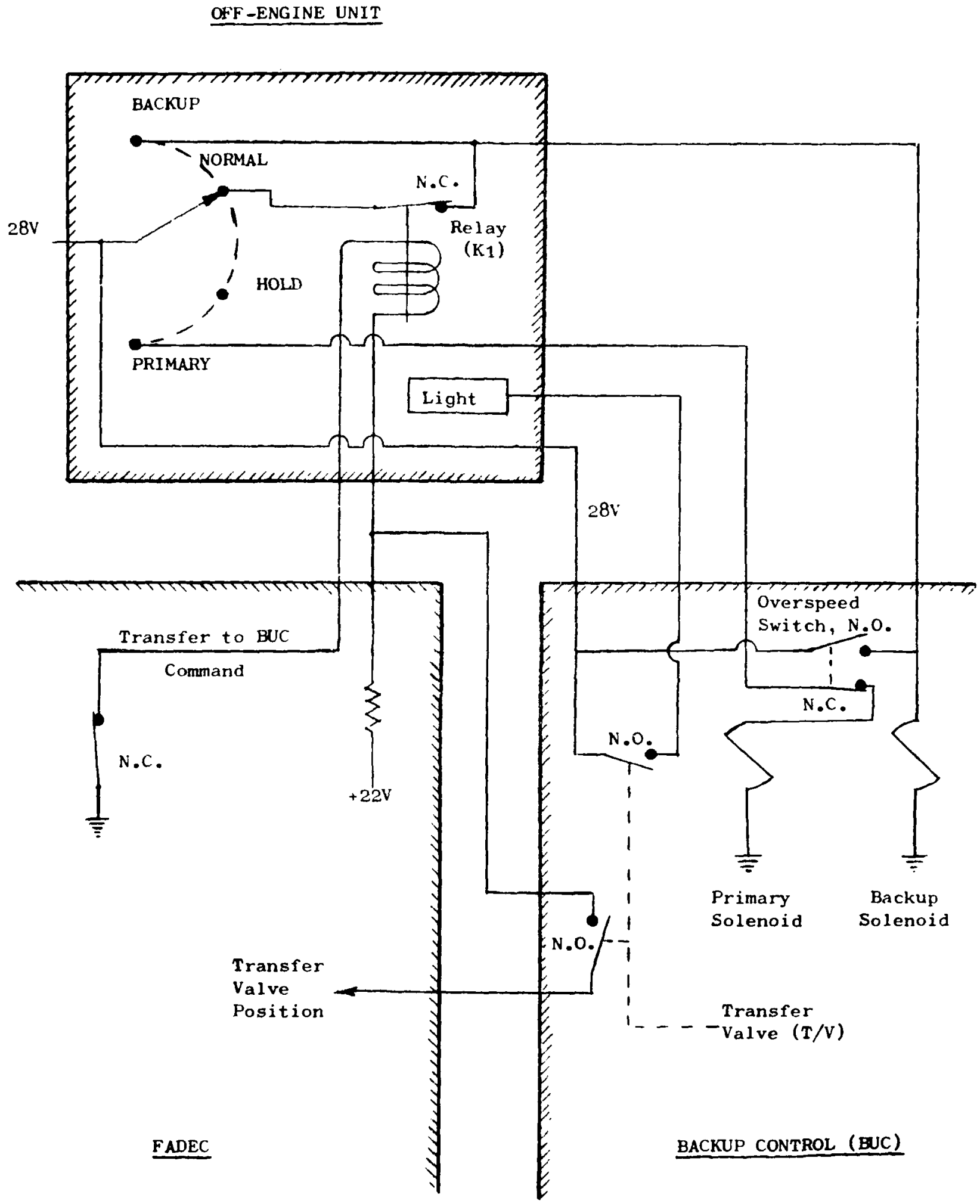

Figure 15. Primary/Backup Control Electrical Interface Block Diagram. 
In Figure 15, the reli:y (kI) In the off-engine unit is held open by the 22-voli signal froll the primary control. Assuming the four-position switch is in the NORMAl, position, loss of primay control telectrical power causes a loss of the 22-\%olt signai. This causes the relay (KI) to close, connecting 28 volts to the backup solenoid. The action thereafter is the sane as for the case when overspeed is detected. The pilot can block this automatic transiter la bickup control by having the four-position switch in the HOLD or PRIMA: positjon.

The primary ueceronic control has a self-test feature which continuously monitors performane'. If a lack of "good health" is detected, the 22-volt signal to the rilay (kl) is interrupted. The action thereafter is the same at for the loss ot wrimary control electrical power.

The solenoids are of the latching type so that the 28-volt aircraftsupplied power med not be continuous. The four-position switch shown for the off-entine uni is not intended to represent aircraft cockpit switch design. Alomentary contact switches could also be used.

\section{TRANSFER VALVE}

The transfer valve (Figure 16) is shown in the primary mode position. The solenoid valve is blocking the orifice flow back to the control case $\left(P_{O}\right)$ so the pressure in the spring chamber is servo supply pressure $\left(P_{S}\right)$. Since the larger pision arcit is at $P$, and the spring force is to the right, the net force is to the right. The solenoid valve (Figure 17) is of the magnetic latching type. When the solenoid valve is opened, the transfer valve spool strokes to the left stop (backup mode). In this position, the transfer valve allows only backup $W_{f}$ and $B_{C}$ servo flows to the metering valve piston and core stator actuatris.

The spool and sleeve are of 4anc stainless steel (.4\% 5630). These parts a re heat treated at $1850^{\circ} \mathrm{F}$ :o $1900^{\circ} \mathrm{F}$ for 50 to 70 minutes in a neutral atmosphere and then quenched. After quenching, the parts are stabilized at $-110^{\circ} \mathrm{F}$ to $-120^{\circ} \mathrm{F}$ for three hours minimum, tempered at $650^{\circ} \mathrm{F}$ to $700^{\circ} \mathrm{F}$ for one hour, stabilized at $-110^{\circ} \mathrm{F}$ to $-120^{\circ} \mathrm{F}$ for three hours minimun, and finally tempered at $650^{\circ} \mathrm{F}$ to $700^{\circ} \mathrm{F}$ for one hour minimum. The expected hardness is Rockwell $15 \mathrm{~N} 87 \mathrm{minimum}$. The spool and sleeve are natched with a diametral clearance of 0.0003 to 0.0006 inch.

The backup control transfer sequence involves two switches which are normally open and are alosed when the transfer valve spool is at or near the backup position. The switches and actuation means are shown in Figure 18. The switches are made by Texis Inst muments Inc. (Part Number MS 24456-3 or vendor Part Number kX5-1-1). This type of switch is used on the F404 engine.

\section{OVERSPEED SWITCH AND VAINE}

As discussed in a previous suctom, a suitoh is used to initiate transfer to the backup mode when NG overspeed is detected by the hydru- 


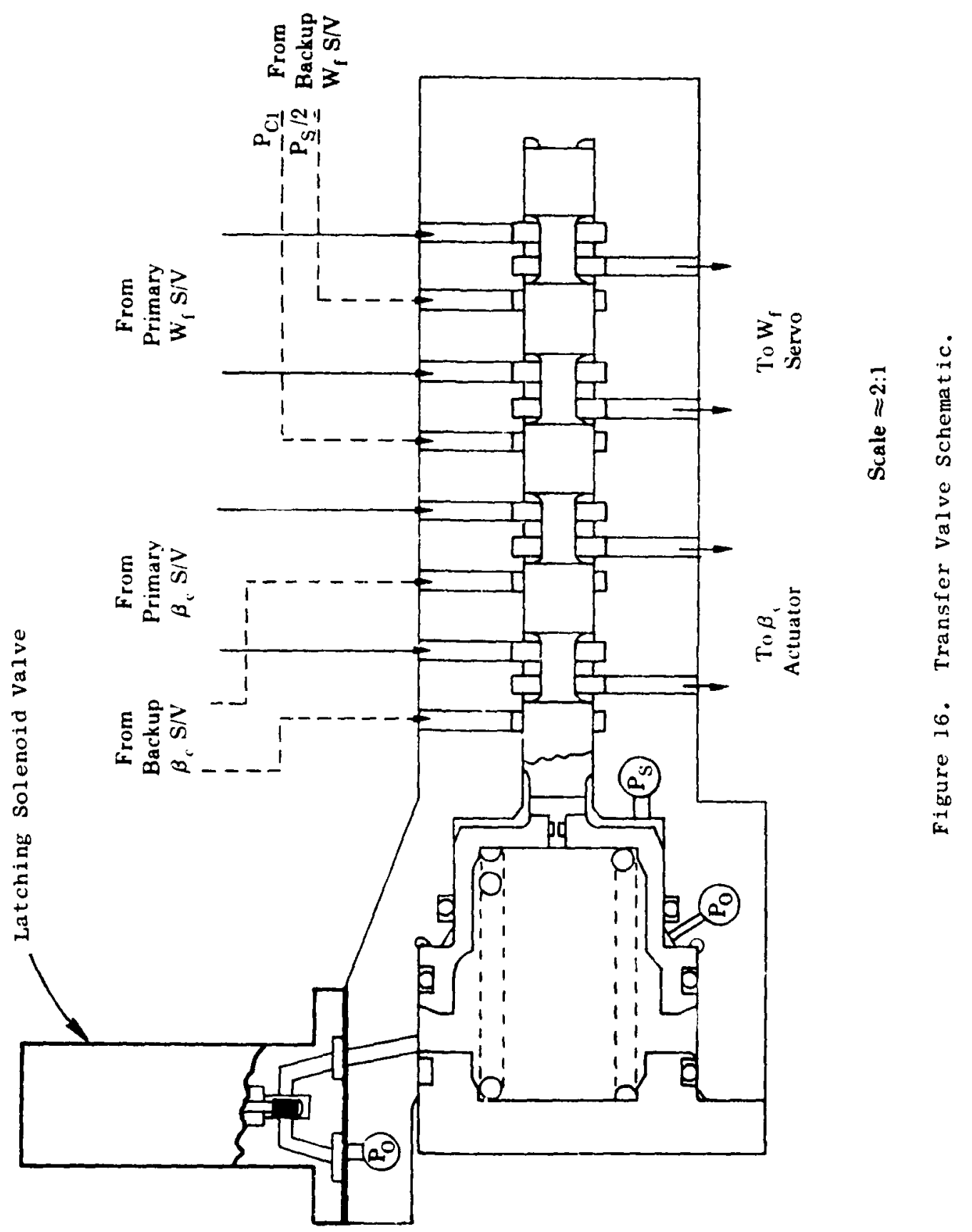




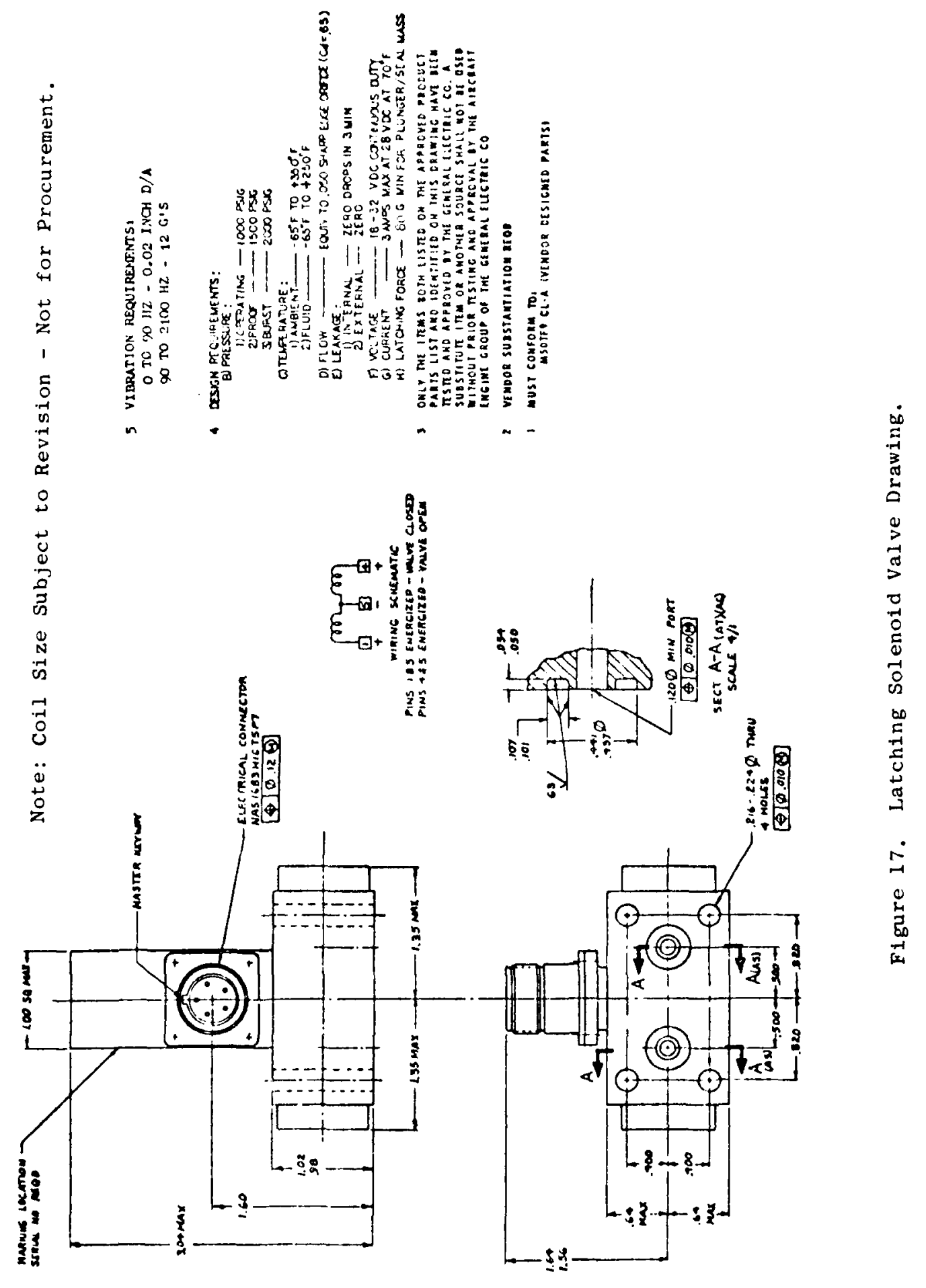




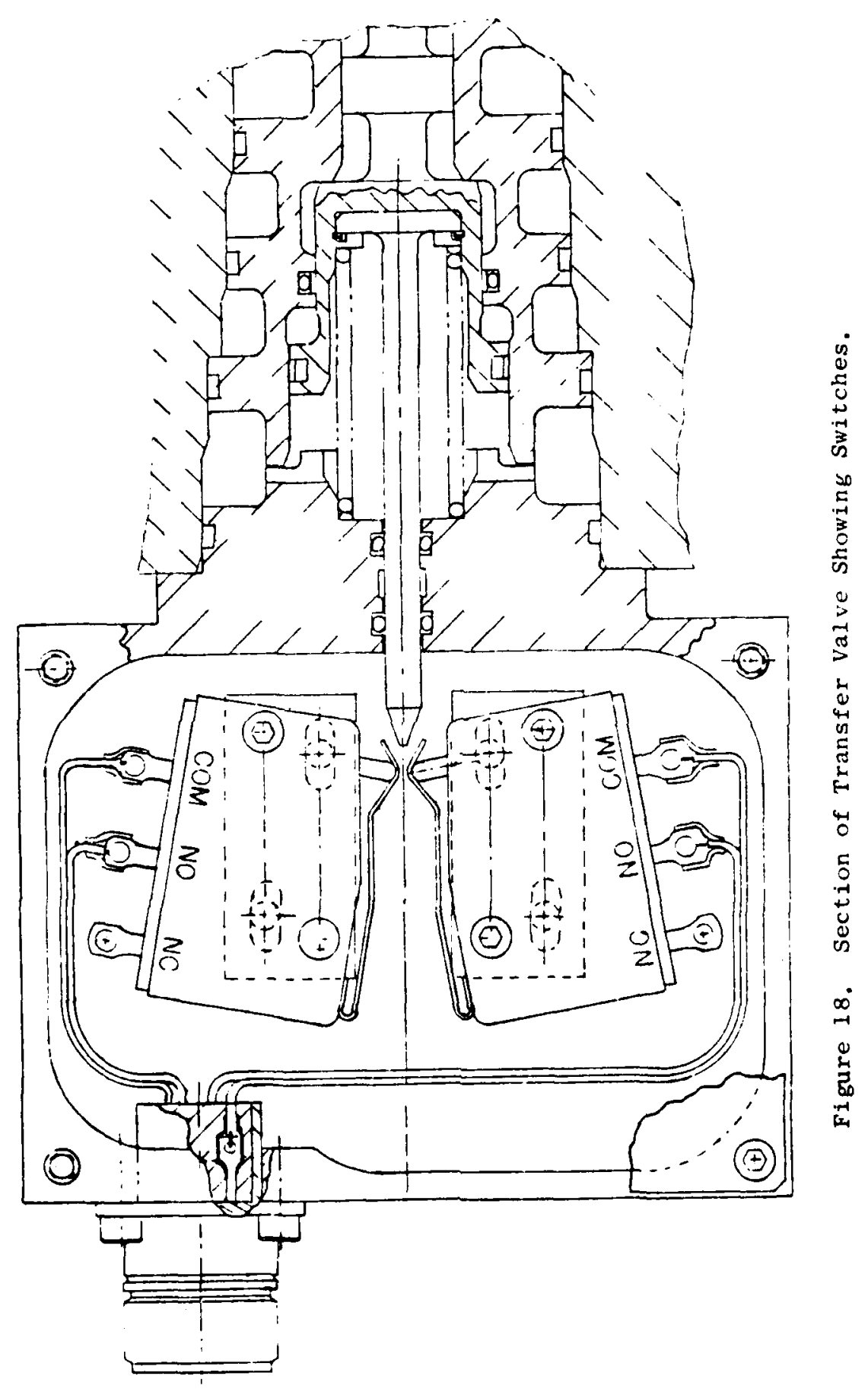


mechanical backup control speed sensor. The switch and the actuat ion means are shown in finnte 19. The swith (lexas Instrument: Part Number MS 24456-3) is the same as those used on the transfer valve. Upon closing, the switch conducts $28-v o l t$ aircrate power to the backup solenoid. (See Figure 1.5.)

The speed sensor piston position is proportional to the square of core RPM ( $\left.\mathrm{N}^{\prime}{ }^{\prime}\right)$. Whon werspeed is encountered, the piston moves the valve spool and spring seat to the left, caming the switch closed.

Referring to Figures 2 and 19 , the spool valve modulates the throttling valve opening pressure $\left(P_{y}\right)$. This action provides $N$; limiting at a level higher than that required to close the overspeed switch. A possible failure mode which makes this additional protection desirable is a stuck-open metering valve.

Both the overspeed switch and the overspeed valve are adjustable. The switch can be moved on it: mounts; and the sleeve for the valve can be shimmed. The nominal RPM settings and range are:

$$
\begin{array}{ll}
\text { Switch } & 104 \%+5 \% \\
\text { Valve } & 107 \%+3 \%,-7 \%
\end{array}
$$

\section{DRIVE AND MOUNTINC, ALAPTER}

The drive and mounting adaiter are shown by Figures 20 through 22 . This adapter mounts the fuel valve, the backup control computer, and the transfer valve. The drive end of the adapter is designed to mount to the JTDE gearbox.

The drive shaft (Figure 20) input is $6690 \mathrm{rpm}$ at $100 \%$ rated JTDE core speed $\left(\mathrm{N}_{\mathrm{G}}\right)$. The drive gear at the computer interface has 45 teeth of 32 diametral pitch. The gear in the computer has 74 teeth so the speed sensor input is $4015 \mathrm{rpm}$. There is an idler gear between the two gears.

A carbon face seal (Sealol Part Number B-56910) rubbing on 440C stainless steel is used to seal fuel from the drive spline area. This seal is used on an aircraft boost pump at approximately the same RPM. The spline at the engine gearbox is oil lubricated and sealed by an o-ring. An overboard drain is provided between the fuel and oil seals.

To allow for possible misalignment, a separate quill shaft is used between the gearbox shaft and the backup control drive shaft. The bearings on the drive shaft are Marlin-Rockwel1 Corporation Part Number 1.04 KS or the equivalent. The outer races of the bearings are clamped by a lock nut. This clamping method is used in engine gearboxes. The second bearing inner race floats to allow for thermal expansion. The expansion was calculated to be 0.016 inch for a temperature change of $300^{\circ} \mathrm{F}$. Bearing loads are modest: $67 \mathrm{lb}$ thrust from a maximum case pressure of 150 psi. The thrust rating for this bearing at $5000 \mathrm{rpm}$ is $500 \mathrm{lb}$. The calculated radial load is $61 \mathrm{~b}$.

The drive shaft and quill shaft are of Nitralloy TM. The gear and 


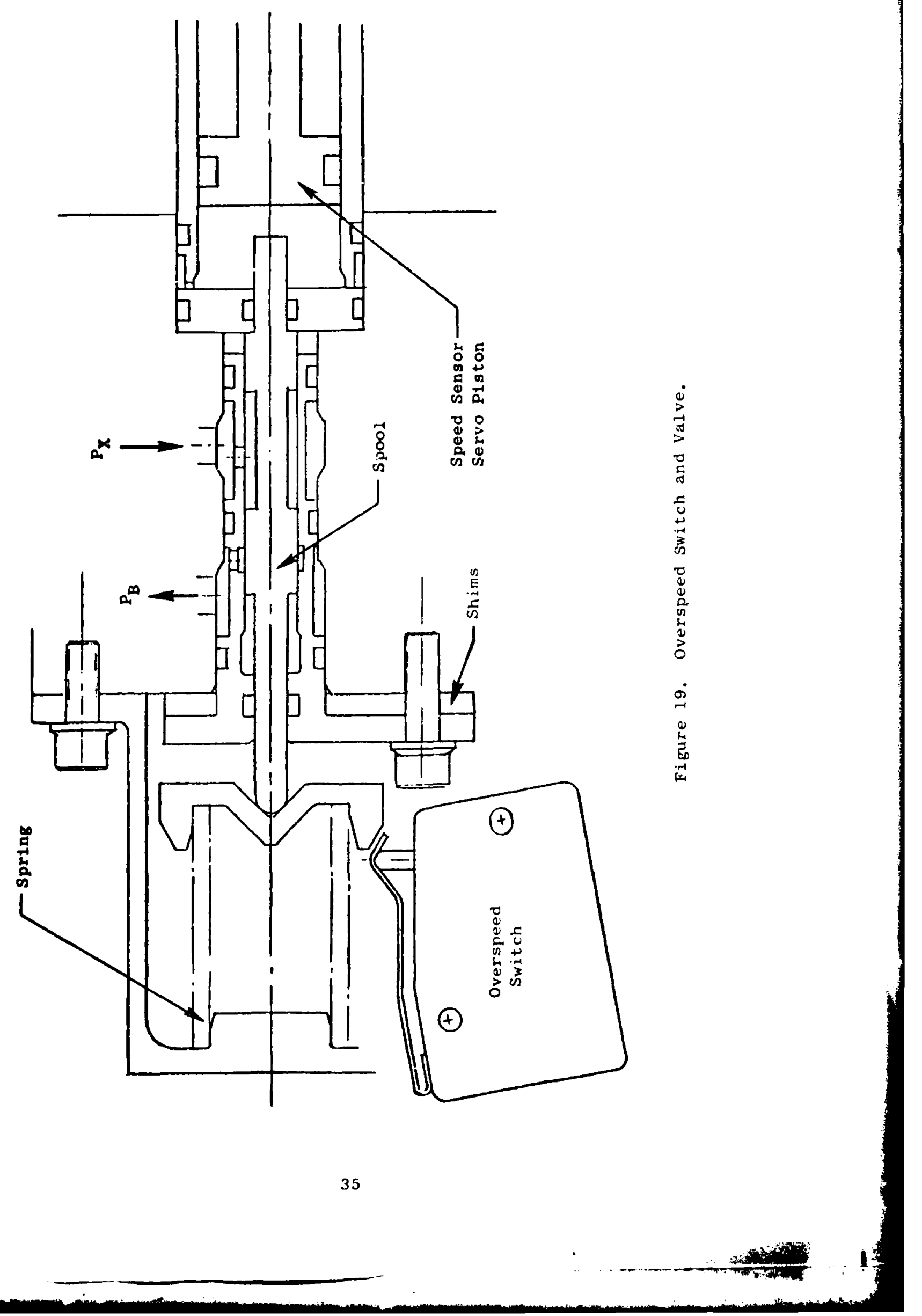




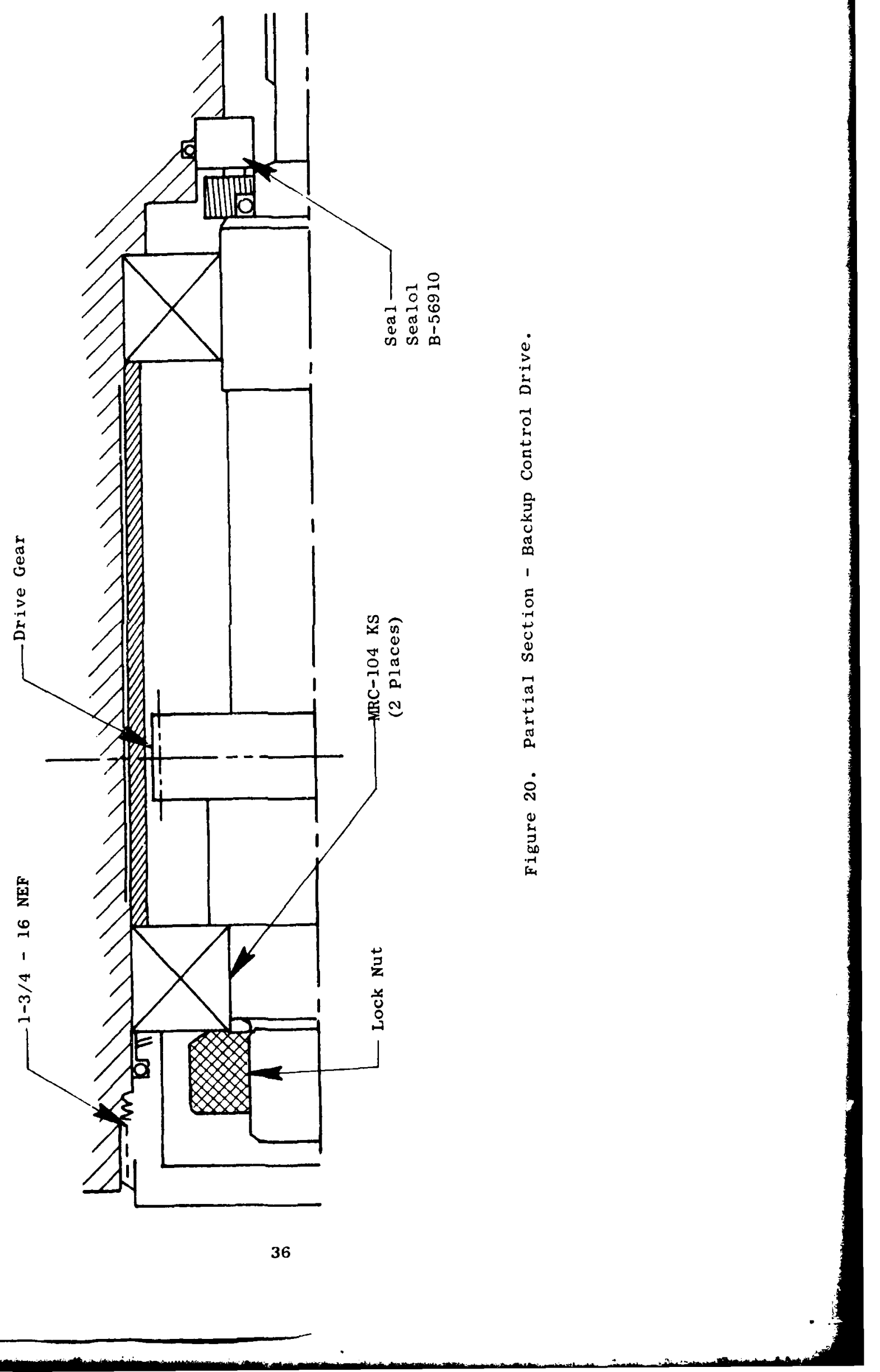




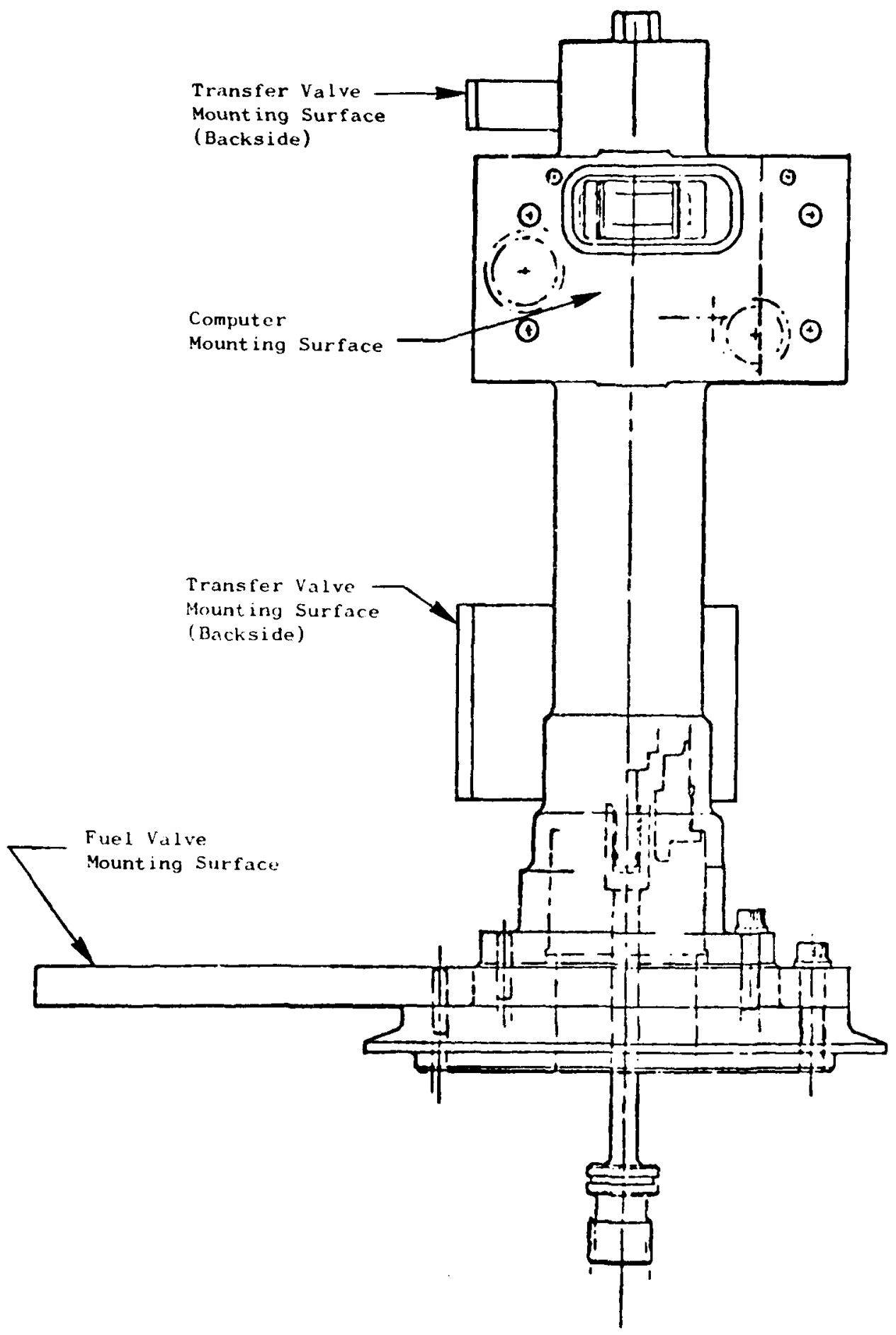

Figure 21. Sketch Showing Drive and Mounting Adapter. 


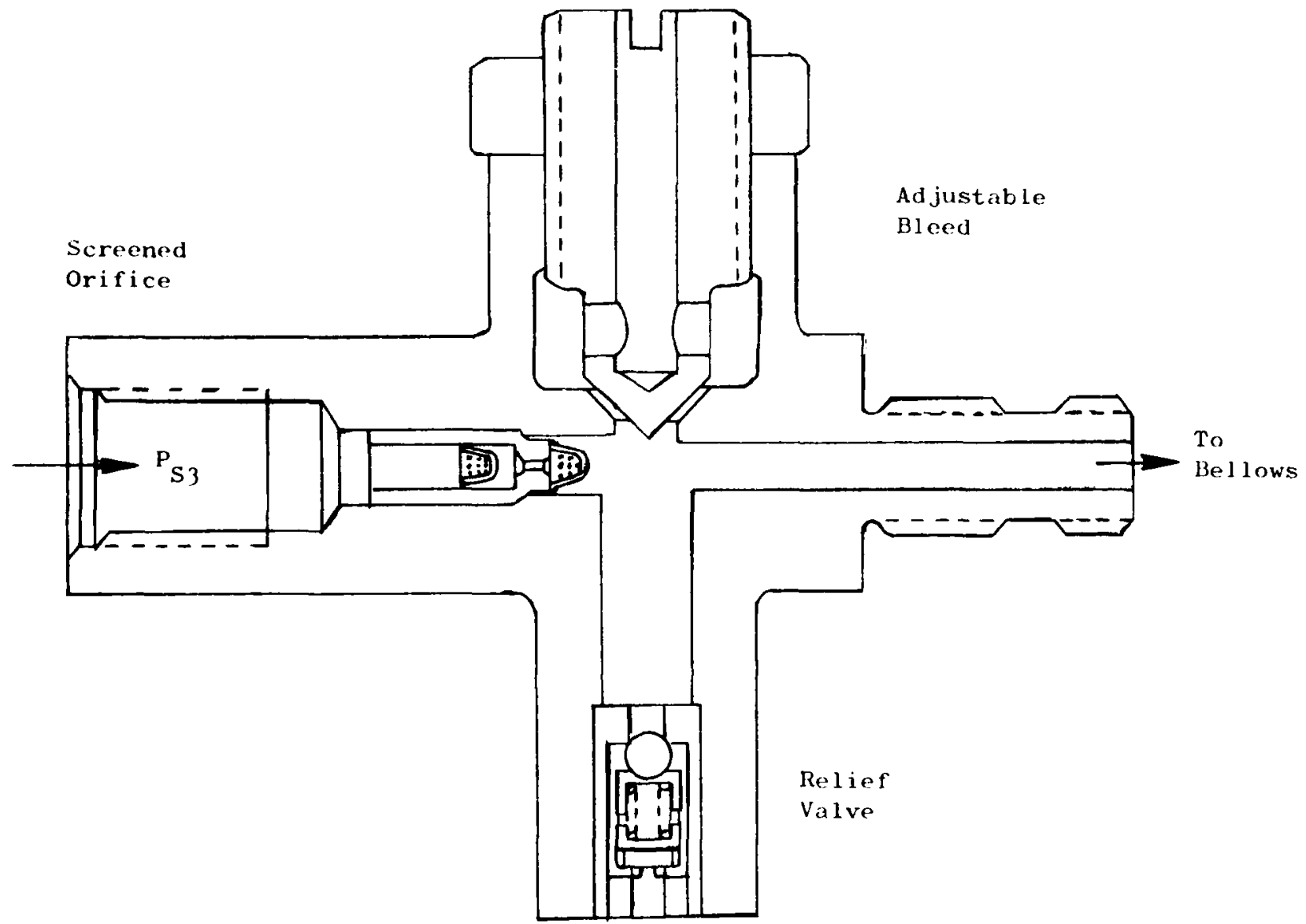

Figure 22. $\mathrm{P}_{\mathrm{S} 3}$ Pressure Divider. 
spline are case hardened (nitrided). The housing is of aluminum alloy AMS $4117(6061-\mathrm{T} 6)$.

Figure 21 shows the adapter. The mounting surfaces for the fuel valve and computer are indicated. The mounting surface for the transfer valve is on the back side of the indicated pad.

\section{PRESSURE DIVIDER}

The $P_{S 3}$ bellows in J85-21 MFC has a 200 psia rated pressure capability. A device consisting of two orifices in series was dosigned (Figure 22). Air from the compressor enters at the left and flows through a screened fixed-area orifice. Air leaves the device through an adjustable bleed which allows calibration. The fitting at the right connects the device to the PS3 transducer in the computer. A reilef valve is provided to protect the bellows in case an overpressure is encountered during test. Both the screened orifice and the relief valve are made by The Lee Company. The pressure divider is adjustable so that the pressure level at the $P_{S 3}$ bellows is 200 psia or less.

A computer program was defined which predicted Wf $/ \mathrm{PS}_{3}$ acceleration schedules using the PS3 pressure divider and the recalibrated T2.5 sensor. Figure 23 shows the predicted schedules for various levels of $\mathrm{T}_{2} .5$ with an existing J85-2l MFC cam (Cam 2108).

\section{OFF-ENGINE UNIT}

The backup control uff-engine unit is shown schematically by Figure 24. This unit simulates the expected pilot's switches normally located in the cockpit. It also contains a relay which allows demonstrating a failure of the primary control. The role this unit plays in regard to backup control transfer logic is discussed in Section II 6 .

Centralab makes the four-position switch (Type PA-2043). Struthers Dunn, Incorporated makes the relay (Part Number FCM-410-109).

\section{TEST CONSOLE}

A test console was designed to substitute for the primary control during bench testing. Figure 25 is the test console block diagram. This unit operated the primary $W_{f}$ and $\beta_{C}$ servo loops. The operator can demand a steady-state $N_{G}$ or an $N_{G}$ ramp just before transfer is initiated. The test console metering valve circuit schematic is shown by Figure 26; the stator circuit schematic, by Figure 27 .

\section{PRODUCTION HARDWARE TESIGN}

The production design of the backup control would have several significant differences. Among these would be:

- The fuel valve, hydromechanical computer, drive, T2.5 sensor, and overspeed valve would all be integrated and housed in one or more machined aluminum castings. 


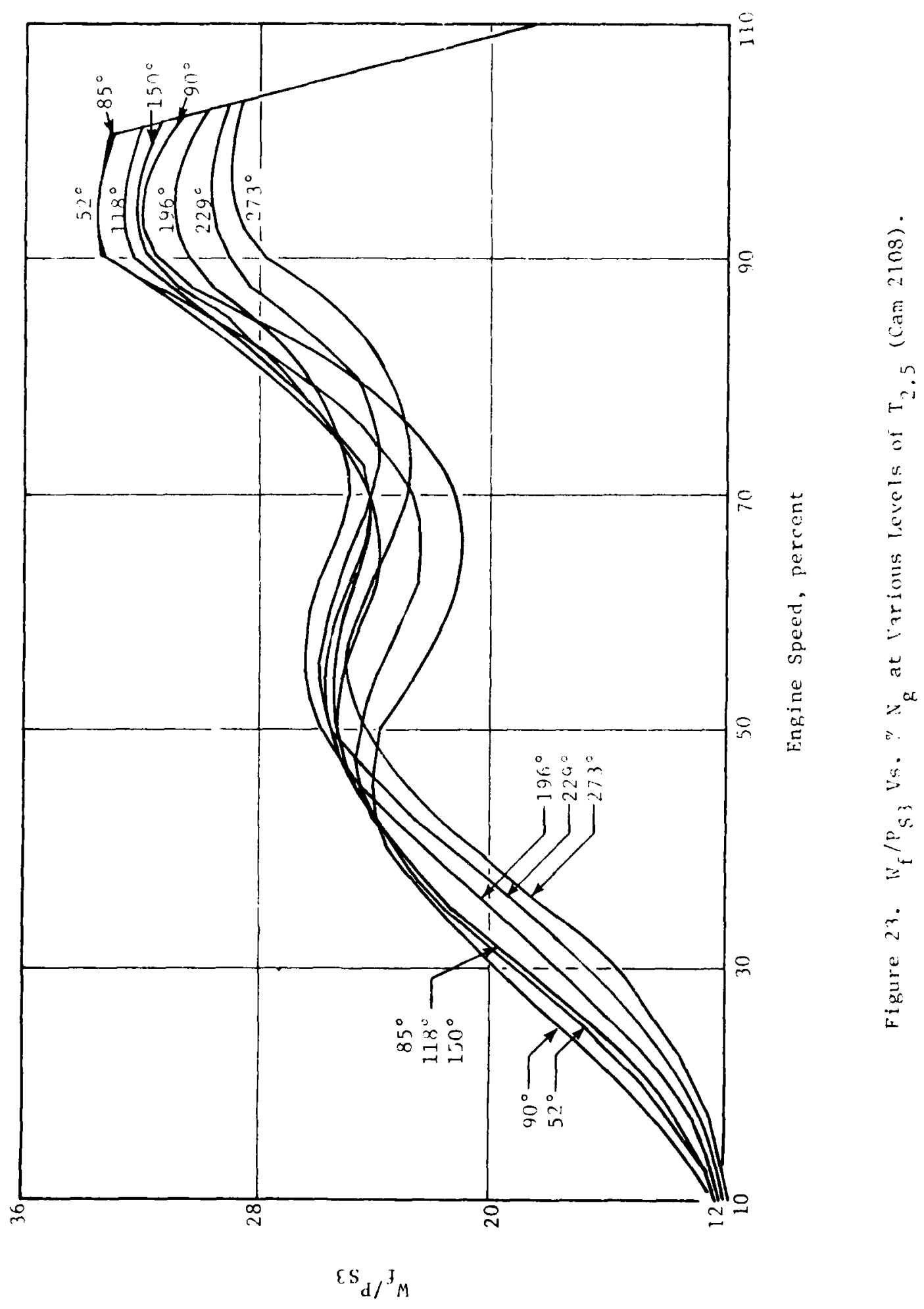




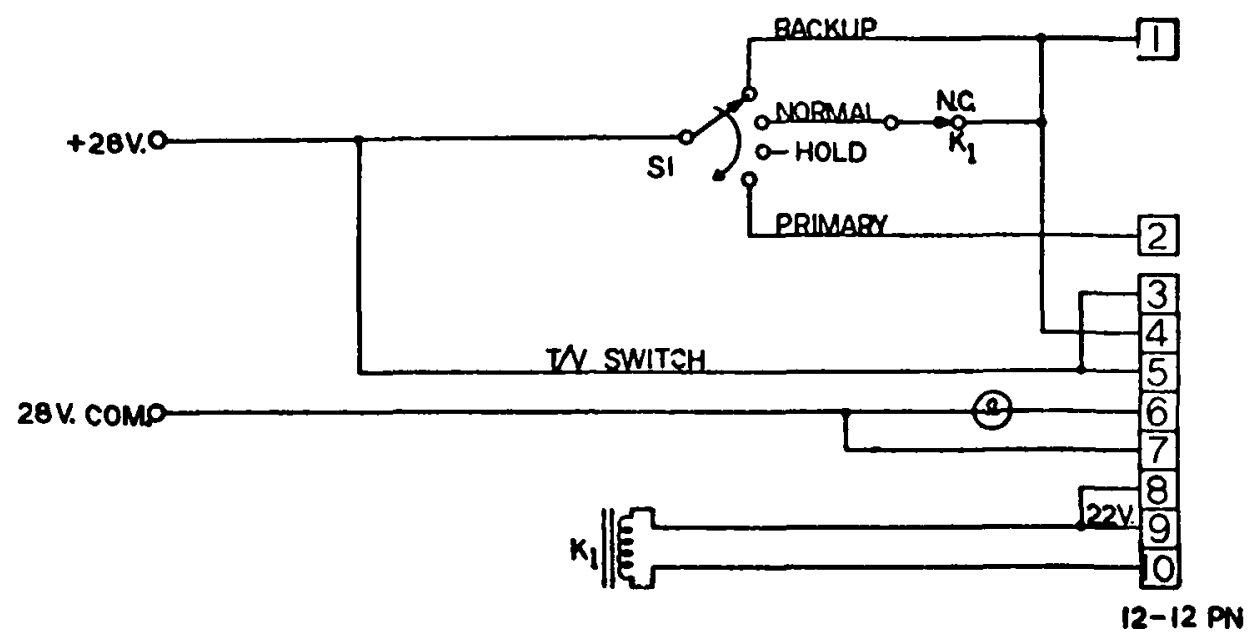

Figure 24. Schematic of the Backup Control off-Engine Unit. 
- The transfer valve assembly would be mounted directly to the housing for the above components and there would be few, if any, external lines. The body would be of cast aluminum.

- The uverspeed switch would be mounted to the computer housing in a manner similar to that shown for this version of the backup control.

- The off-engine unit would te replaced by equivalent parts in the cockpit and in the primary contro1.

The anticipated external appearance of the backup control would be similar to that of a conventinnal hydromechanical main fuel control with a transfer valve assembly mounted to one side.

The cost, weight, and size of the production version of the backup control were estimated during Phase I of this program. The results were:

Cost (1977 dollars)

Weight

Size
$\$ 11,800$

$20.21 \mathrm{~b}$

259 in. 3 


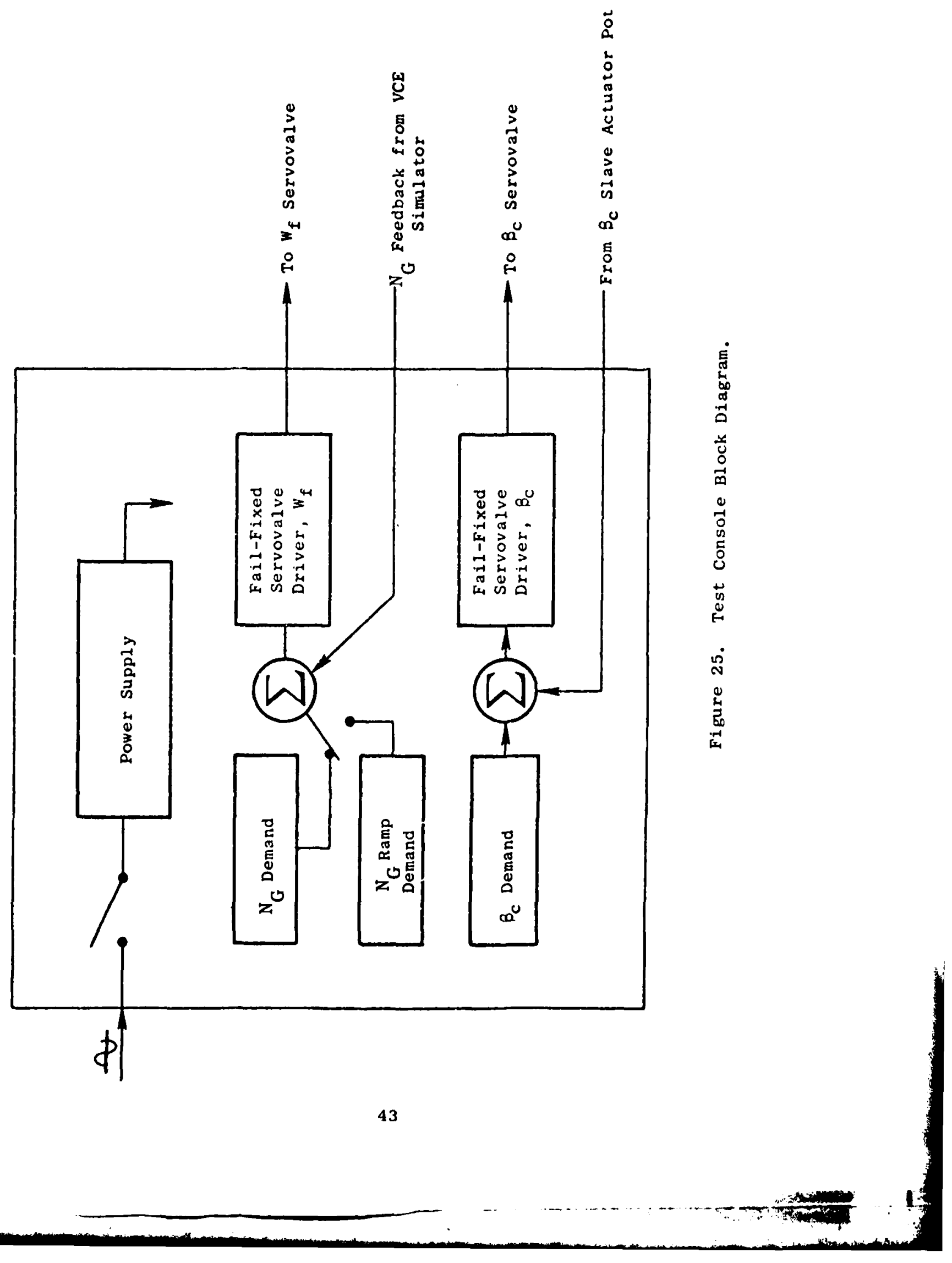




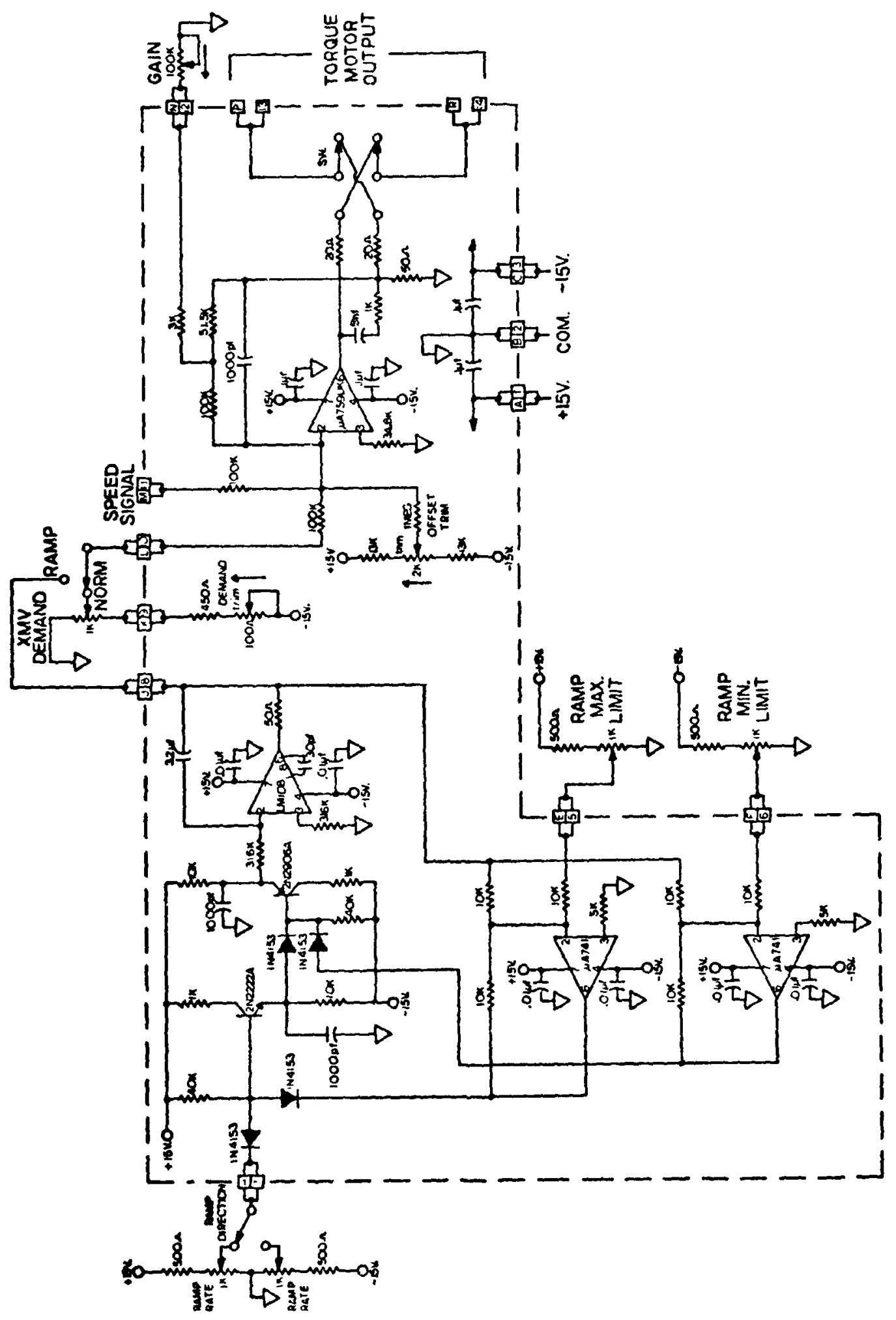

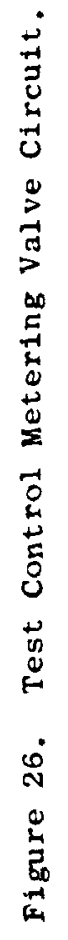

44 


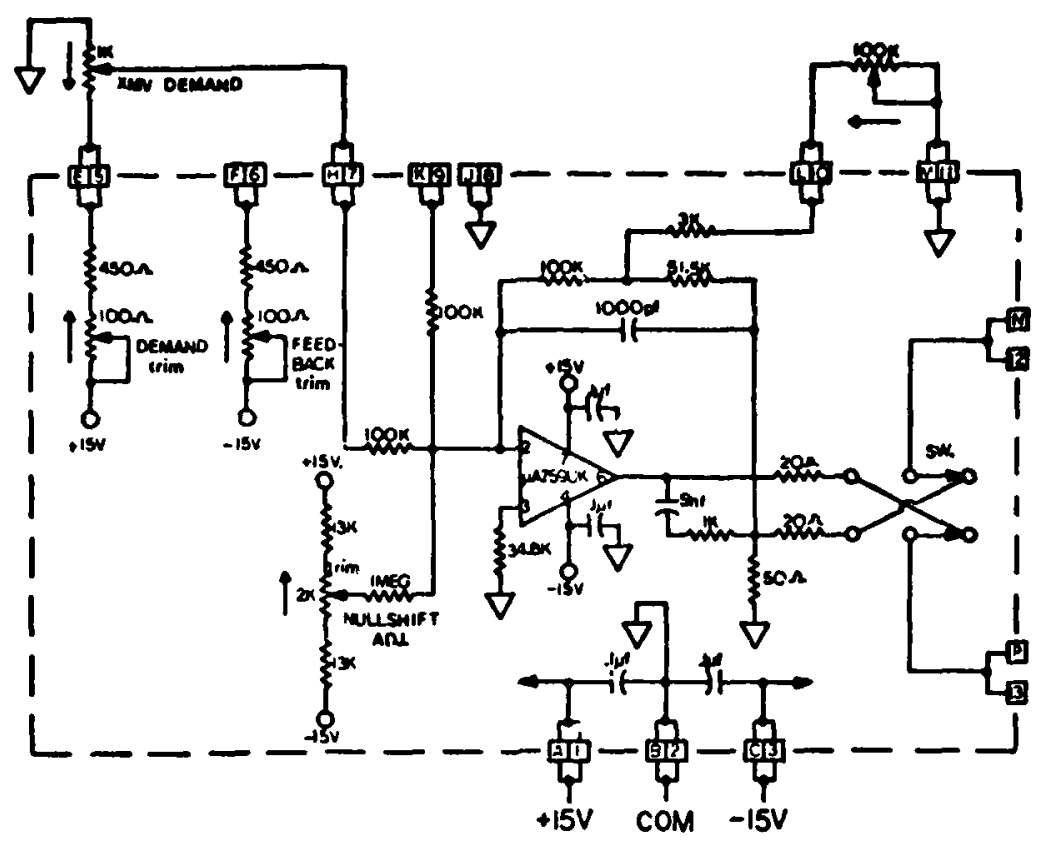

Figure 27. Test Console Stator Circuit.

45 
SECTION II 1

FABRICATION OF HARDWARE

\section{HYDROMECHANTCAL COMPUTER AND COMPRESSOR INLET TFMPERATURE SENSOR}

The hydromechanical computer and compressor inlet temperature sensor $\mathrm{T}_{2.5}$ for the backup control are the equivalent portion of the J85-CE21 Main Fuel Control. These components are production items at General Electric's AEG, Lynn, Massachusetts, facility. The housings for both assemblies are of cast aluminum.

Figlire 28 shows the computer and sensor.

\section{FUEL VALVE ASSEMELY}

The fuel valve was designed at the General Electric AEG, Evendale, Ohio, facility. Most of the detail parts are the same as those used for the fuel valve designed, fabricated, and tested for the Light weight Fuel Delivery System Program conducted by General Electric for the U.S. Navy.

The detail parts were manufactured by various independent machine shops. The body was machined from 6061-T6 aluminum. The other parts are prototype flight-type design. Figure 29 shows the fuel valve parts.

The fuel valve was assembled at the General Electric Company facility in Evendale, Ohio.

\section{TRANSFER VALVE ASSEMBLY}

The transfer valve assembly was specifically designed for the backup control. The detail drawings were prepared at General Electric's Evendale, Ohio facility.

The detail parts were manufactured by outside machine shops. The housing was machined from aluminum plate stock. The valve spool and sleeve are of AMS 5630 stainless steel, hrat treated to a minimum hardness of Rockwe11 $15 \mathrm{~N}-87$.

The transfer valve assembly also involves some major purchased components. These include:

- The fuel metering servovalve, which is of the jet-pipe fail-safe type, was purchased from the Aerospace Division of the Abex Corporation (Vendor Part Number 72144).

- The $B_{C}$ servovalve, also of the jet-pipe fail-safe type, was purchased from Aerospace Division, Abex Corporation (Vendor Part Number 72137).

- The latching solenoid vaive, which is a shear type, was purchased from the Valcor Engineering Corporation (GE Part Number 4013145-337). 


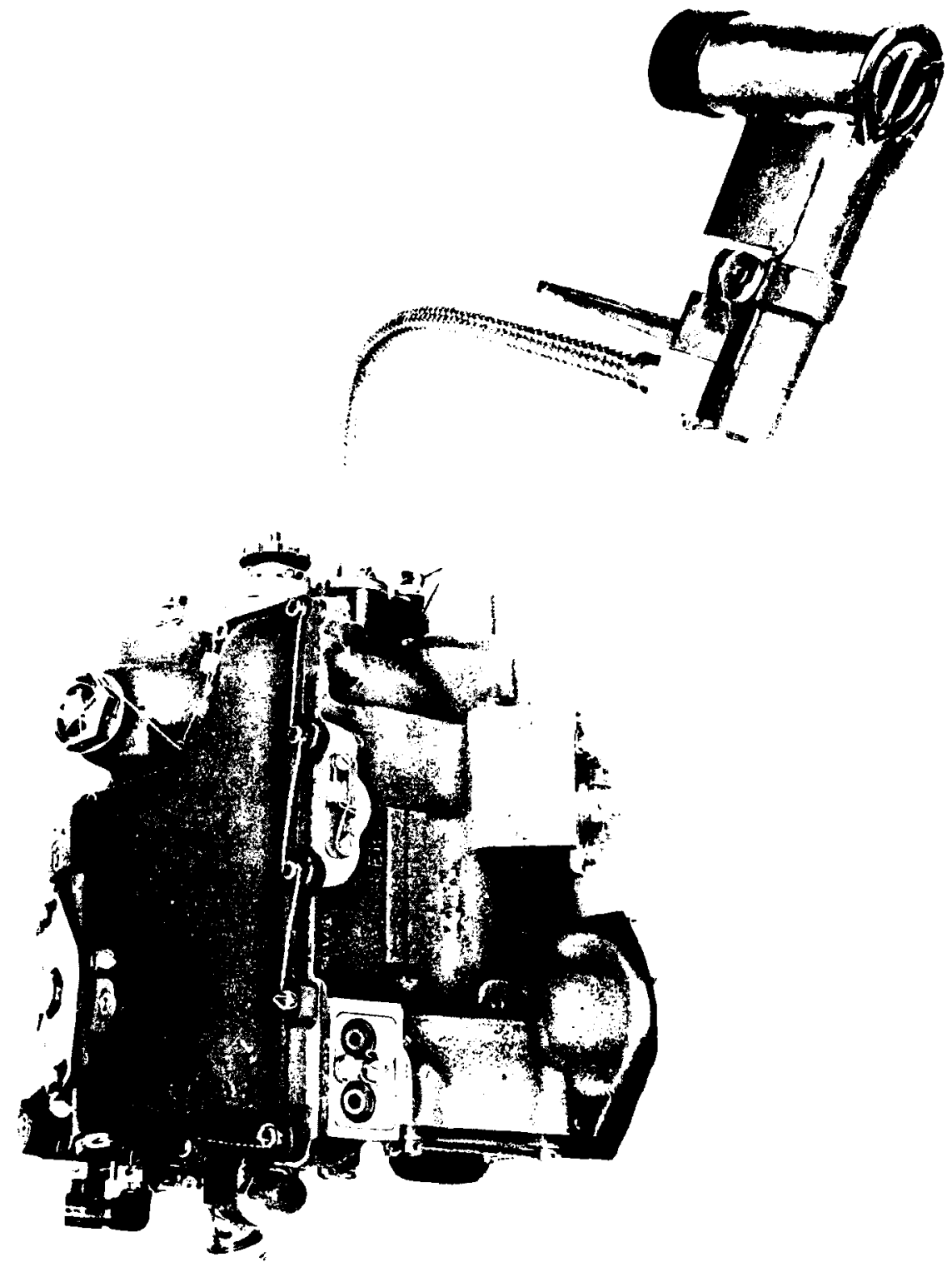

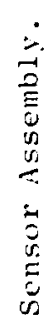

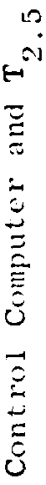

$\stackrel{x}{N}$

$\underset{\substack{0 \\:}}{0}$ 


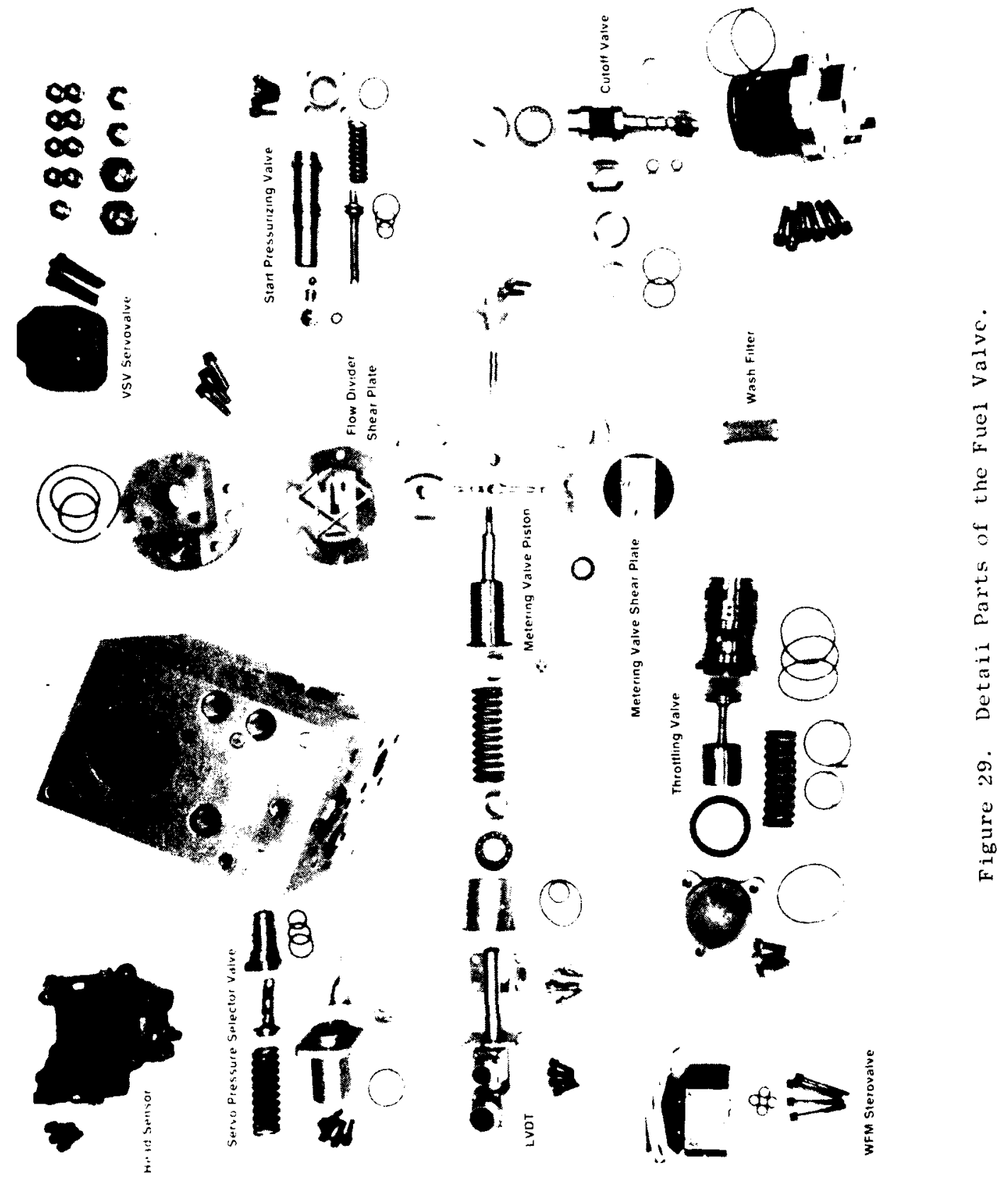


30.

The overall transfer valve assembly is shown (photographed) in Figure

\section{DRIVE ADAPTER, MECHANICAL POSITION FEEDBACK, AND OVERSPEED ASSEMBLIES}

The drive adapter, mechanical position feedback and overspeed assemblies were designed specifically for the backup control. The detail drawings were prepared at the General Electric Company, Lynn, Massachusetts, facility.

The detail parts were manufactured by outside machine shops. All housings were machined from aluminum bar or plate. The parts were assembled internally at General Electric's Lynn, Massachusetts, facility. Where rework was necessary, this was also done at the Lynn facility.

Figure 31 shows the drive adapter, mechanical position feedback mechanism and overspeed switch detail parts. Figure 32 shows the hydromechanical portion of the backup control.

\section{OFF-ENGINE UNIT AND BACKUP CONTROL TEST CONSOLE}

The off-engine unit and the test conscle are electrical assemblies that were designed within the Advanced Controls and Accessories Electrical Engineering Unit of General Electric's AEG located at Evendale, Ohio. The piece parts were purchased. Assembly was done by the same people who designed the two units.

Figure 33 shows the resulting hardware. 


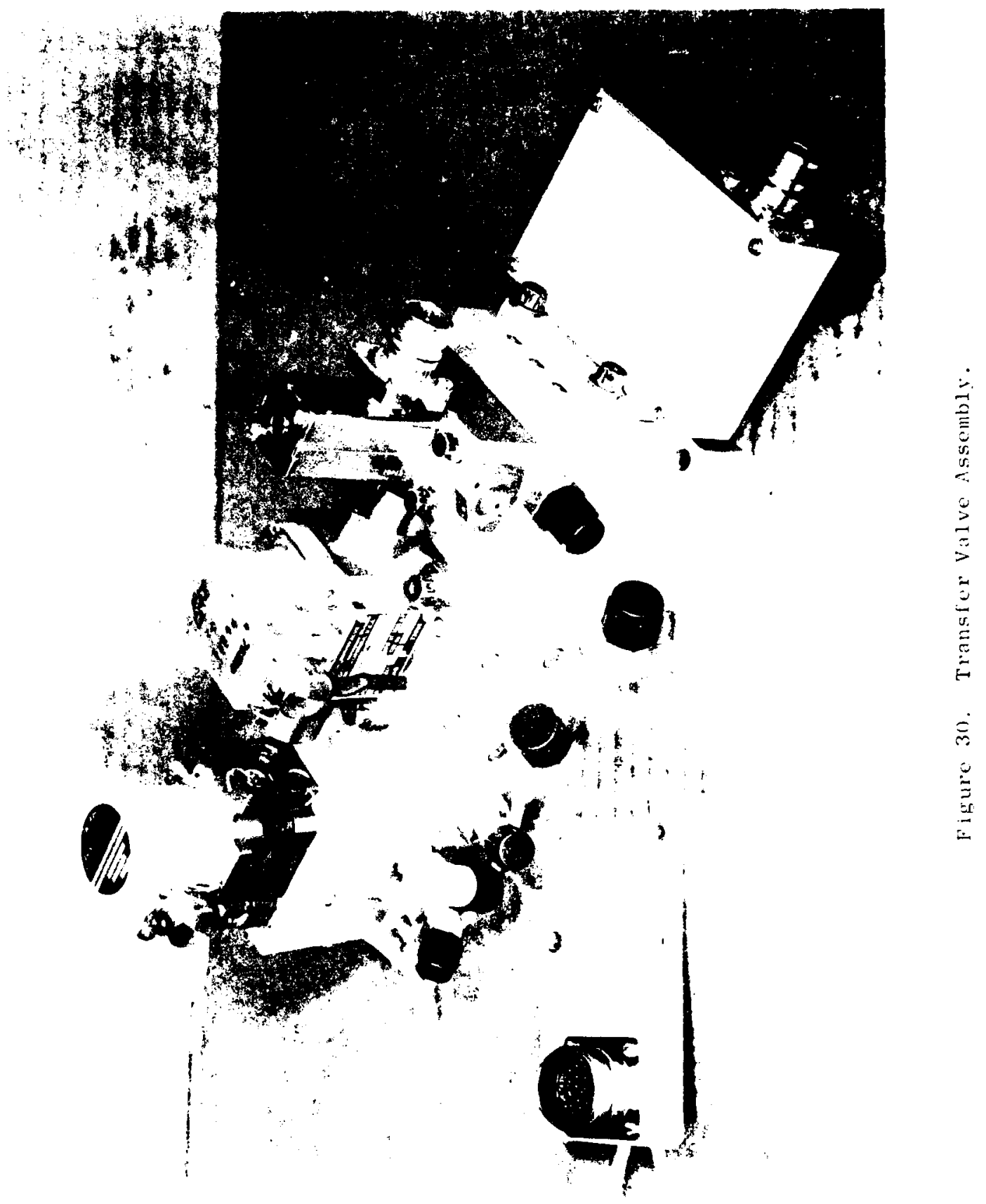




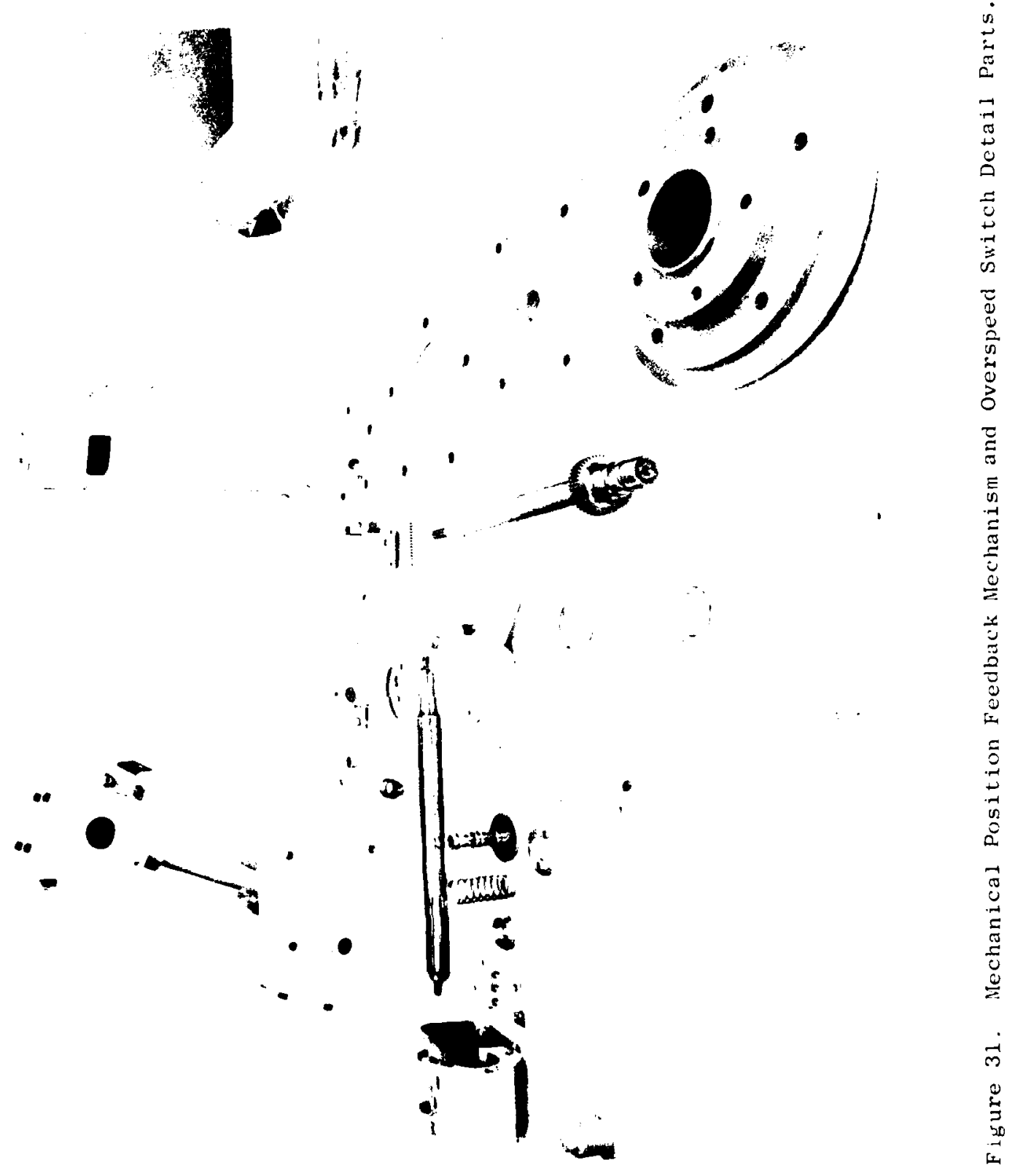

51 


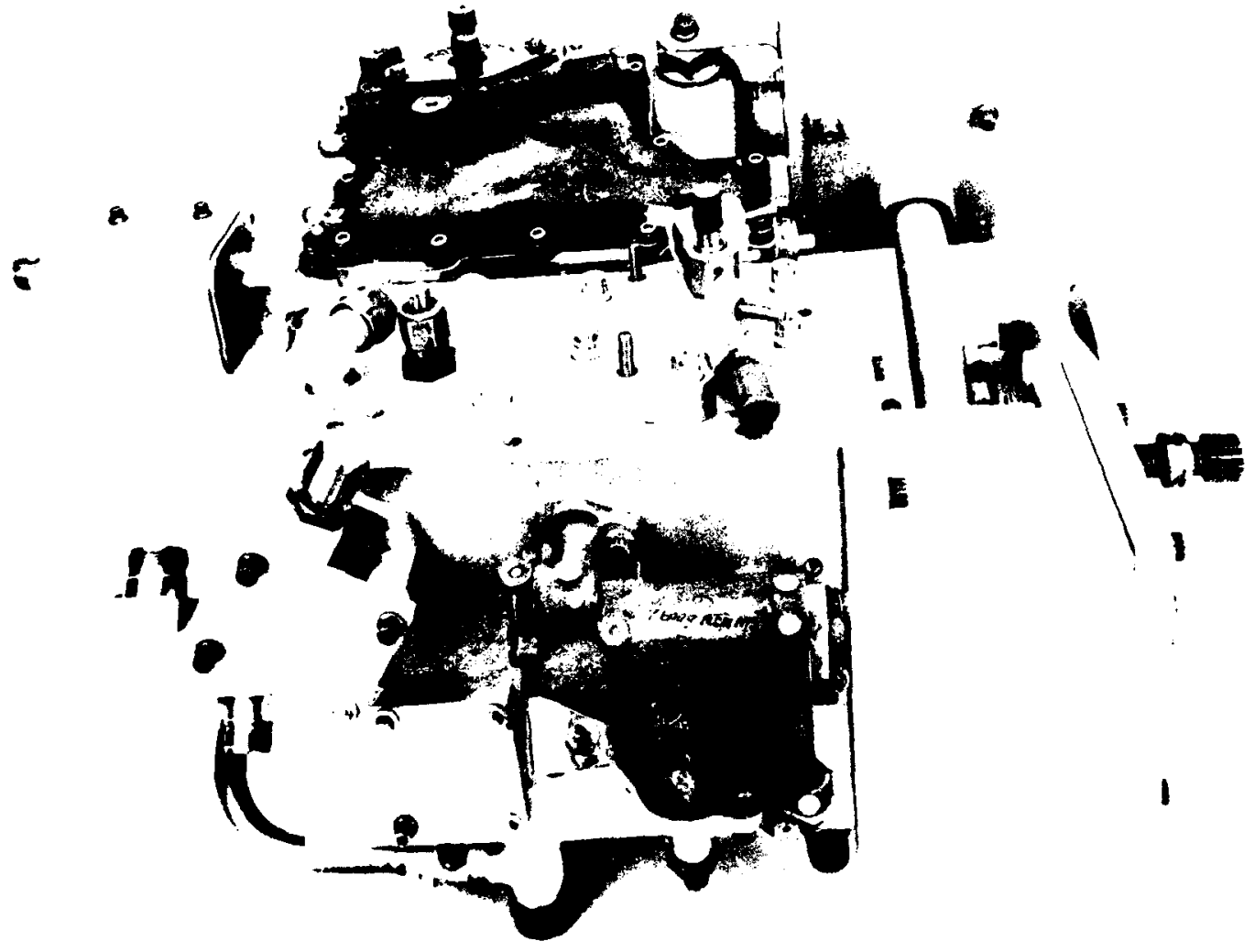

Figure 32. Hydromechanical Portion of the Backup Control. 


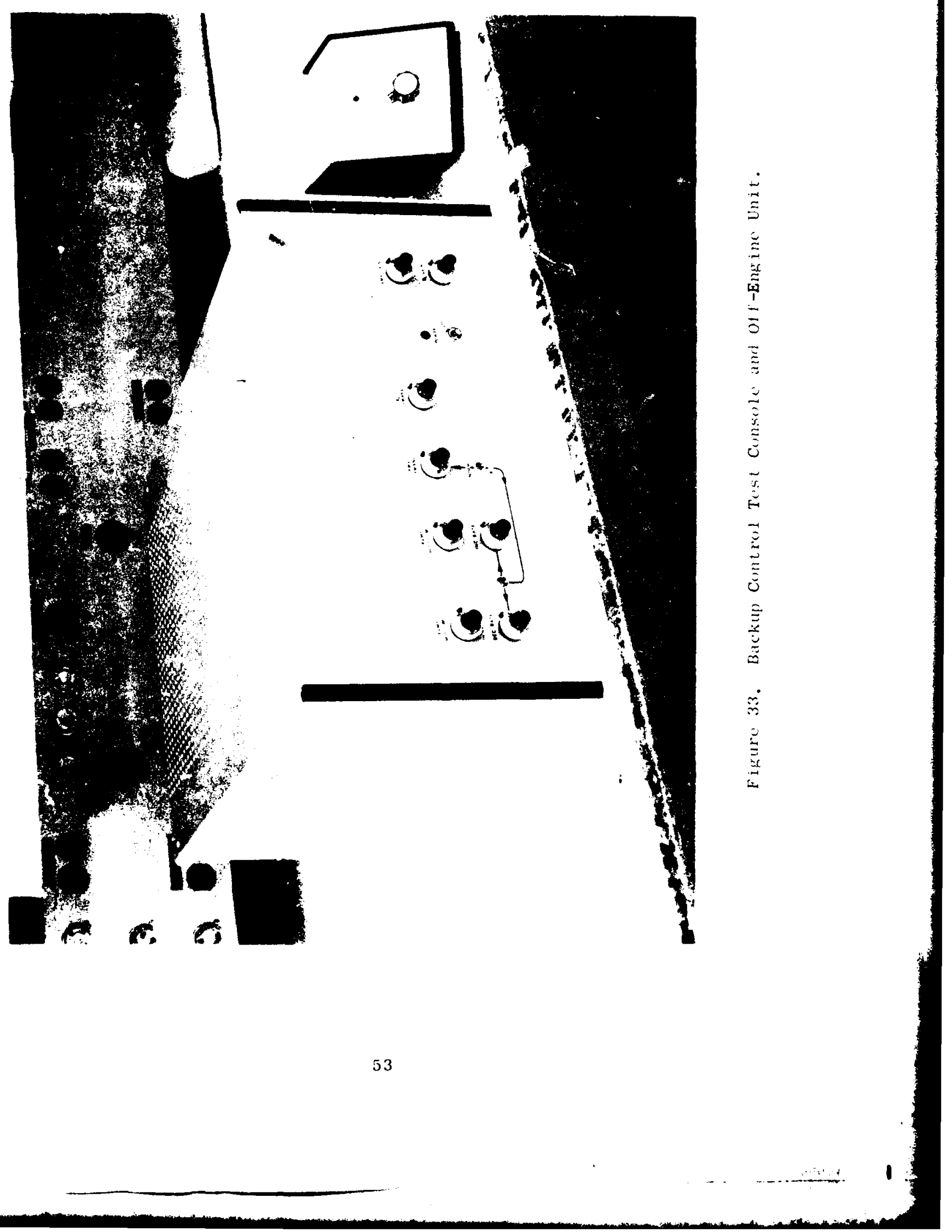




\section{SECTION IV}

TEST PLANNING

\section{ACCELERATION SCHEDULE}

The GE23/J1A3 engine acceleration schedule was selected as the goal for calibrating the backup control. The plan was to use the J85-21 Main Fuel Control 3-D cam (2108) and make modifications so that the GE23/J1A3 acceleration schedule at the nominal $\mathrm{T}_{2}$, and $\mathrm{P}_{\mathrm{T} 2}$ test condition $\left(\mathrm{T}_{2.5}=\right.$ $224^{\circ} \mathrm{F}$ and $\mathrm{P}_{\mathrm{T} 2}=20$ psia) could be approximated.

The modifications to the computer and $\mathrm{T}_{2.5}$ sensor were:

- A pressure divider (see Paragraph II-10) was added between the P 3 source and the control, reducing the pressure at the bellows to $63 \%$ of the actual $\mathrm{P}_{\mathrm{S} 3}$.

- The $T_{2}$ sensor (see Paragraph II-3) was recalibrated so that its range was $20^{\circ} \mathrm{F}$ to $360^{\circ} \mathrm{F}$ instead of the J85 range of $-65^{\circ} \mathrm{F}$ to $275^{\circ} \mathrm{F}$.

- A bias force equivalent to -5.0 psia $P_{S 3}$ was applied by means of an available adjustment.

The predicted analytical results are shown in Figure 34. The GE23/ JlA3 acceleration schedule was for the digital electronic engine control. The two schedules are quite similar. The approximation was considered very satisfactory for the planned bench tests of the backup control. These data were used to determine the acceleration schedule limits for the calibration $\log$ sheets.

\section{ENGINE MODEL}

The GE23/J1A3 engine model was selected for the closed-loop testing of the backup control. The model is shown by Figures 35 through 37 . This core engine is very similar to the core engine for the JTDE. The rated engine rotational speed at the control drive pad is 6739 rpm versus $6690 \mathrm{rpm}$ for the JTDE - a close match.

\section{EXPECTED TRANSIENT RESPONSE}

Fuel flow response in both transfer and backup operation is dictated by the characteristics of the metering valve servo system, which includes the nutcracker and metering valve piston. Referencing Figure 38, the basic equations describing this portion of the control are derived as follows: 


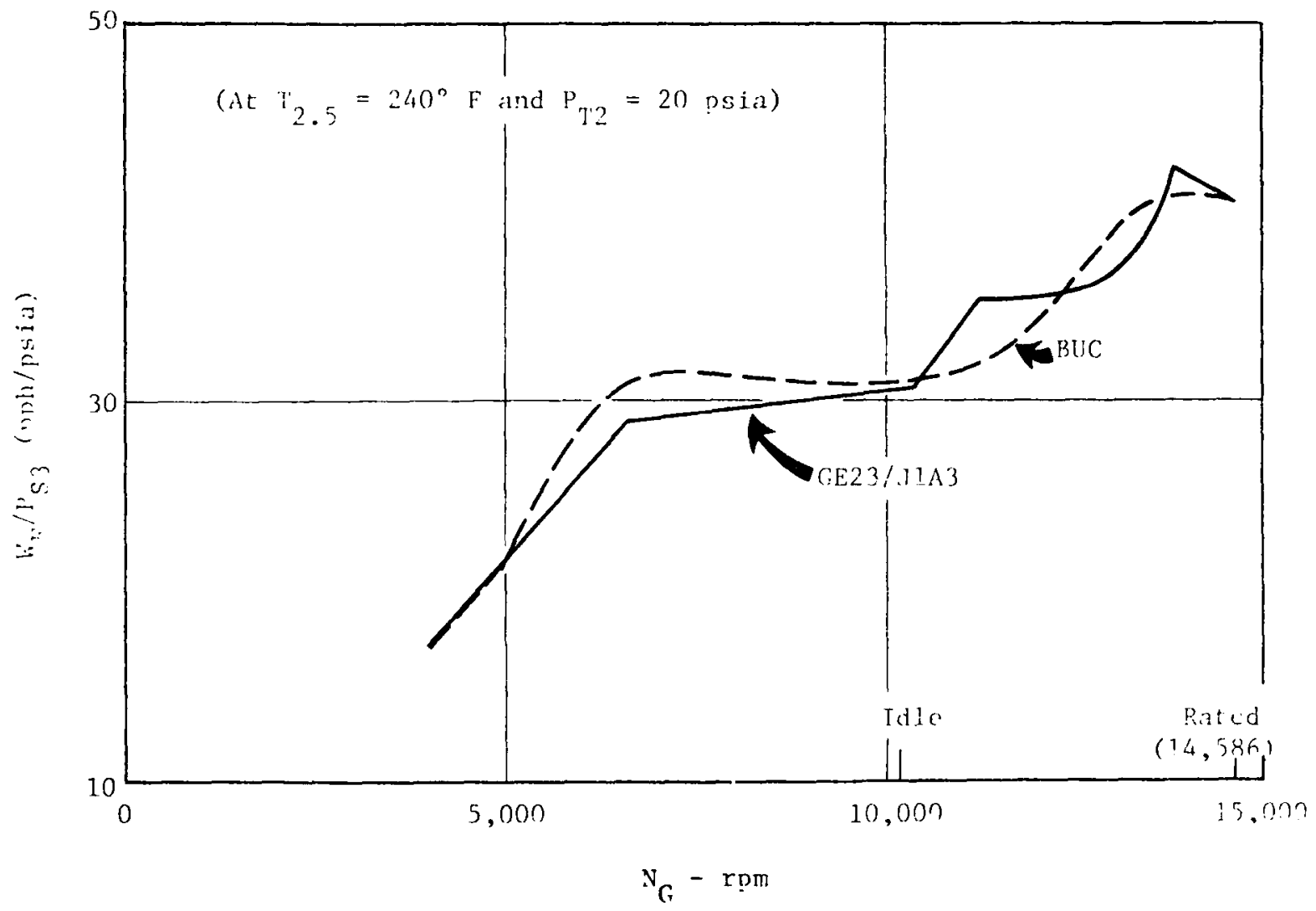

Figure 34. Comparison of Accel Schedules. 


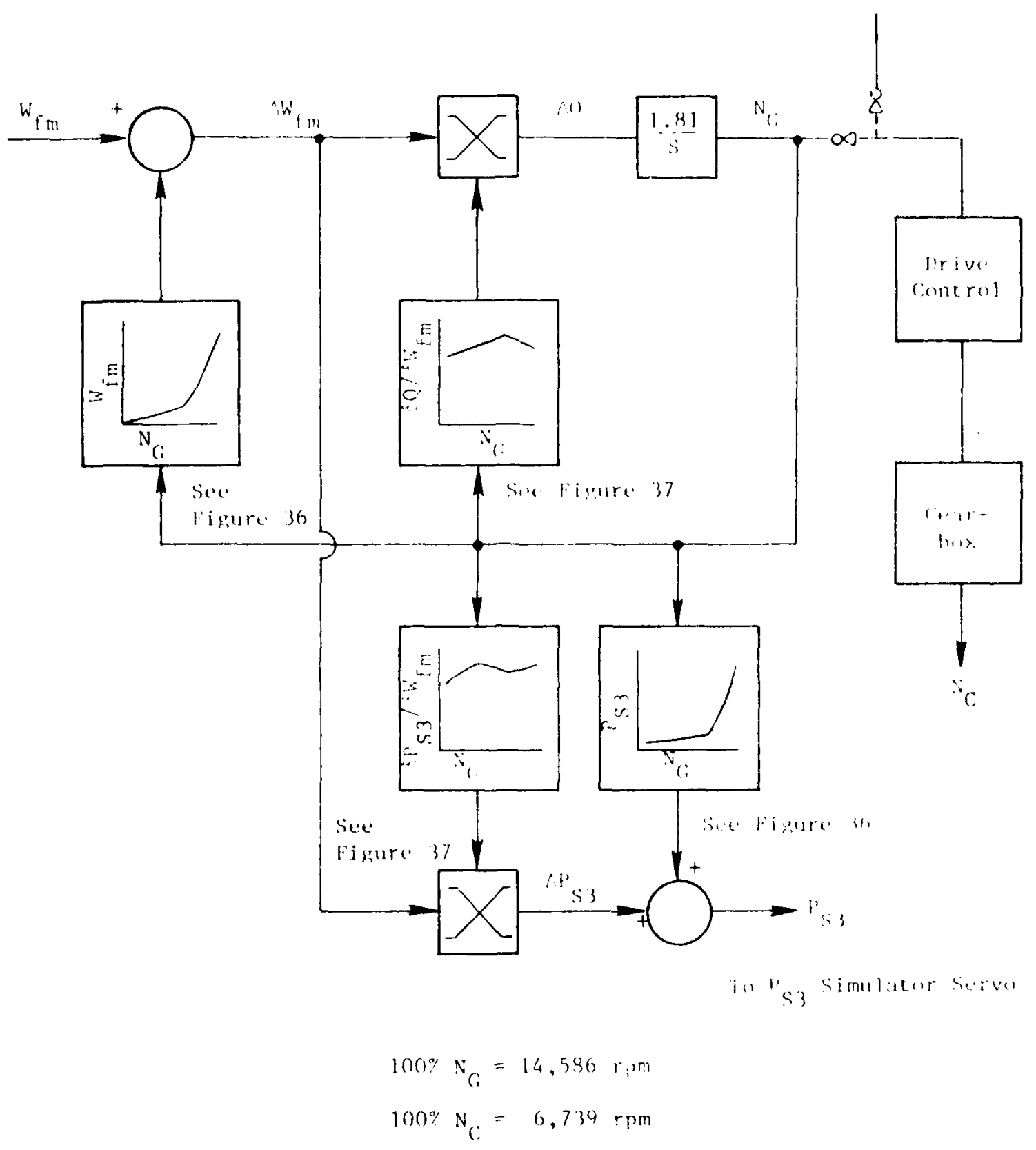

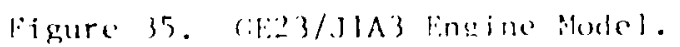



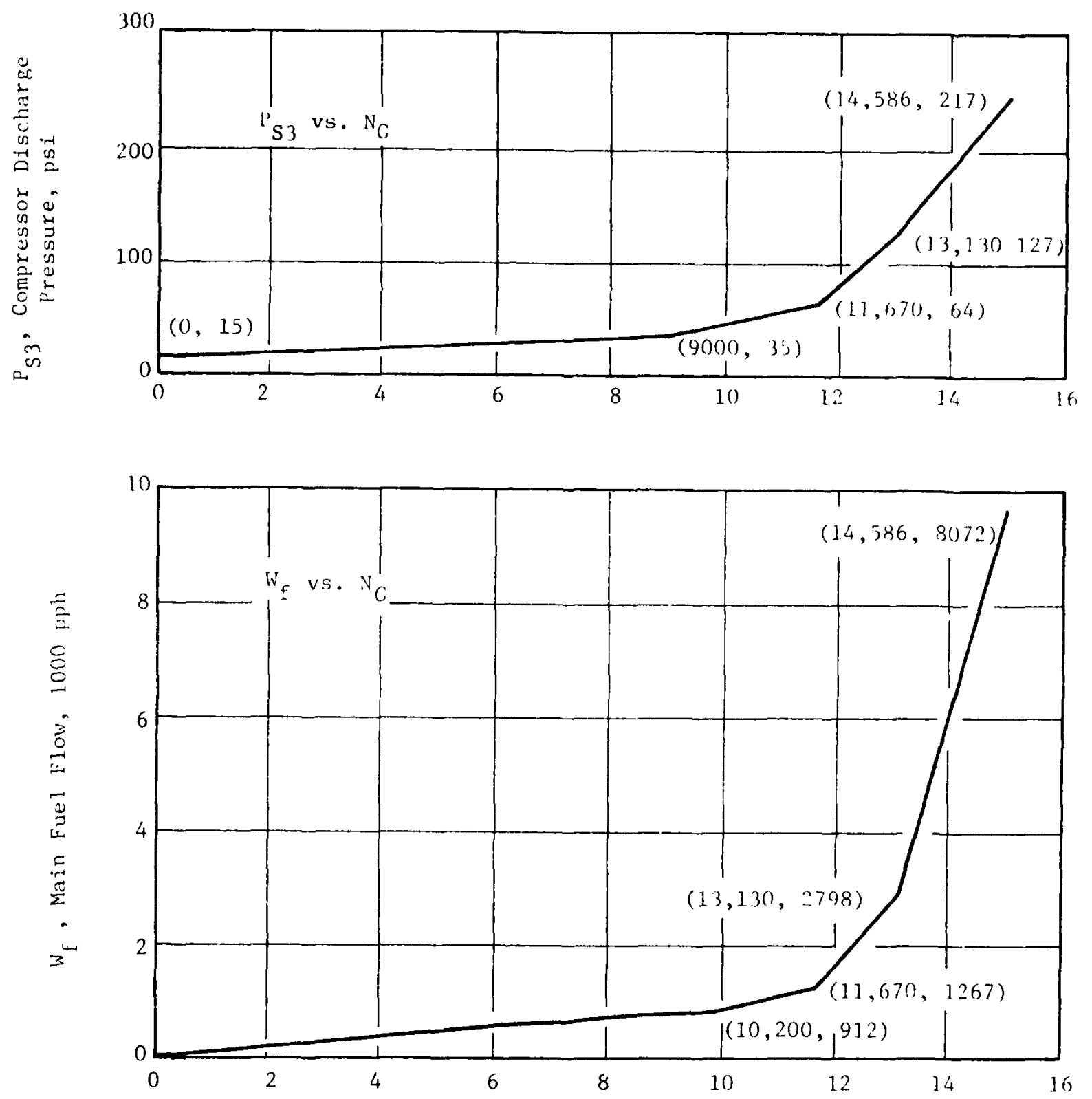

$\mathrm{N}_{G}$, Core Rotor Speed, $1000 \mathrm{rpm}$

Figure 36. GE23/J1A3 Loop Closure Functions. 

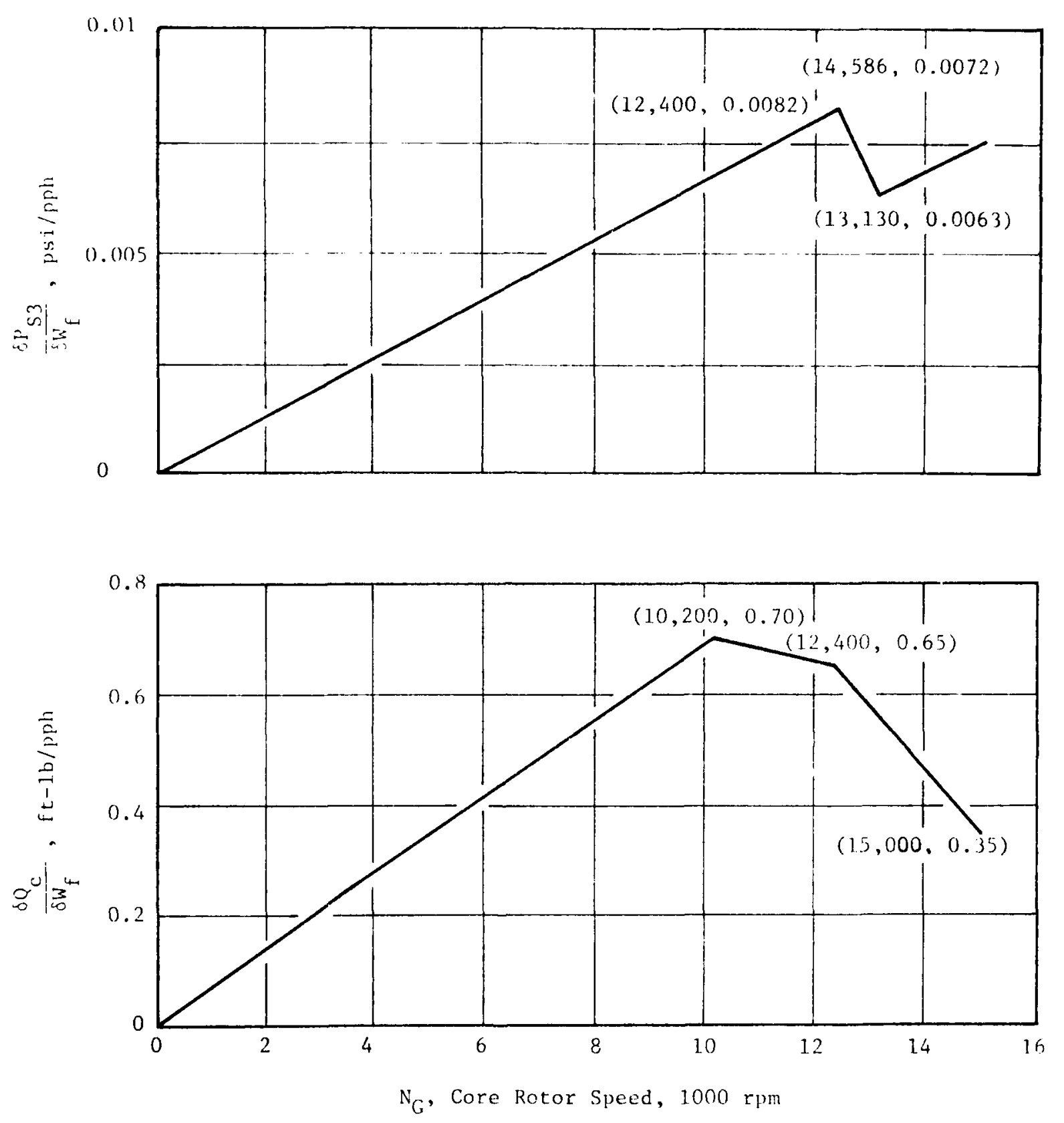

Figure 37. CE23/JlA3 Loop Closiure Partials. 


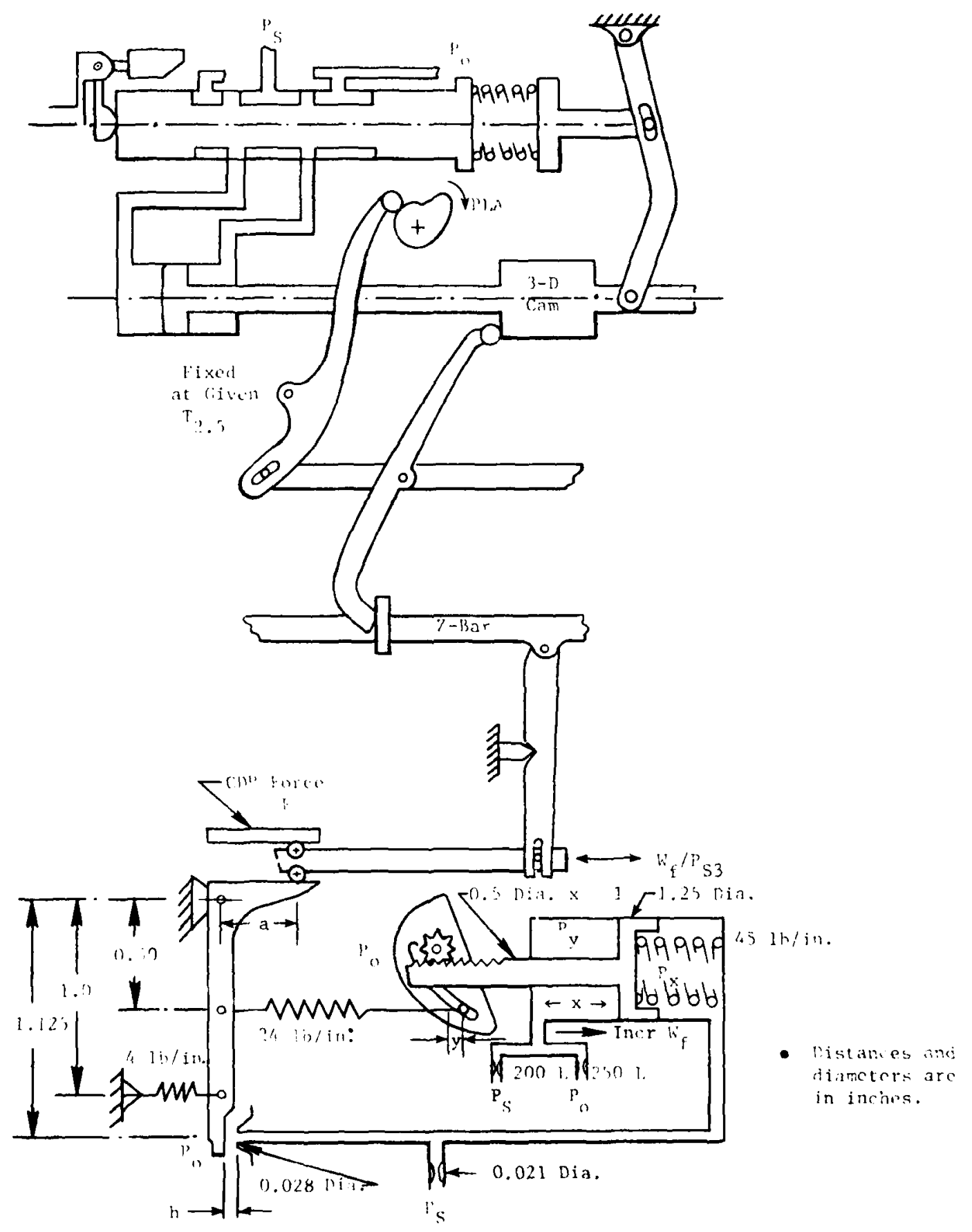

Figure 38. Backup Control Governor, Nutcracker, and Metering Valve Servo Mechanization. 
The input, "a," is linear with $\mathrm{W}_{\mathrm{f}} / \mathrm{P}_{\mathrm{S} 3}$ demand. Therefore,

$$
a=k_{0}\left(W_{f} / P_{S 3}\right)
$$

where " $\mathrm{a}$ " is positive in the direction that opens the flapper.

From a moment balance on the error bar, we get:

$$
\begin{aligned}
& F(a)+R_{4}\left[L_{4}-\frac{1}{1.125}\left(h-h_{0}\right)\right]=R_{24}\left[L_{24}+\frac{0.5}{1.125}\left(h-h_{0}\right)+\right. \\
& \left.\left(y-y_{0}\right)\right](0.5)
\end{aligned}
$$

From a force balance on the power piston, we get:

$$
\begin{aligned}
& \mathrm{R}_{45}\left(\mathrm{~L}_{45}+\mathrm{x}\right)+(0.785) \mathrm{D}_{1}^{2}\left(\mathrm{P}_{\mathrm{x}}-\mathrm{P}_{\mathrm{o}}\right)=(0.785) \\
& \left(\mathrm{D}_{2}^{2}-\mathrm{D}_{1}^{2}\right)\left(\mathrm{P}_{\mathrm{y}}-\mathrm{P}_{\mathrm{x}}\right)
\end{aligned}
$$

A pressure balance from rod-to-case gives:

$$
\left(P_{y}-P_{0}\right)=\left(P_{y}-P_{x}\right)+\left(P_{x}-P_{0}\right)
$$

From a flow balance on the head end of the power piston, we get:

$$
\begin{aligned}
& \frac{146(0.785) D_{0}^{2}}{\sqrt{\rho}} C_{0} \sqrt{\left(P_{s}-P_{x}\right)}+(0.785) D_{2}^{2} \dot{x}= \\
& 146 \underset{{\sqrt{N} \frac{\left.\pi B_{N} h\right)}{\rho}}^{\left(P_{x}-P_{0}\right)}}{\sqrt{\left(P_{x}\right.}}+
\end{aligned}
$$

From a flow balance on the rod end of the piston, we get:

$$
\frac{77}{200} \sqrt{\left(P_{s}-P_{y}\right)}=(0.785)\left(D_{2}^{2}-D_{1}^{2}\right) \dot{x}+\frac{77}{250} \sqrt{\left(P_{x}-P_{0}\right)}
$$

(in LOHM form)

A LOHM is a unit of resistance to fluid flow where 1000 LOHMS will flow $50 \mathrm{pph}$ of water at 25 psid.

More pressure balances give:

$$
\begin{aligned}
& \left(P_{s}-P_{0}\right)=\left(P_{s}-P_{y}\right)+\left(P_{y}-P_{0}\right) \quad\left(P_{s}-P_{0}=\text { Constant }\right) \\
& \left(P_{s}-P_{0}\right)=\left(P_{s}-P_{x}\right)+\left(P_{x}-P_{0}\right)
\end{aligned}
$$


The feedback spring cam motion gives:

$$
y=1.152 x^{2}
$$

In the above nine equations, there are ten variables, all of which, except for the input $\left(\mathrm{W}_{\mathrm{f}} / \mathrm{P}_{\mathrm{S3}}\right)$, appear at least twice. It is therefore possible to find $x$ as a function of $W_{f} / P_{S 3}$.

Linearizing, transforming, and combining the above equations gives:

$$
\begin{aligned}
& \Delta \mathbf{a}=\mathrm{K}_{\mathrm{o}} \Delta\left(\mathrm{W}_{\mathrm{f}} / \mathrm{P}_{\mathrm{S} 3}\right) \\
& F \wedge a-R_{4}\left(\frac{1}{1.125}\right) \Delta h=R_{24}\left(\frac{0.5}{1.125}\right) \Delta h(0.5)+R_{24}(0.5) \Delta y \\
& \mathrm{R}_{45} \Delta \mathrm{x}+(0.785) \mathrm{D}_{1}{ }^{2} \Delta\left(\mathrm{P}_{\mathrm{x}}-\mathrm{P}_{\mathrm{o}}\right)=(0.785)\left(\mathrm{D}_{2}^{2}-\mathrm{D}_{1}{ }^{2}\right)\left[\Delta\left(\mathrm{P}_{\mathrm{y}}-\mathrm{P}_{\mathrm{o}}\right)-\right. \\
& \left.\Delta\left(\mathrm{P}_{\mathrm{x}}-\mathrm{P}_{0}\right)\right] \\
& \frac{-146 C(0.785) D_{O}^{2}}{2 \sqrt{\rho} \sqrt{\left(P_{s}^{\left.-P_{x}\right)}\right.}} \Delta\left(P_{x}-P_{0}\right)+(0.785) D_{2}{ }^{2} s \Delta x=
\end{aligned}
$$

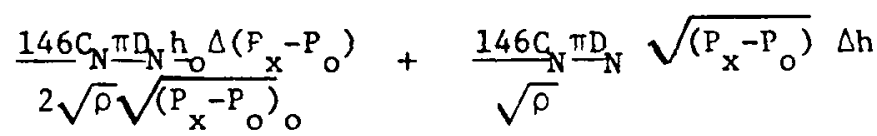

$$
\begin{aligned}
& \frac{-77}{2(200) \sqrt{\left.P_{s}-P_{y}\right)_{0}}} \Delta\left(P_{y}-P_{0}\right)=0.785\left(D_{2}^{2}-D_{1}^{2}\right) S \Delta x+ \\
& \frac{77}{2(250) \sqrt{\left(\mathrm{P}_{y}-\mathrm{P}_{0}\right)_{0}}} \Delta\left(\mathrm{P}_{\mathrm{y}}-\mathrm{P}_{\mathrm{o}}\right) \\
& \Delta y=2(1.152) x_{0} \Delta x
\end{aligned}
$$

Figure 39 shows the above equations in block diagram form.

Figure 40 is a repeat of Figure 39 using the following constants and steady-state conditions for $13,500 \mathrm{pph}$ flow and $\mathrm{P}_{\mathrm{s}}-\mathrm{P}_{\mathrm{o}}=1050 \mathrm{psi}$ : 


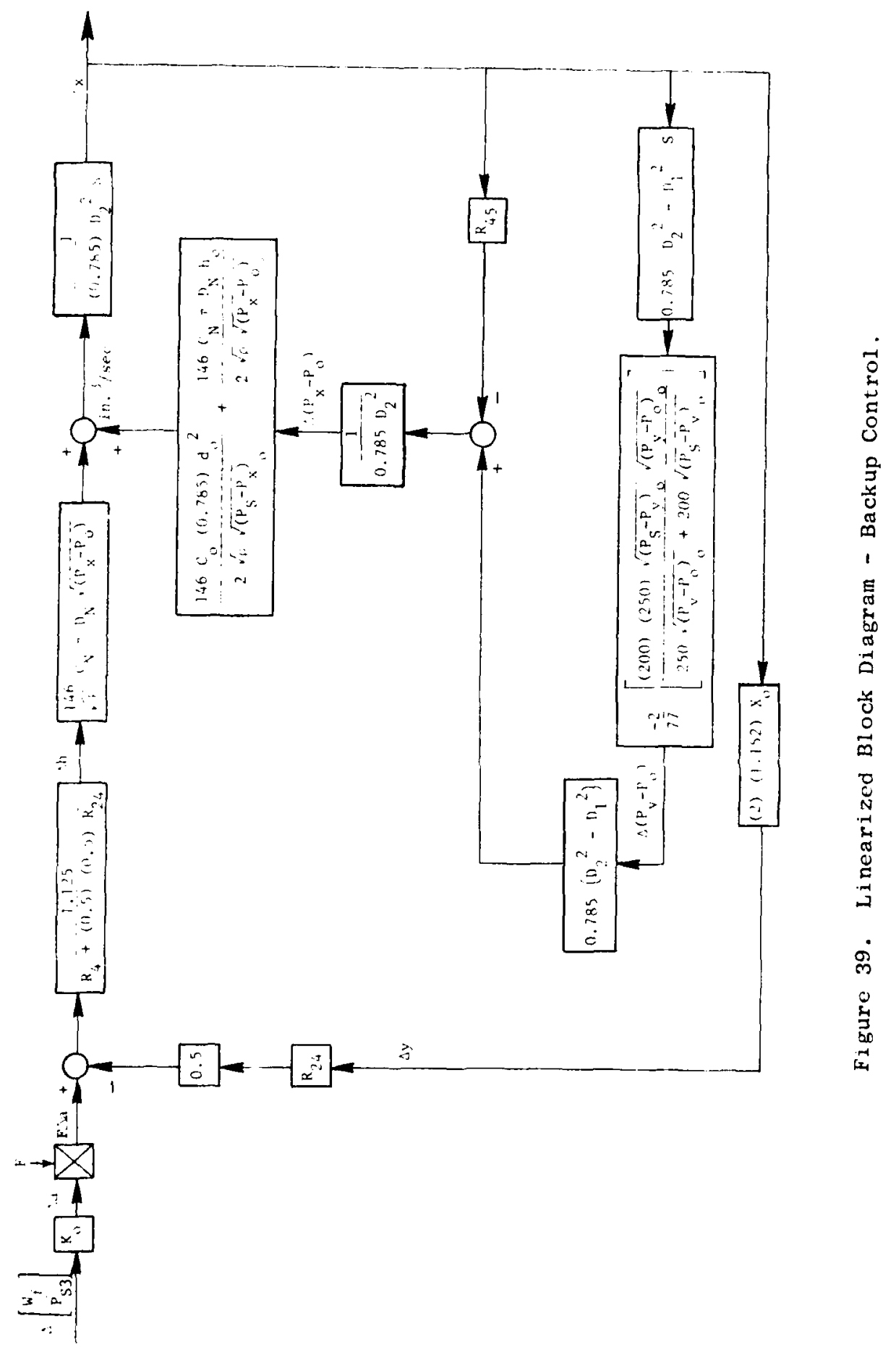




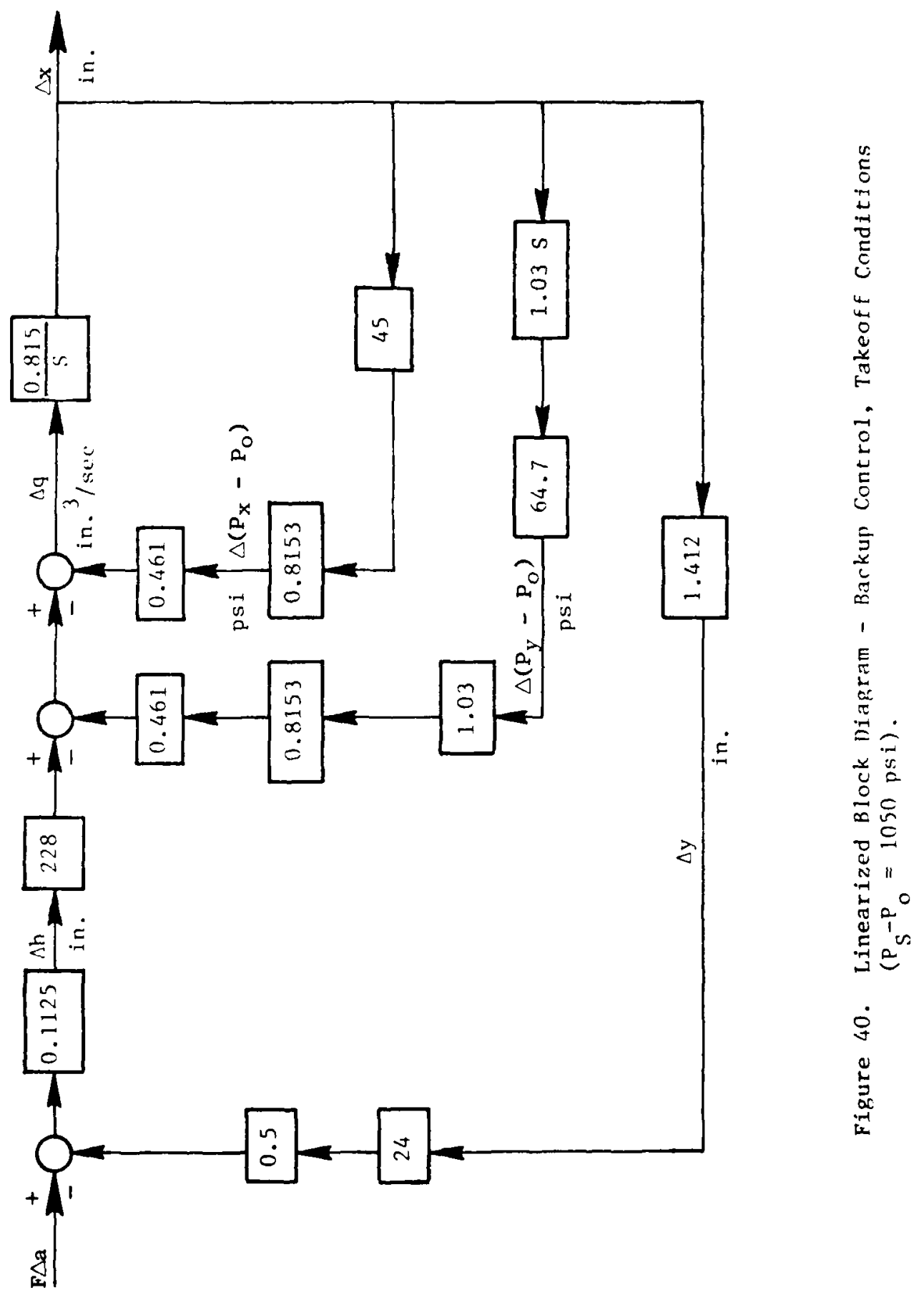




$$
\begin{aligned}
& k_{4}=416 / \mathrm{in} \quad \quad 12, \quad=1.25 \mathrm{in} . \\
& R_{24}=24 \mathrm{lb} / \mathrm{in} . \quad \mathrm{P}_{X}-\mathrm{P}_{0}=490 \mathrm{mi} \\
& C_{X}=11.7 \quad P_{S}{ }^{-1}:=554 \mathrm{pei} \\
& C_{0}=0.75 \quad P_{y}-P_{0}=620 \mathrm{psi} \\
& { }^{\mathrm{D}} \mathrm{N}=0.02 \mathrm{in} . \quad \mathrm{P}_{\mathrm{s}}-\mathrm{P}^{\mathrm{P}}=430 \mathrm{pos} \\
& \mathrm{D}_{1}=0.021 \mathrm{in} . \quad \mathrm{r}_{1} \quad=0.004 \mathrm{in} . \\
& R_{45}=45 \mathrm{lb} / \mathrm{in} . \quad \therefore 0=0.613 \mathrm{in} . \\
& \mathrm{D}_{1}=0.5 \mathrm{in} \text {. }
\end{aligned}
$$

The wetering; valve is contoured to give:

$$
\begin{aligned}
w_{f} & =41,500 \mathrm{x}^{2} \\
\text { Thus, } \quad \therefore h_{f} & =83,000 \mathrm{x}_{\mathrm{o}} \Delta \mathrm{x}
\end{aligned}
$$

Assuming that the throttling valve effect introduces a 0.03 second lag, and applying block diagram alycbra to Figure 40 , the overall system of interest can be shown to be:

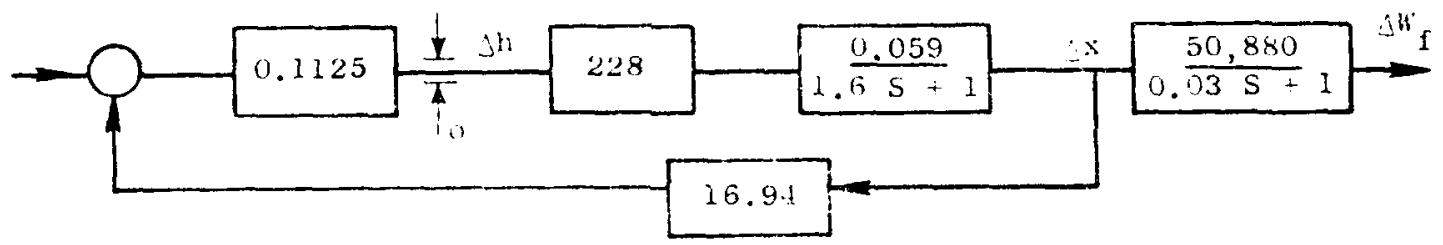

The speed servo loop was neglected since its time constant is less than 0.001 second. Second-order effects from component and fluid inertia were also neglected. An estimate of the governor frequency response was obtained by treating the control as a second-order system composed of two time constants, 0.062 second and 0.03 second. Using the expected 0.053 $W_{\mathrm{f}} / \mathrm{P}_{\mathrm{S} 3}$ ratios per rpm, the calculated governor frequency response, with $P_{S 3}$ constant, is shown in Figure 41.

\section{EXPECTED TRANSFER CHARACTERISTICS}

An estimate of the fuel flow response following a transfer, assuming a large difference in primary and backup demands existed, was made previously and reported in AFAPL-TR-77-92 (Reference 1). The resulting $W_{f}$ transient (Figure 42) showed no tendency to overshoot, even with a relatively large $W_{f}$ difference (2540 $\mathrm{pph}$, or about 17 percent) between 


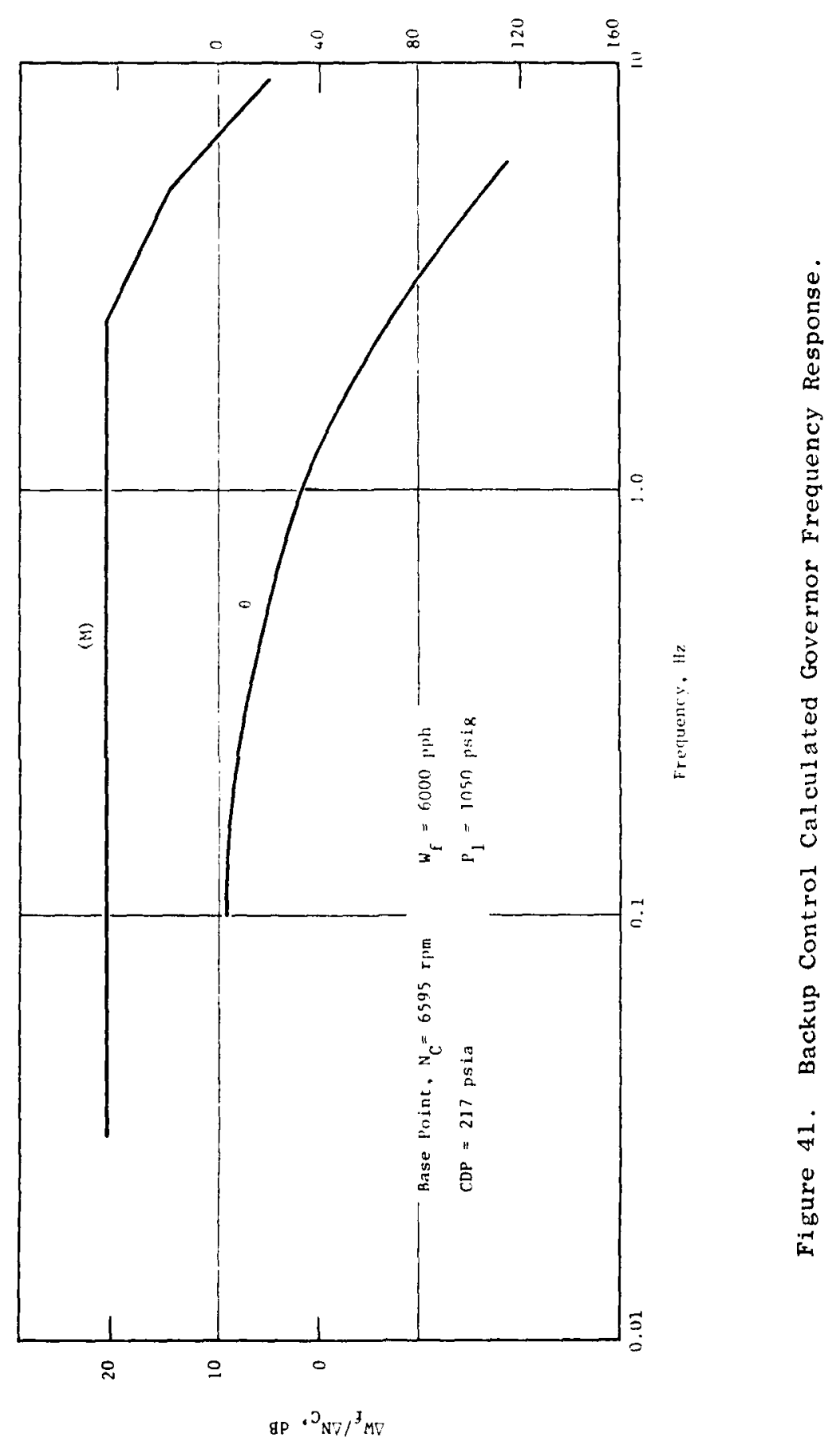




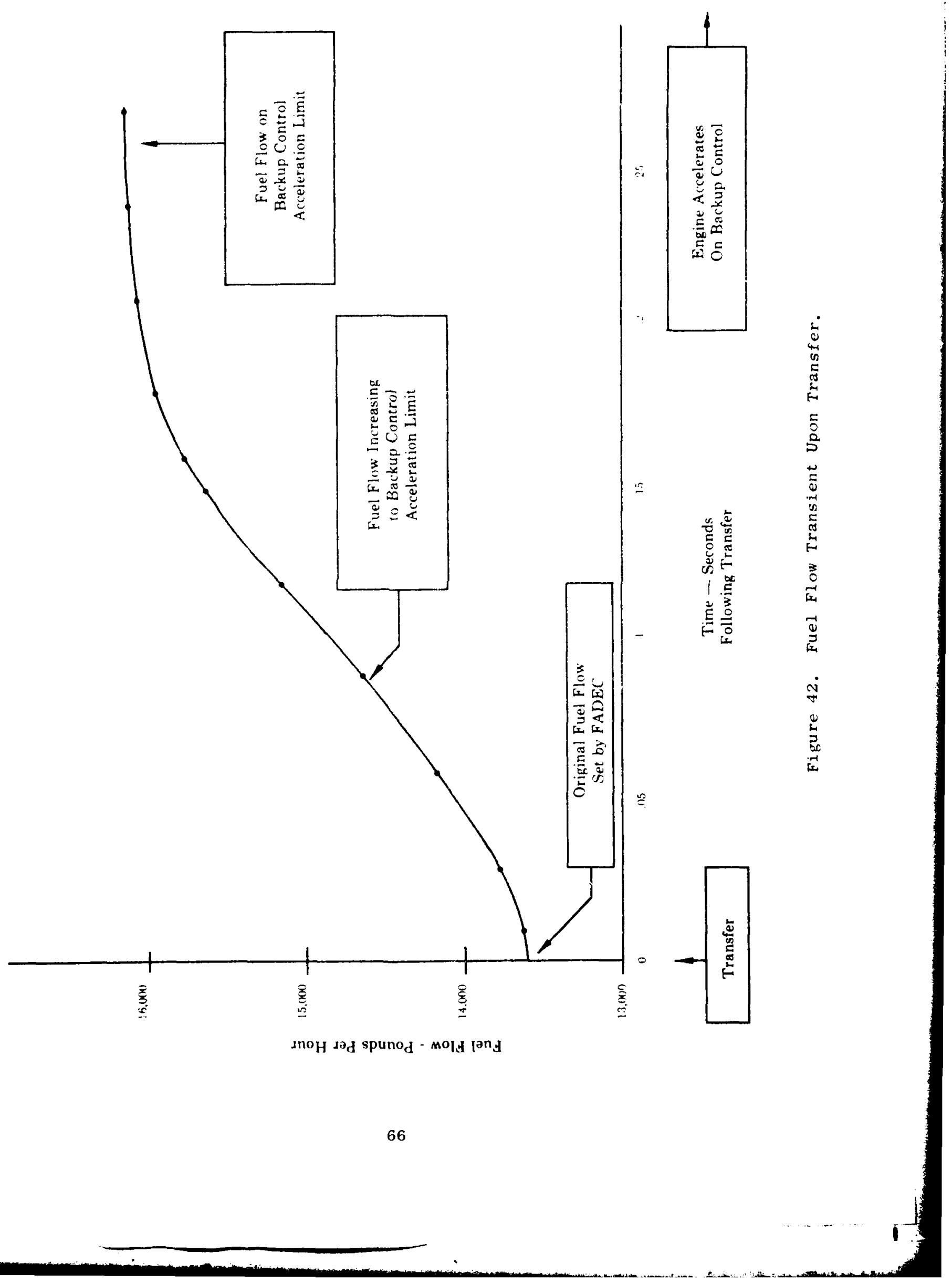


the two controls.

The previous study made the simplifying assumption that the pressure on the rod side (see Figure 38 ) of the metering valve power piston was a constant 69 percent of the supply pressure. This resulted in an effective time constant for the metering valve of 0.0043 second. Referencing the schematic of Figure 38, and applying equations 3 through 8 of the basic system description of Section IV-3, it was shown that the slew velocity of the metering valve is limited by the sizes of the orifices on the rod side of the power piston. For a 0.036 inch diameter orifice on the return side, a 0.033 inch diameter orifice on the supply side, and a $P_{S}-P_{0}=$ $1050 \mathrm{psi}$, the slew velocity in the open-flapper direction is $0.34^{\circ}$ inch per second. When the effect of the two orifices is considered in the transient analysis, as was done in Section IV-3, the effective time constant of the metering valve is found to be 0.062 second. The resulting change in the expected response following a transfer was small - about 0.15 second longer than the response previously calculated. 


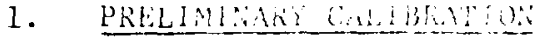

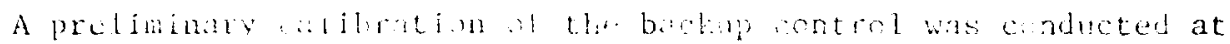

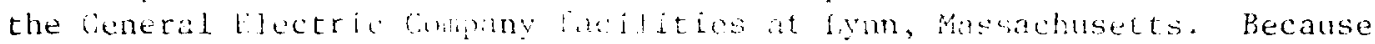

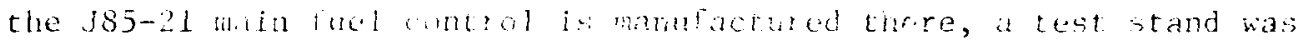

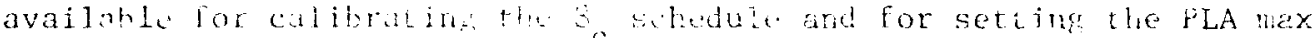
and min stops, the werspeed sich, and the hydromechaniall averspoed

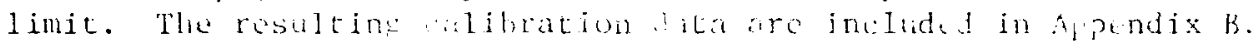

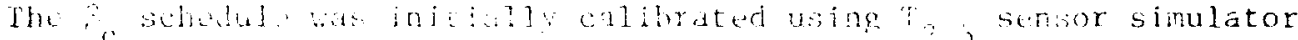

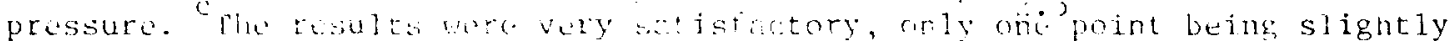
out of linit:

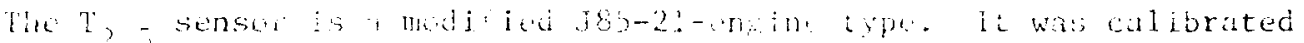

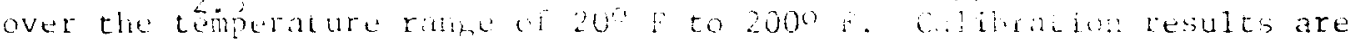

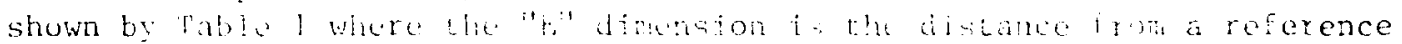

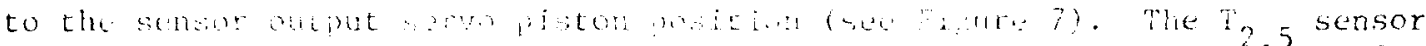

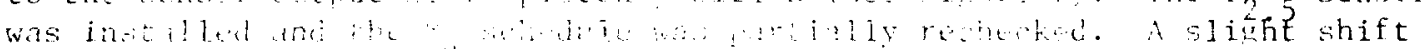

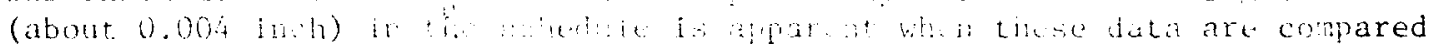

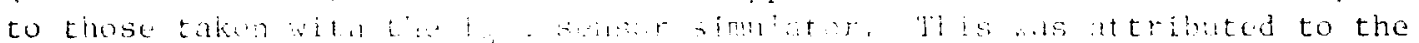

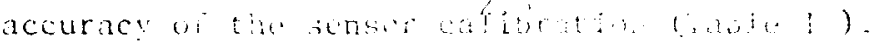

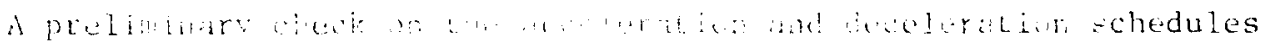

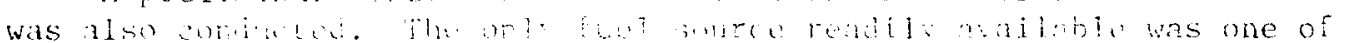

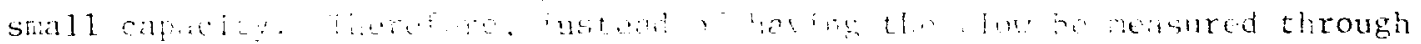

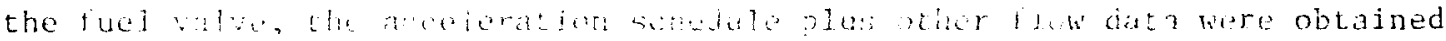

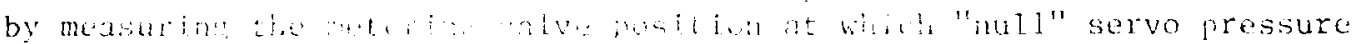

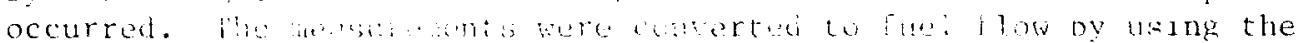
equation:

$$
\because=9,6,60 x^{2}
$$

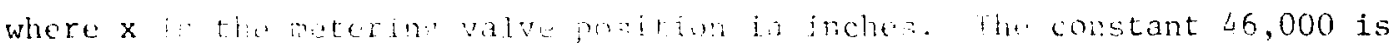

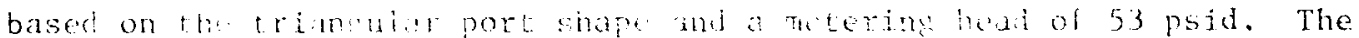

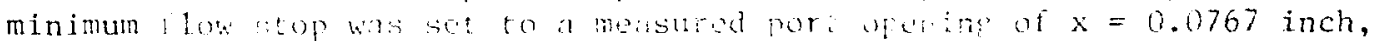
which converts th a 270 ppli flow. This ralu of $x$ wits used as the refer-

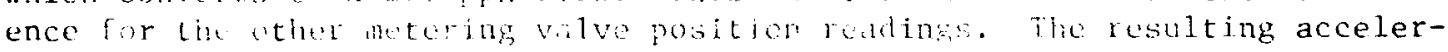
ation schedule datis irdicated onlv minor diviatias. The deceleration schedule wa: within limits.

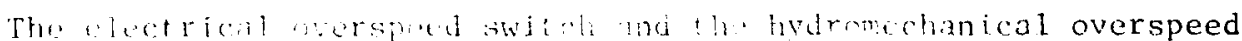

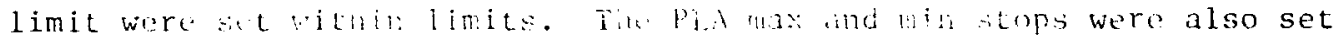
within linits. Ihe bak h, antrol was then shippei to the ceneral

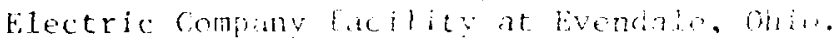


TABLE 1.

TEMPERATURE SENSOR CALIBRATION

\begin{tabular}{|c|l|l|}
\hline $\begin{array}{c}\text { Temperature } \\
\mathrm{T}_{2.5} \mathrm{O}_{\mathrm{F}}\end{array}$ & $\begin{array}{c}\text { Desired } \\
\text { Reference } \\
\text { Dimension, } \\
\text { "E" - In. }\end{array}$ & $\begin{array}{l}\text { Measured } \\
\text { Reference } \\
\text { Dimension, } \\
\text { "E" - In. }\end{array}$ \\
\hline 20 & 1.6004 & 1.6072 \\
40 & 1.5849 & 1.5903 \\
60 & 1.5696 & 1.5752 \\
80 & 1.5546 & 1.5564 \\
100 & 1.5398 & 1.5410 \\
120 & 1.5253 & 1.5262 \\
140 & 1.5110 & 1.5110 \\
160 & 1.4970 & 1.4955 \\
180 & 1.4832 & 1.482 \\
200 & 1.4696 & 1.4685 \\
220 & 1.4563 & \\
240 & 1.4431 & \\
260 & 1.4302 & \\
280 & 1.4175 & \\
300 & 1.4050 & \\
\hline
\end{tabular}


The test setup used lor the above testing at AFr Lynn is shown by Fisures; 43 and 4.4. looking at Figure 43 , the dial indidator at the upper lal-hand corner was used to measure feedback cable travel ( $\beta$ ). The dial indiantor at the right center was used to measure the metering, valve position. A $R$ actuator is shown below the $B$ calibration fixture. Figure 44 shows the Gther side of the backup control. The power lever shaft and the shutoll valve shaft are shown pointed toward the upper edge of this picture.

\section{CALIBKALION}

The romainder of the backup control calibration was conducted at Evendale, Ohio. The results are included in Appendix B. The data taken at Lynn, Massachusetts, for the throttle stop adjustments, the core stator schedule $(\beta)$, the electrical overspeed signal, and the hydromechanical overspeed linit are also included.

The acceleration schedule limits used for the calibration log sheets were calculated based on an existing J85 main fuel control cam (2108). However, the nost readily available hardware was selected to build the backup control. In this particular control this resulted in using a cam that is different (2103). Figure 45 shows a comparison of the two cams at $\mathrm{T}=224^{\circ} \mathrm{F}$. At that time, the cam difference was consicered to be the reason the first, thirteenth, and fourteenth points on the acceleration schedule were slightly out of limits. The acceleration schedule calibration required a high metering valve pressure drop. This was considered to be the cause for the "rich" deceleration schedule. The decel schedule is a fixed $W_{f} / P_{S 3}$ ratio and not a function of the 3-D carit. The resulting acceleration and deceleration schedules, however, allowed sufficient margins between themselves and the engine steady-state oncrating line. This was necessary for the subsequent transient response testing.

Early in the subsequent transient testing, when the loop was closed on the stators $\left(B_{3}\right)$, it was found that the stators did not respond to $T_{2} 5$ changes. Investigation revealed that the temperature sensor had not been properly installed - that is, the feedback link did not engage the servo piston (see Figure 8). This caused the sensor to remain at a low $\mathrm{T}_{2}$. position - about $20^{\circ} \mathrm{F}$. The effect this was presumed to have had on the acceleration cam is shown in Figure 45. The wide difference in the expected schedules for $2108\left(\mathrm{~T}_{2}=224^{\circ} \mathrm{F}\right)$ and $2103\left(\mathrm{~T}_{2}=20^{\circ} \mathrm{F}\right)$ further explains why the acceleration ${ }^{2} \dot{s}^{5}$ hedule did not calibrak $\dot{e}^{5}$ as expected and why the required metering velve pressure drop was 63 psid instead of the expected 53 psid.

The backup control was shipped from the AEG Lynn facility, where the $\mathrm{T}_{2}$ sensor had been removed to reduce the risk of shipping damage to the capillary tube. The sensor was reinstalled at the AEG Evendale facility, and this is when the feedback lirik failed to get engaged with the servo pistnn. Once the sensor was roinstalled in the normal manner, the stators responded to $\mathrm{T}_{2.5}$ changes. 


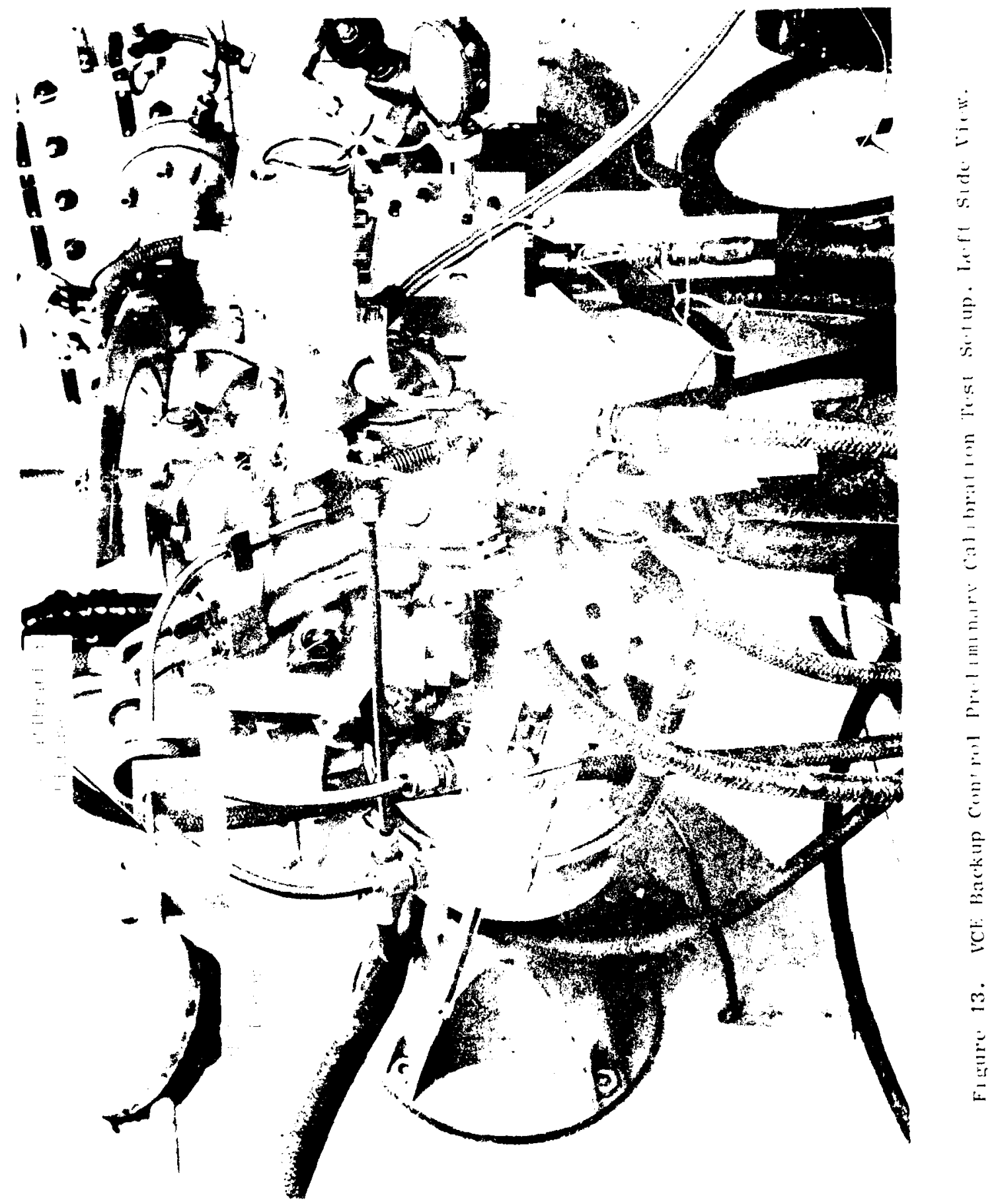




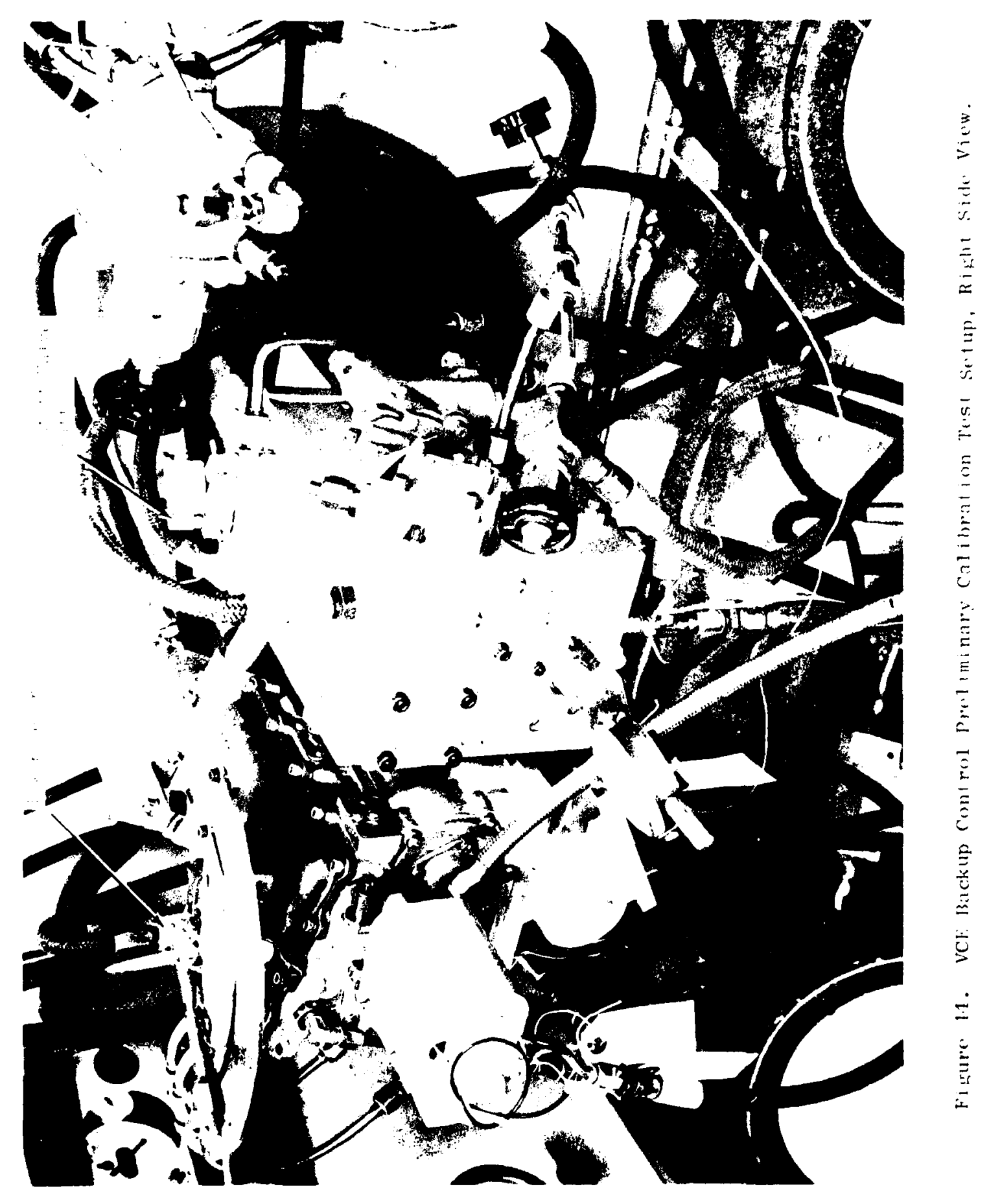




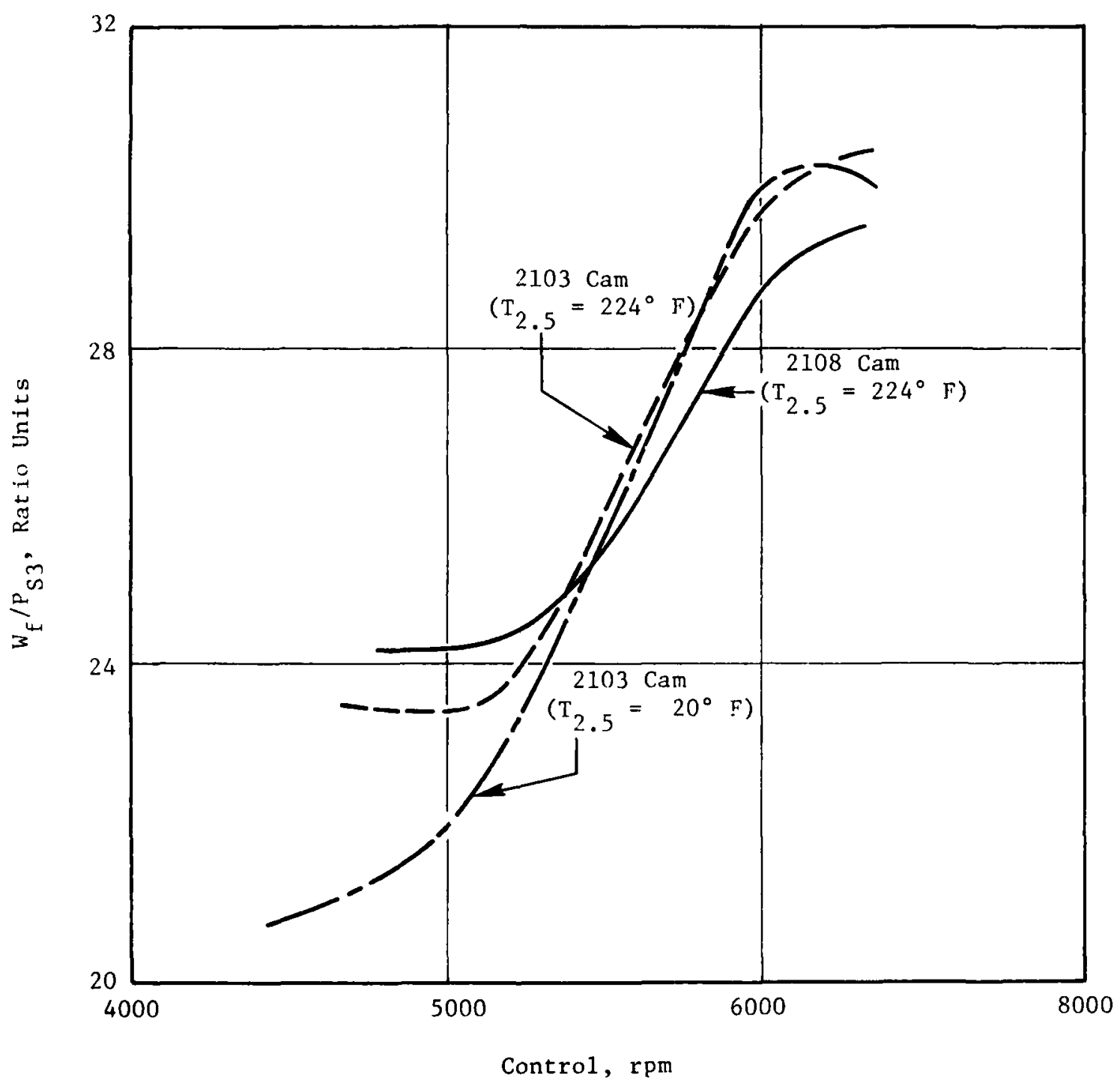

Figure 45. Comparison of Cam Schedules. 
The shucolf valve leakage was out of limits. The leakage indicates that the mating parts require additional lapping, which will be done before the control is used on any engine test.

The test setup usod for calibration and subsequent transient response testing is shown by the three photographs that constitute Figures 46,47 , and 48 . Figure 46 shows the backup control on the test stand at the left and the F10l augmentor fuel pump on the test stand at the right. Figure 47 is a view of the backup control showing the hydromechanical computer. In contrast with the machined bodies for the other subassemblies, the computer is enclosed in a cast housing. The enclosure wrapped in white insulating material is the test fixture for the $\mathrm{T}$, 5 sensor. Figure 48 shows the F101 augmentor fuel pump. This type of pump is intended for the JTDE testing. An F101 aummentor fuel filter, mounted to the pump inlet, is also shown. This pump and filter were used as the fuel pressure source for all the testing.

\section{BACKUP CONTROL TRANSIENT RESPONSE}

When operating in the backup mode, hydromechanical components provide the normal engine control functions:

- rpm governing as a function of power lever position

- Scheduling of main fuel flow as a function of $\mathrm{N}_{2}, \mathrm{P}_{\mathrm{S}}$, and $\mathrm{T}_{2.5}$ on accelerations, and as a function of $P_{S 3}$ on decelerations

- Scheduling of $\beta_{c}$ as a function of $\mathrm{N}_{2}$ and $\mathrm{T}_{2.5}$

Steady-state and transient response characteristics, when in the backup mode, were of interest because of the adaptation of the larger flow metering valve to the $J-85$ computer mechanization. Testing to determine the performance of the backup control consisted of the following:

- Defining fuel flow $\left(W_{f}\right)$ and variable stator vane $\left(\beta_{c}\right)$ oscillations on accelerations and decelerations.

- Defining governor droop characteristics.

- Determining frequency responses of fuel flow and stators to $\mathrm{N}_{2}$ and of fuel flow to $\mathrm{P}_{\mathrm{S} 3}$.

Figure 49 shows the bench setup used for testing the backup control. Both open-loop and closed-loop testing, were employed. Open-loop fuel flow and stator oscillations, obtained by operating the control at fixed values of $\mathrm{N}_{2}$, $\mathrm{P}_{\mathrm{S} 3}$, i' ${ }^{2}$, PLA, and control inlet fuel pressure, showed random drifts of ' $\pm 23^{\prime}$ pounds per hour (fuel. Elow) and \pm 0.001 inch (stator). Head regulator oscillations were typically \pm 0.2 psi. Figure 50 is a typical steady-state trace. 


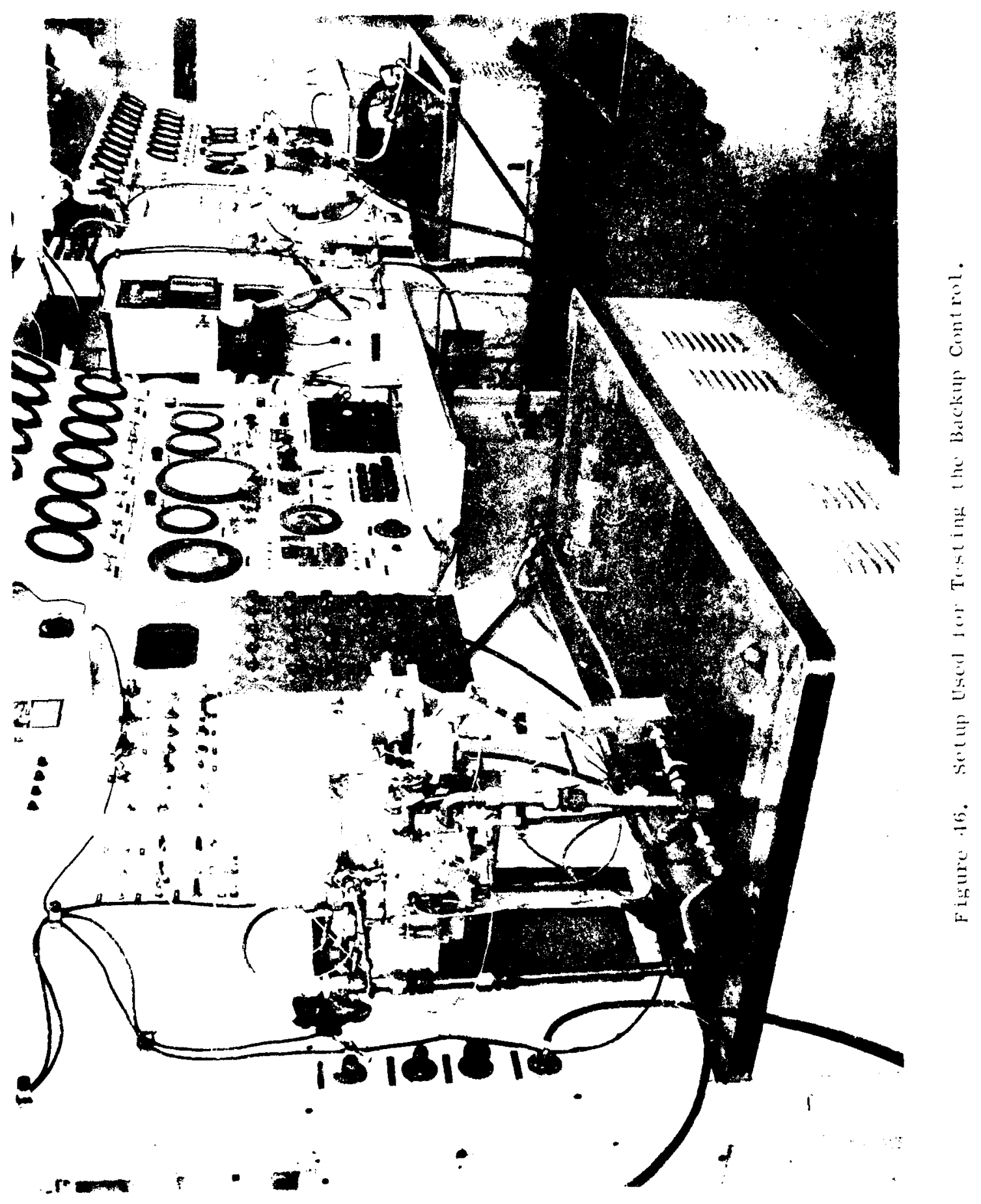




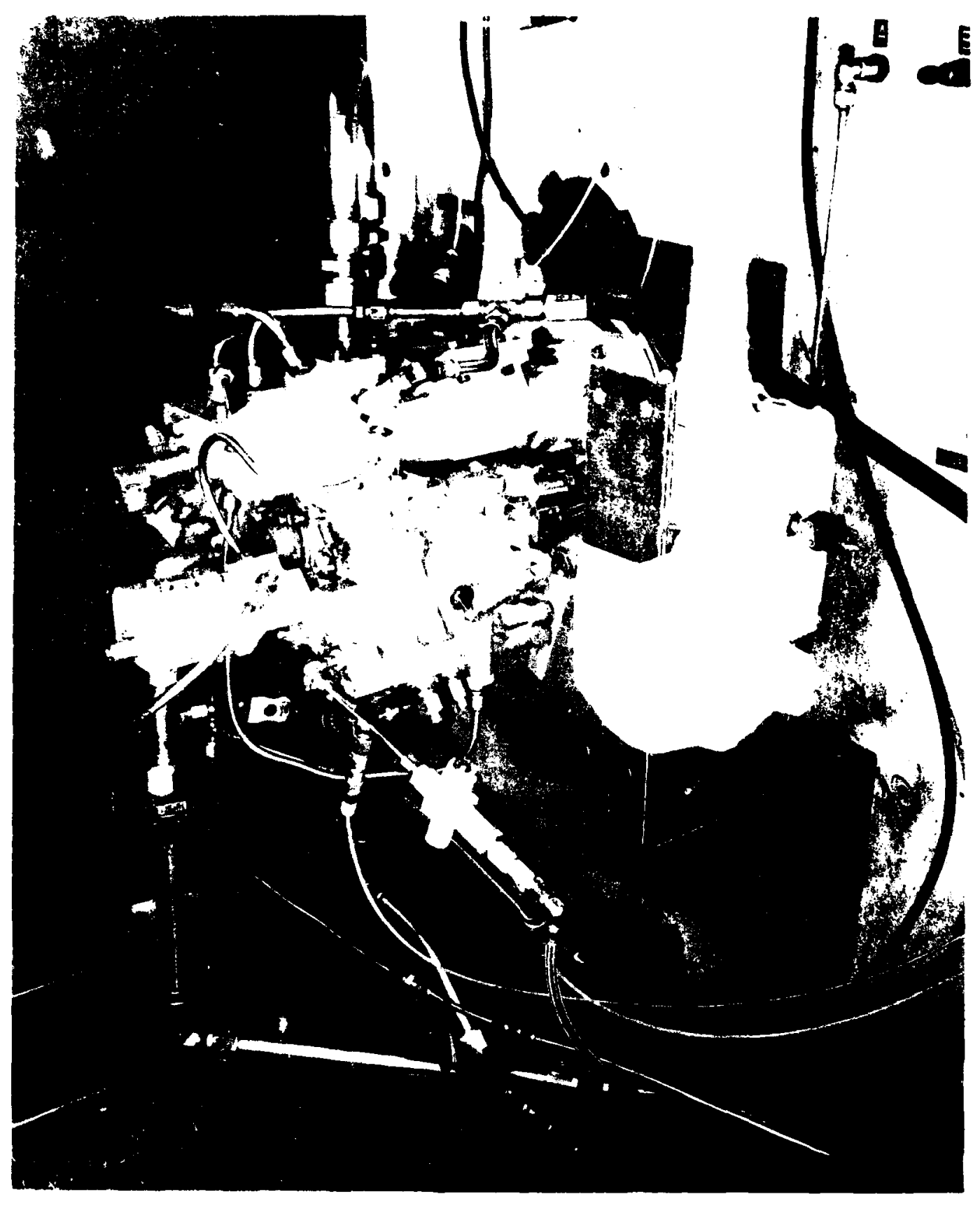

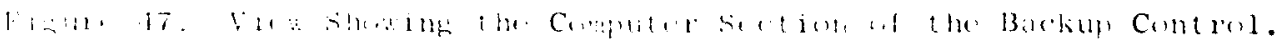




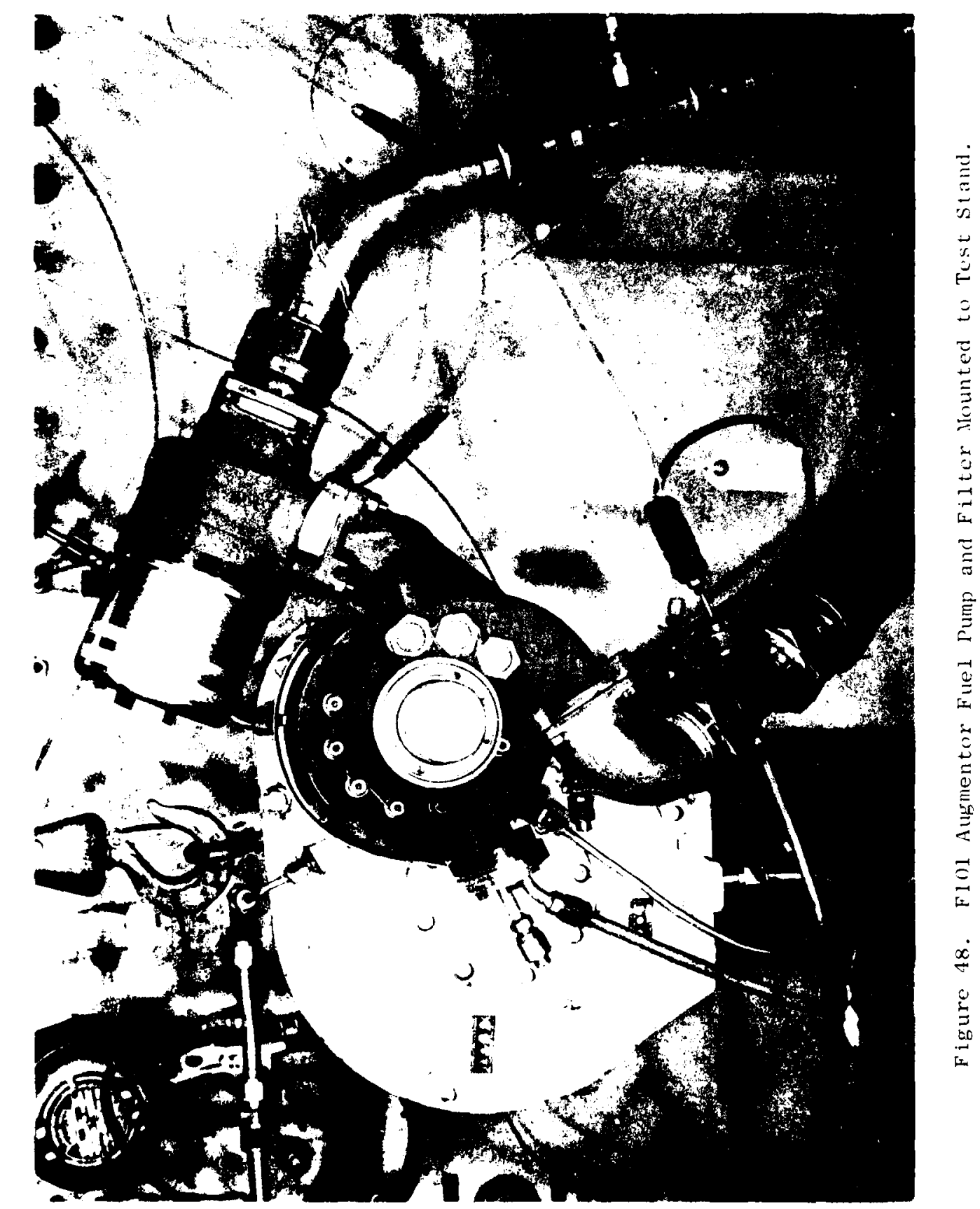




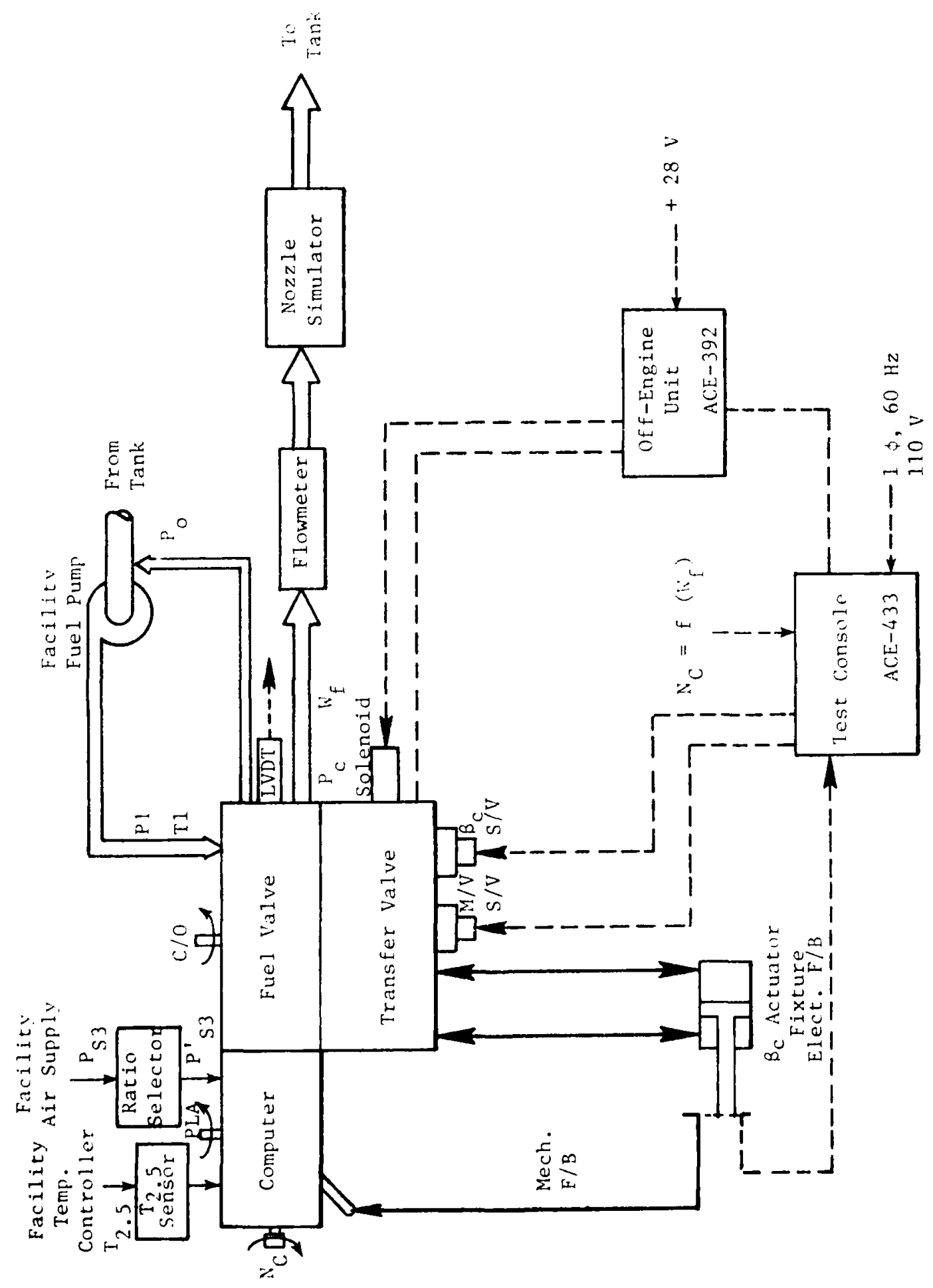

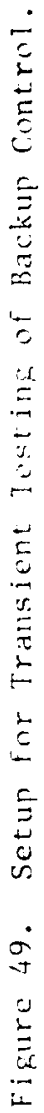




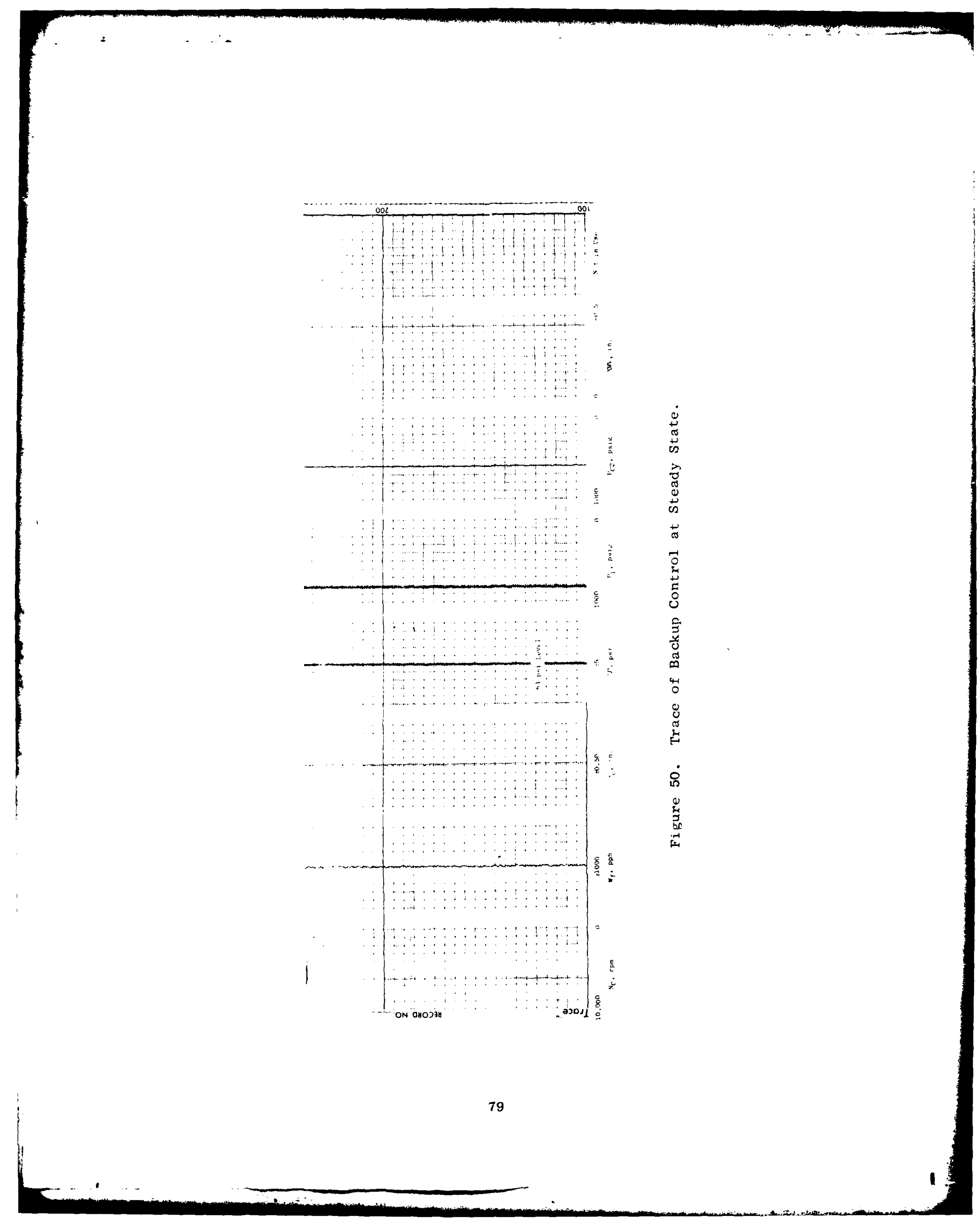


Figures 51 and 52 show Euel flow, variahle stalor pissition, and head weillations on a spees ramp condition of 1600 rpmper socond, with Ps, I. F, IA, and control inlet fuel pressure fixed. Fuel flow can te secn $\therefore$ he atahle, with little oscillation on the acceleration and deceleration an! Iitt d. overshont during goverwor cut-in, when the governor takes over the control of fuel flow.

Figures 53 and 54 show typical throttle bursts and chops, operating closed-loop and using the dynamics of the gk? engine in the closcu-loop simulation. The control can be seen to ride the acceieration or deceleration until the governor modulates $W_{f}$ to hold $N_{2}$ at the deminded power setting.

Figures 55, 56, and 57 show typical oper-loop governor characteristics which define the governor droop and hysteresis. The droop characteristics are seen to vary with $N_{2}$ level, yielding higher gain at higher power settings. The displayed $0.053 \mathrm{~W} / \mathrm{p}$ g ratios per rpm at the high speed points here expected with the J-35 computer. Speed hysteresis, which increased inversely with power setting, is observed to be constant at a given power setting regardless of speed swings.

In the $J-85$ main fuei control, the $W_{f}$ feedback spring is attached directly to the metering valve. To allow using a larger metering valve with a triangular port for the backup control, a rack and pinion, a cam and a bellcrank were added becween the metering valve and the feedback spring. This resulted in more iriction, which increases hysteresis and reduces repeatability. Although the increased hysteres is is still acceptable for this backup control, the production version of the backup control would be mechanized similarly to the J-85 main fue? control. Its hysteresis would be less, compaxable to that of the $J-85$ main fuel control.

Frequency response testing on the governor $\left(\triangle W_{f} / \Delta N 2\right)$ and the stators $\left(\Delta \theta^{2} / \Delta N_{2}\right)$, typical traces of which are shown in Figure 58 , produced magnitude and phase characteristics shown in Figures 59 and 60 . Flow response to $\mathrm{P}_{\mathrm{S}_{3}}\left(\Delta \mathrm{P}_{\mathrm{S}_{3}} / \Delta \mathrm{N}_{2}\right)$ was almost identical to flow response to $\mathrm{N}_{2}$, since both speed and $\mathrm{F} 3$ work through the nutcracker/flapper and fuel valve power piston system.

Fuel flow response was lower than anticipated, primarily because of governor hysteresis. As seen in Figure 59, correcting the calculated response of Figure 41 for magnitude and phase effect of 50 rpm hysteresis gives relatively close correlation to the test data.

\section{TRANSFER TO BACKLIF MODE}

When operating in the primary mode, the transfer valve blocks the backup $W_{f}$ and servovalve outputs so that interforence between the two controls is prevented. During this mode of operation the backup control 


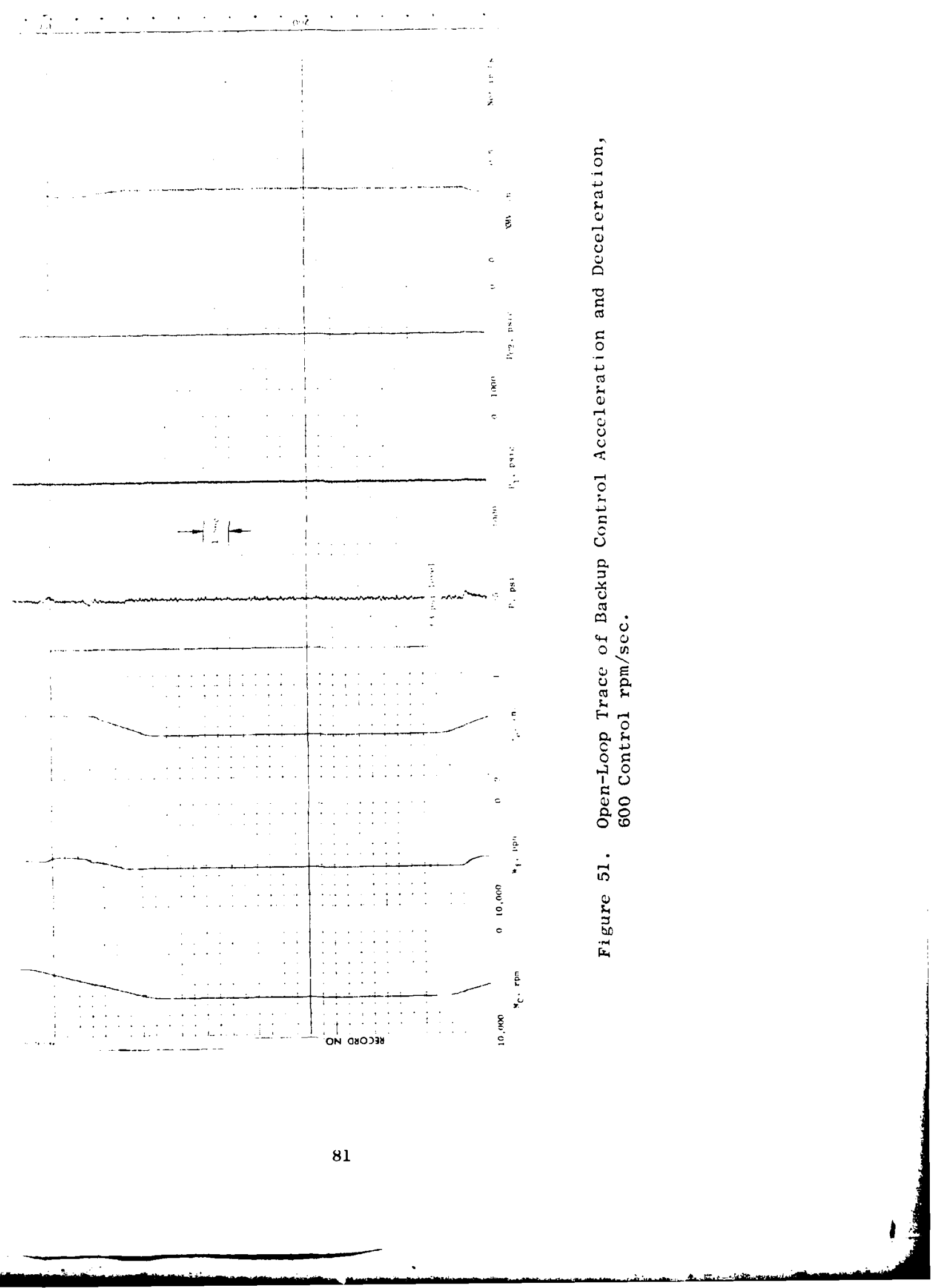




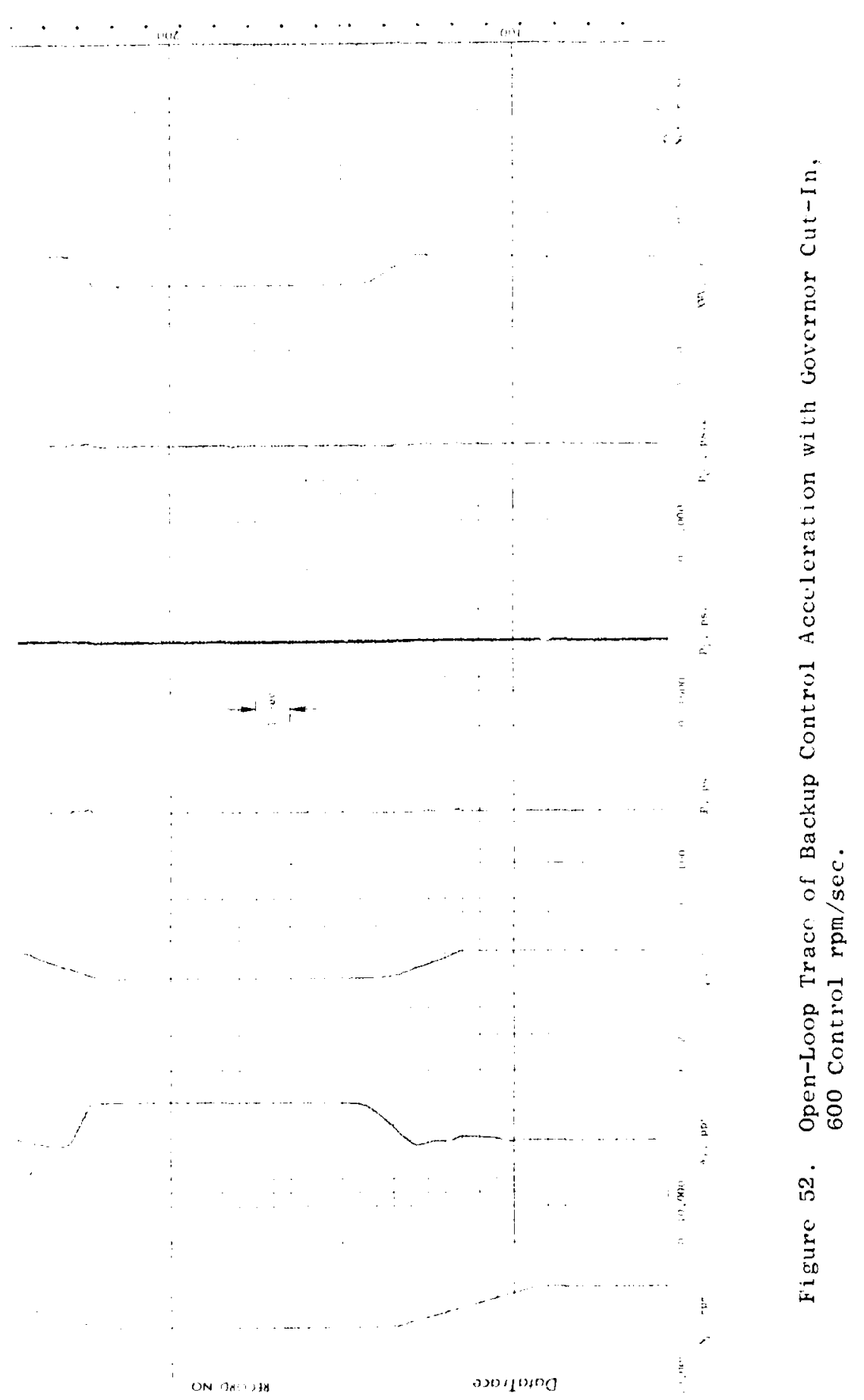




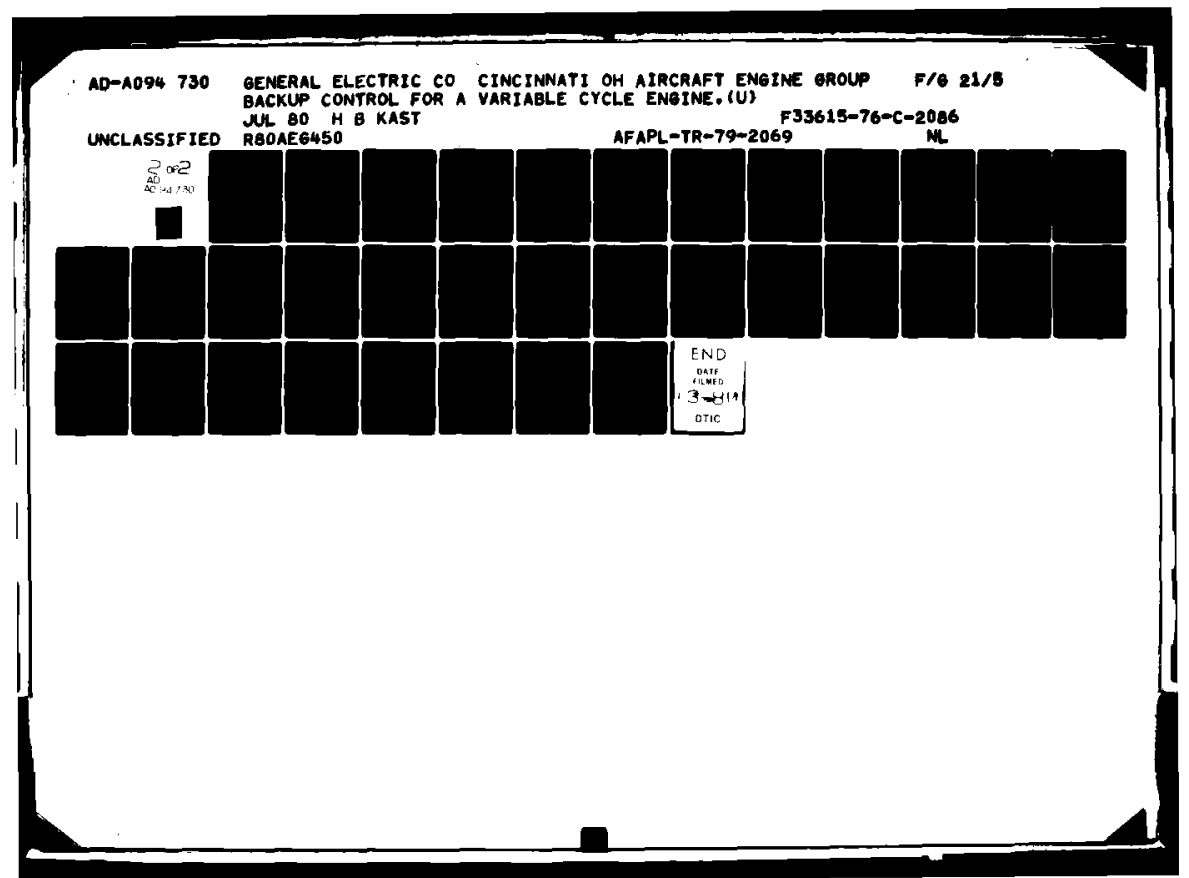




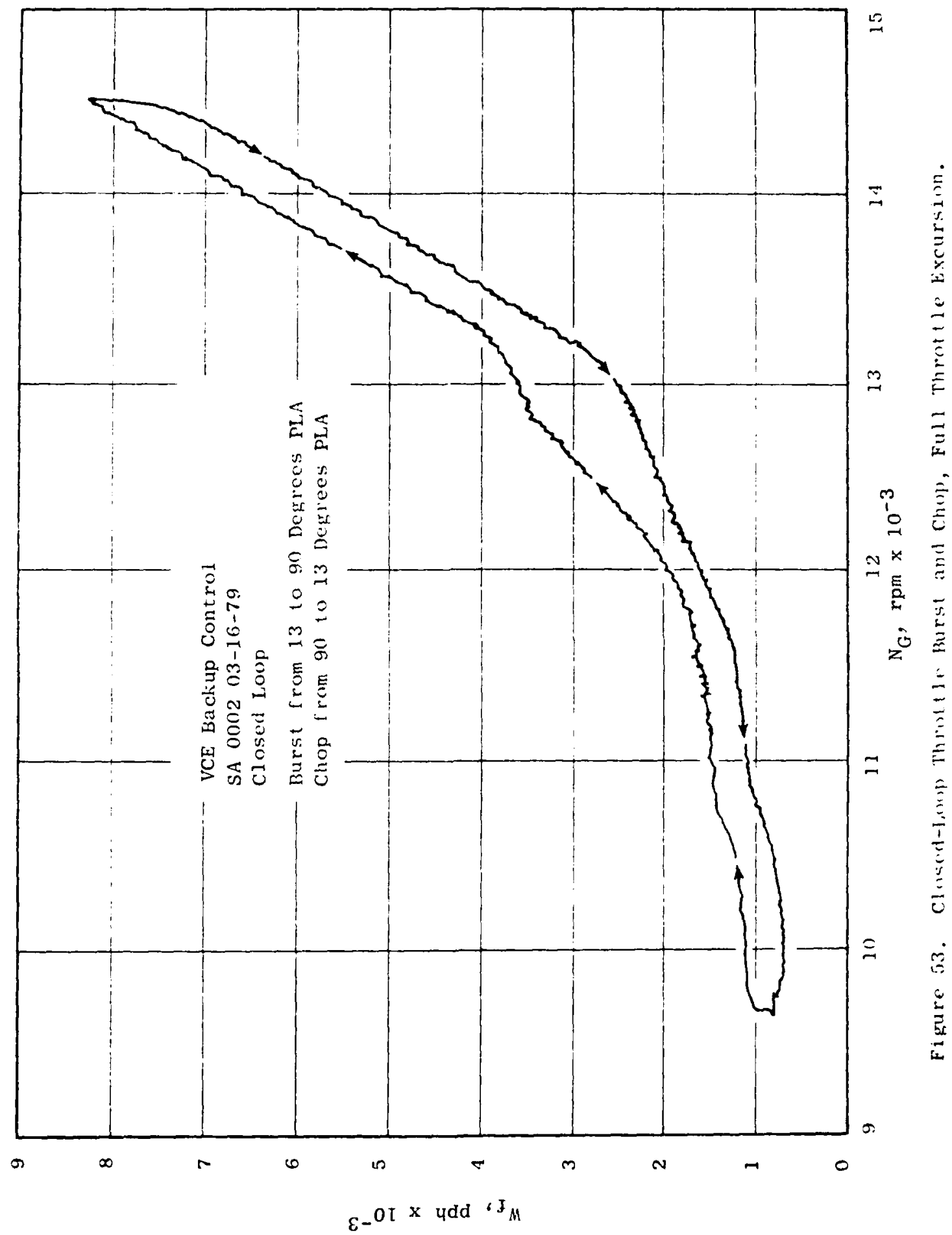




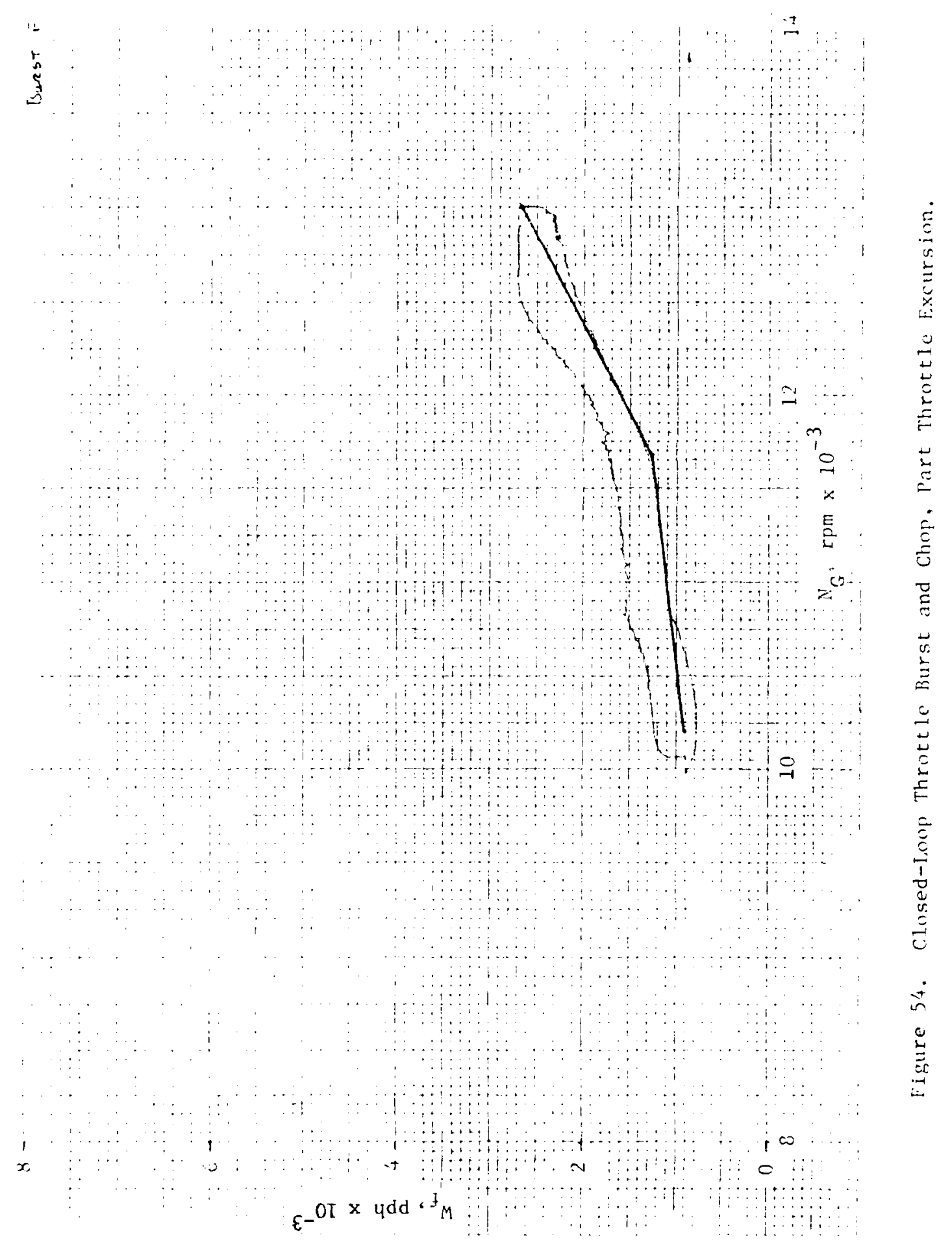




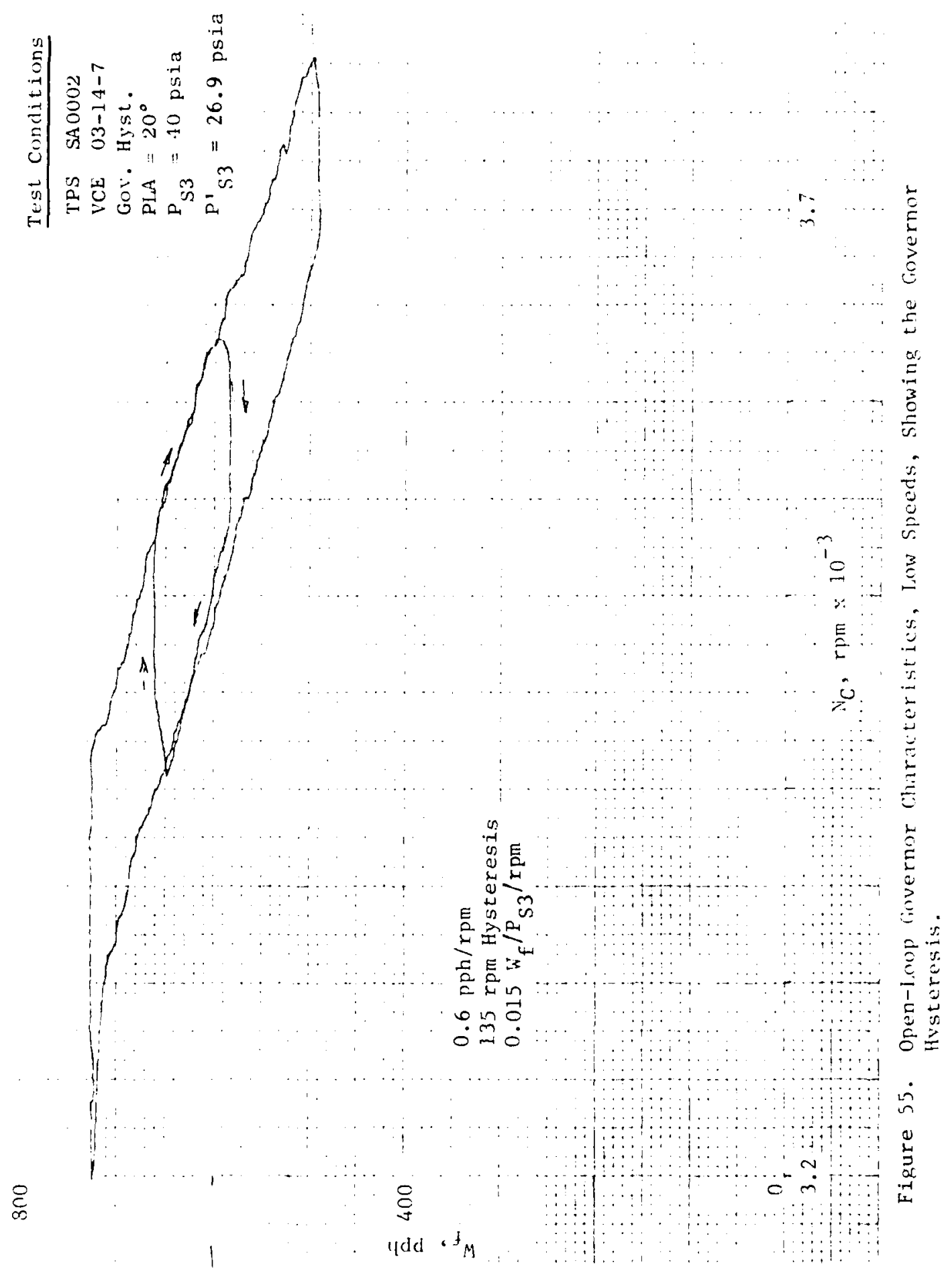




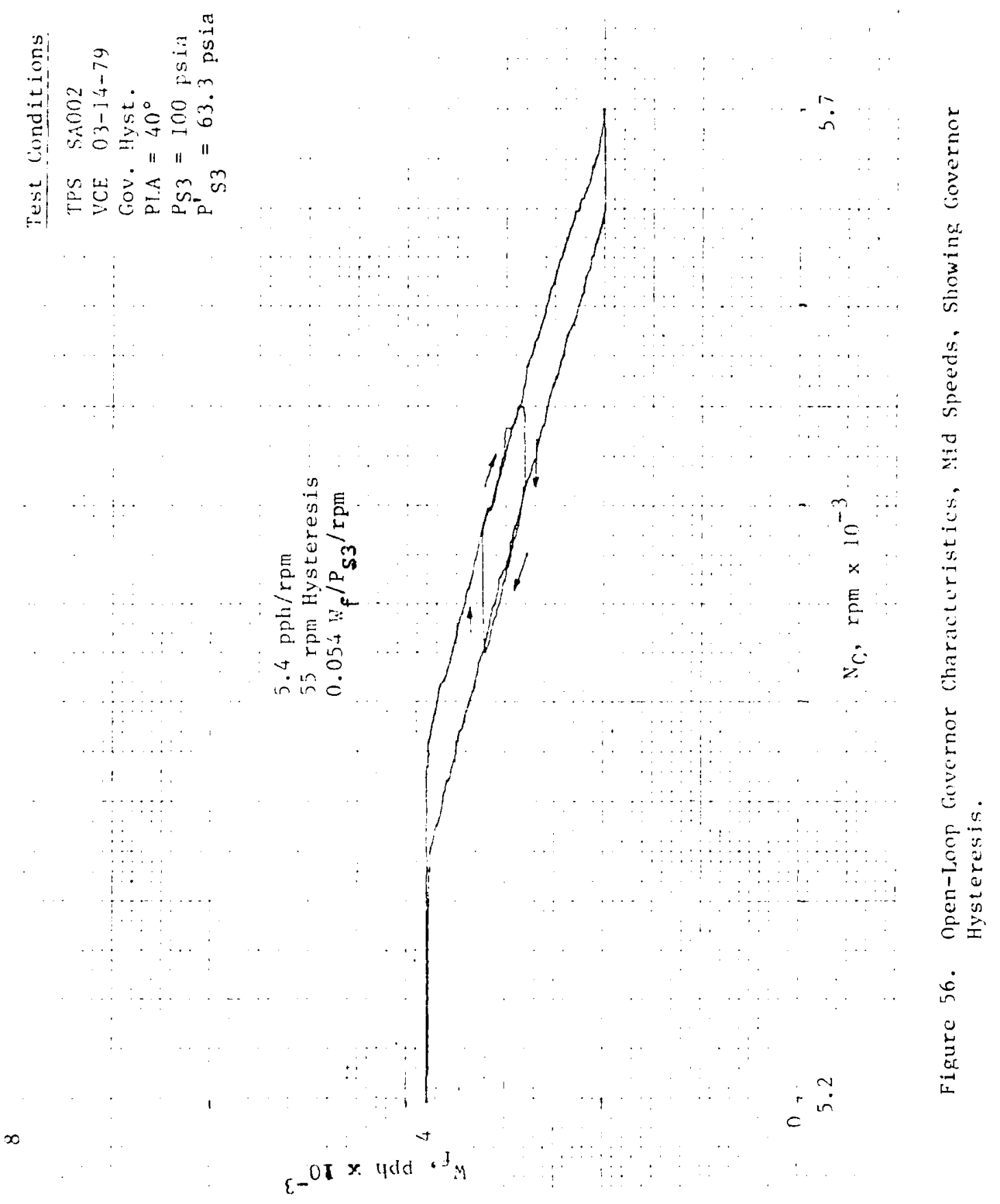




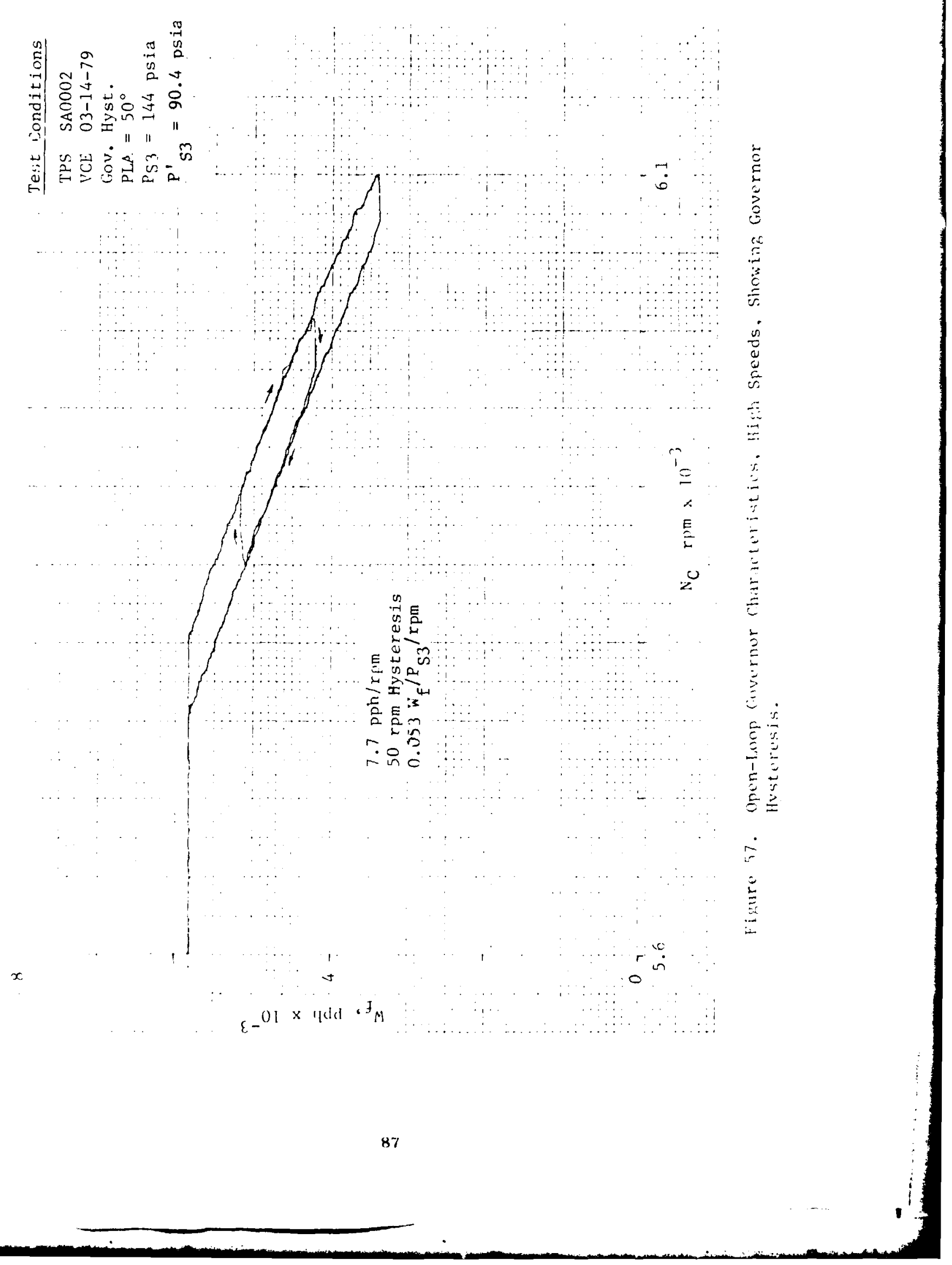




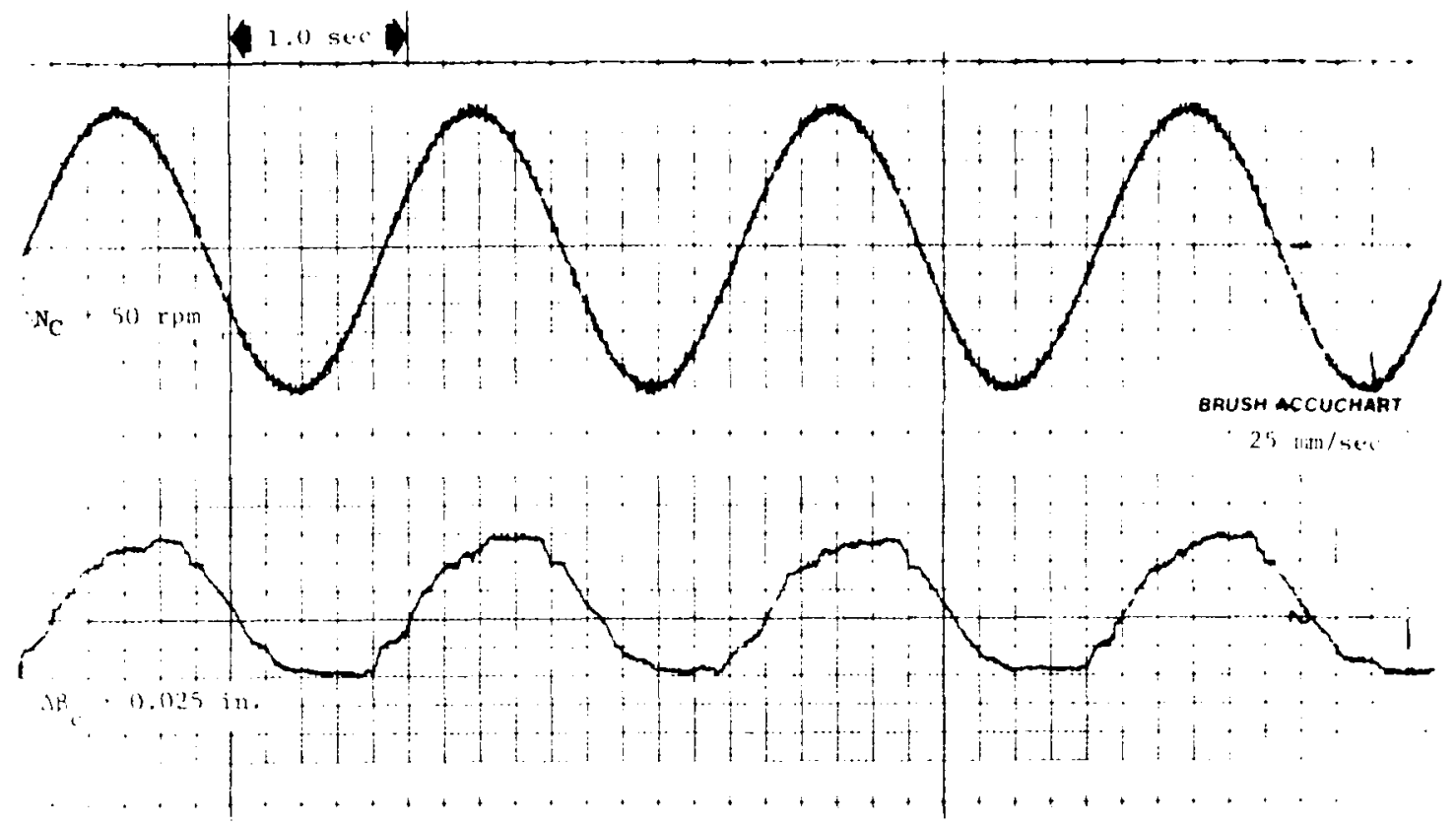

$\therefore$ Frequent y Response, $0.5 \mathrm{~Hz}$

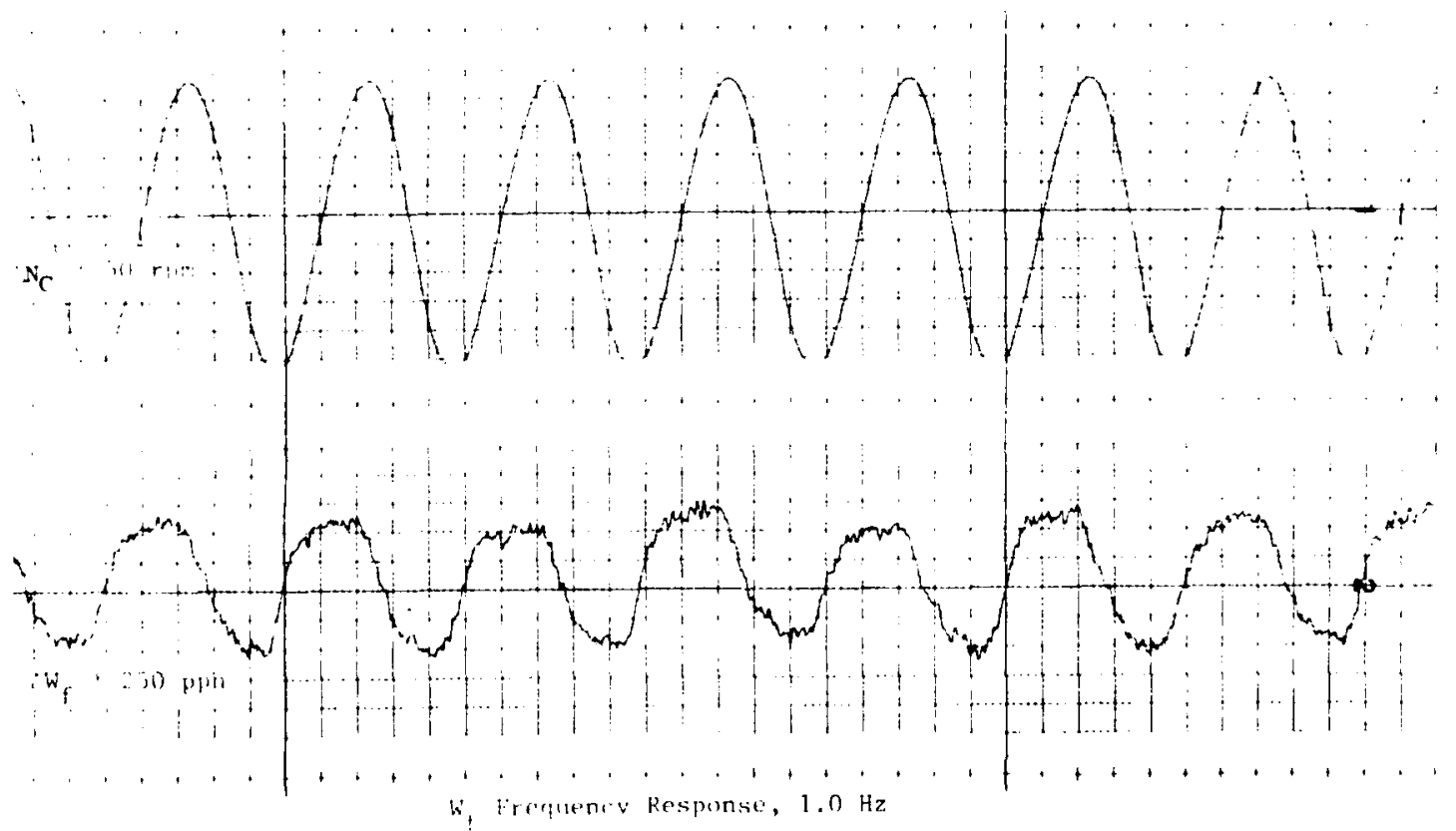

Figure 58. Typical Frequency Response Traces.

88 


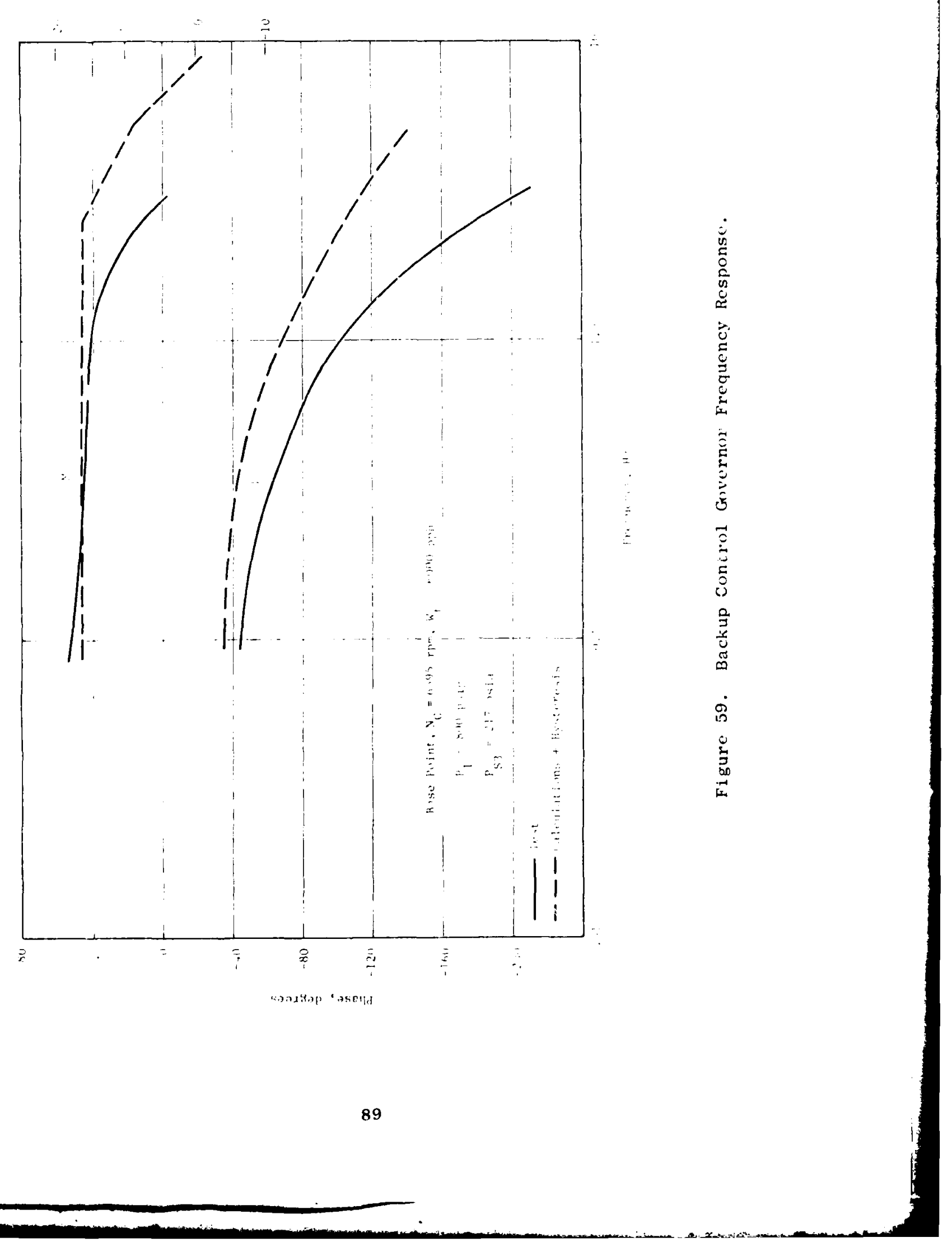




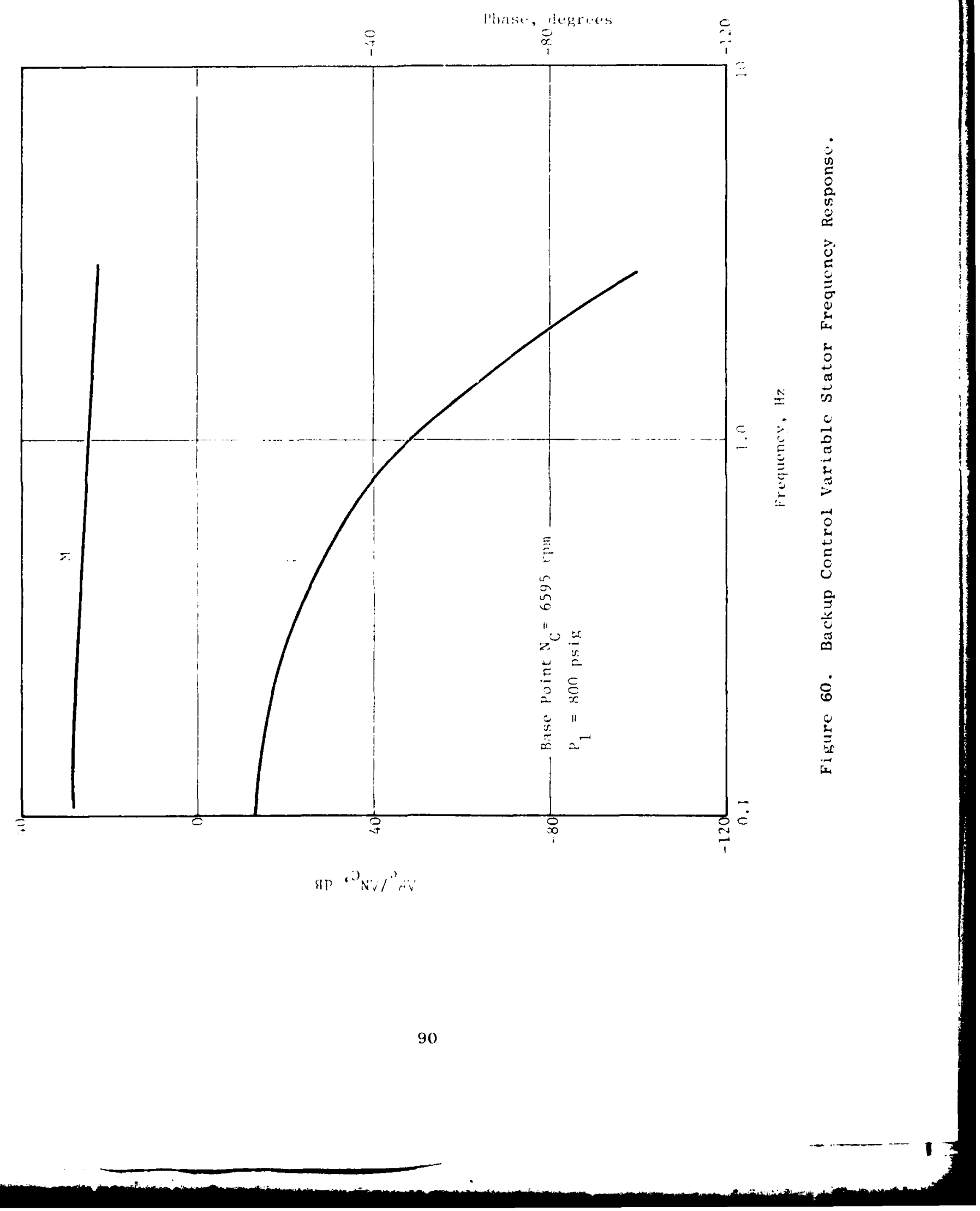


is continuously tracking the engine. Because there are schedule differences between the two controls, backup control errors can exist which ci.id pusition the hydraulic error amplifier (or servovalve) to a saturited c.ndition at the instant of transfer. Thus transfer transients ibluwing a switch from primary operation were of primary concern. Testing to dotermine the transient performance of the backup control consisted of:

- Defining the responses obtained following a transfer to backup from various steady-state and transient conditions

- Defining transfer characteristics upon automatis switching to backup mode by the overspeed switch

- Defining governor action upon modulation of the throttling valve by the valve driven by the hydromechanical speed sensor upon extreme ovirspeed.

Transient behavior following transfer from the primary mode to the backup molu was obtained by establishing an error between the two controls while operating closed-loop. Both small and large errors were intentionally set. Transfers at both steady-state and ramp conditions were made. Typical transient behavior following transfer at steady-state conditions is shown in Figures 61 through 64. As seen on the traces, small errors between the two modec produced only slight momentary transients. Fuel flow peaked approximately 200 pounds per hour rich but recovered to the backupdemanded flow within 0.6 second. Stator transients showed a similar result. With intentional larye errors existing at the instant of transfer, fuel flow merely went to the acceleration or deceleration schedule, causing the simulated engine to accelerate or decelerate normally until fuel flow was modulated to hold speed at the condition demanded by the backup control power lever setting. Stators followed speed with a slight overshoot and undershoot before stabilizing at their new requested position.

Automatic transfers to backup upon overspeed conditions were identical transients to those shown in Figure 64. The system transferred at the proper preset overspeed, and fuel flow responded to the level called for by the power lever.

Figure 65 shows the action of the hydromechanical governor, which acts to close the throttling valve to reduce flow in an extreme overspeed. Fuel flow was cut back at the proper overspeed condition. With the test bench operating closed loop, speed decreased when flow dropped, opening the thrnttling valve. Speed then increased until the overspeed point was reached and flow reduced. A limit cycle with a period of approximately 3.1 seconds was established, with control speed varying between 7000 and $7500 \mathrm{rpm}$. 


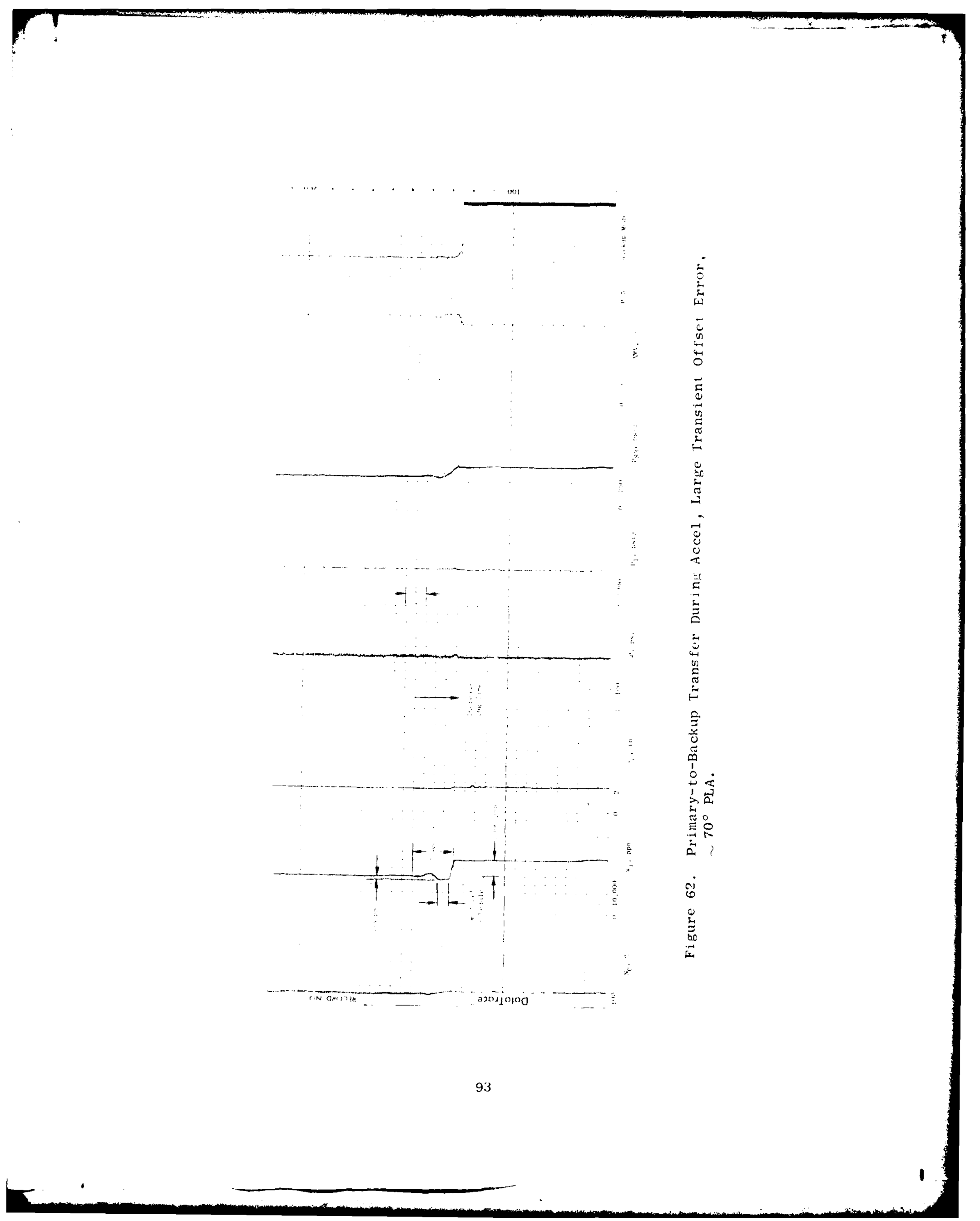




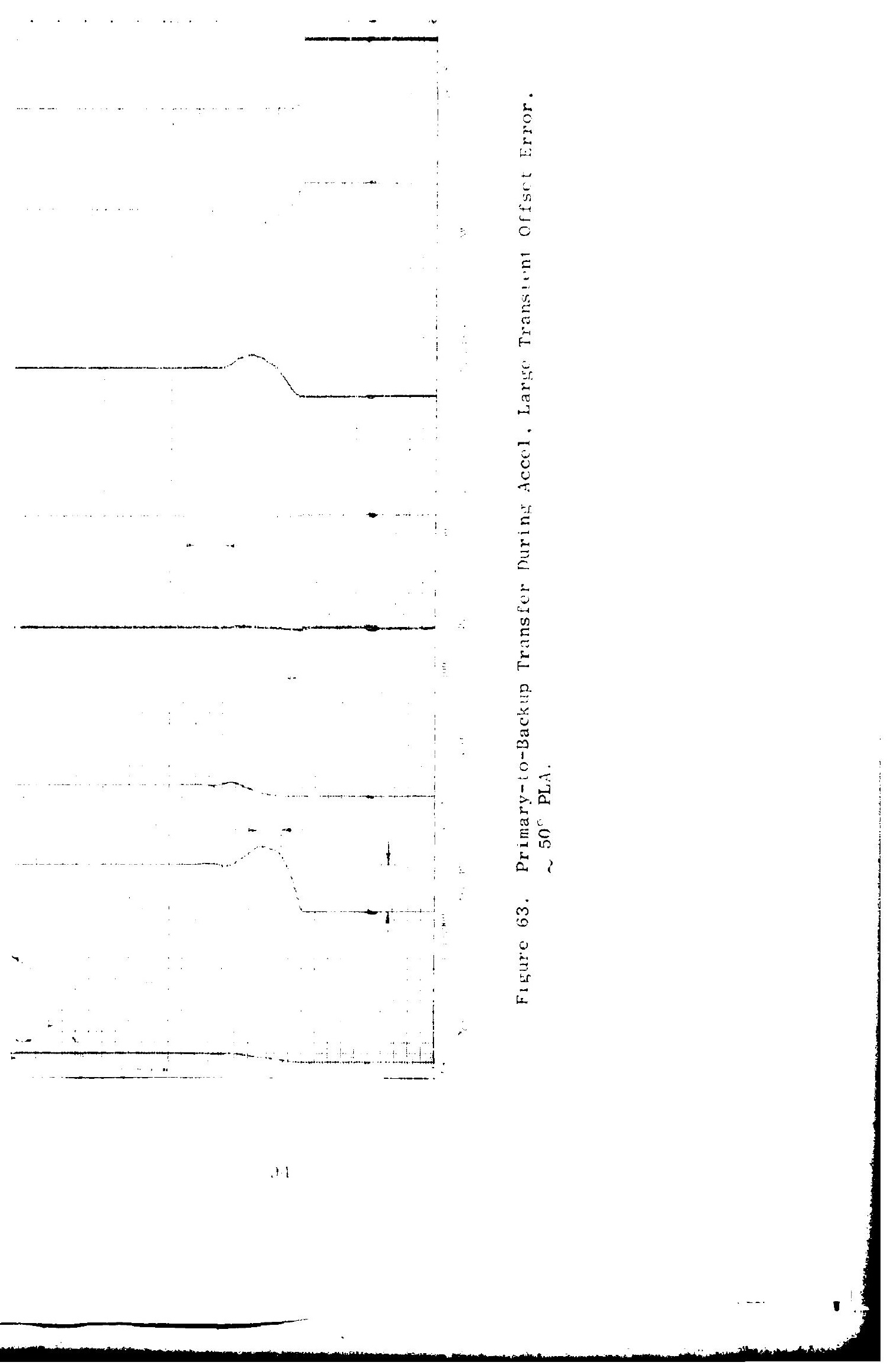




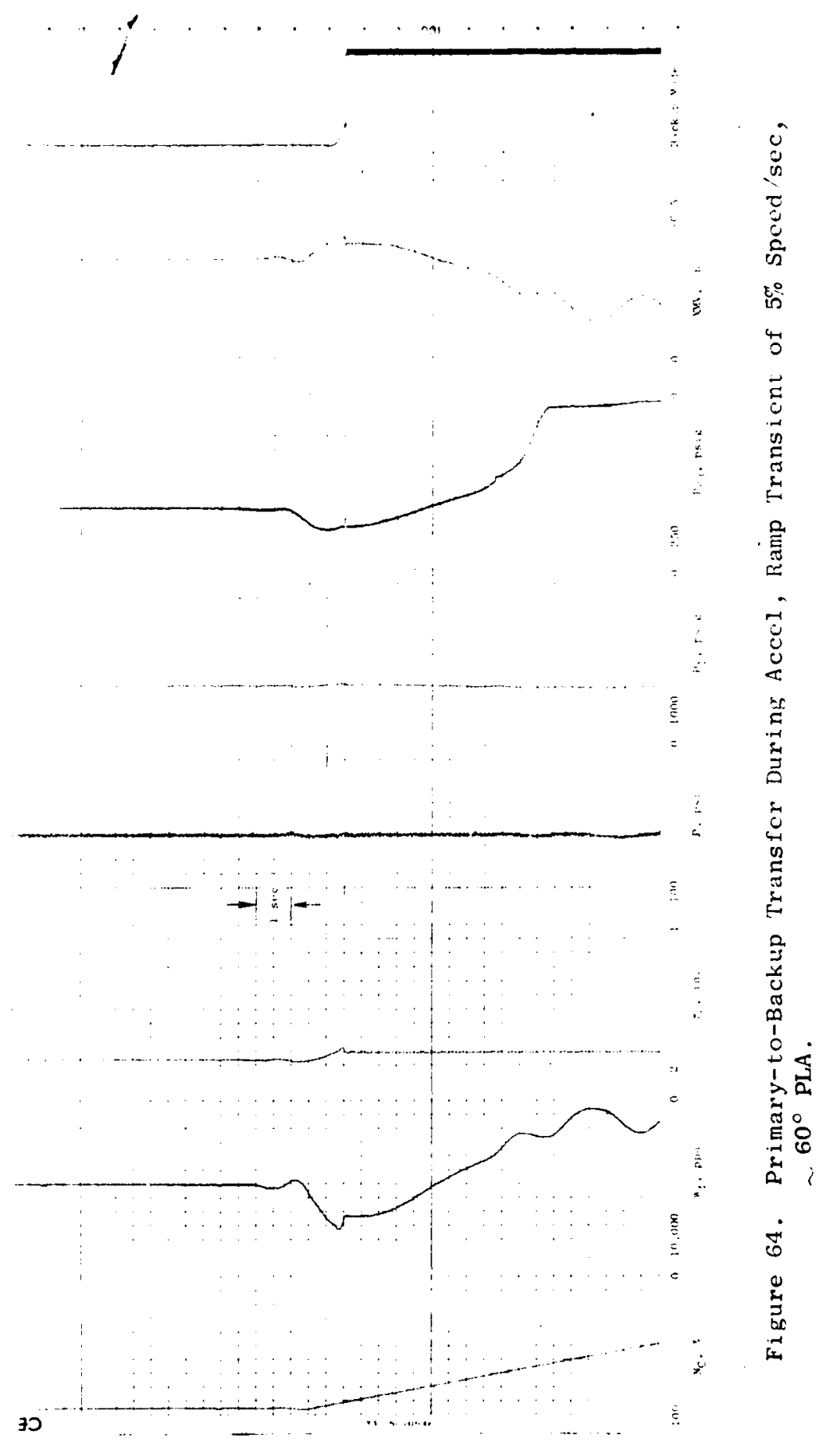

95 


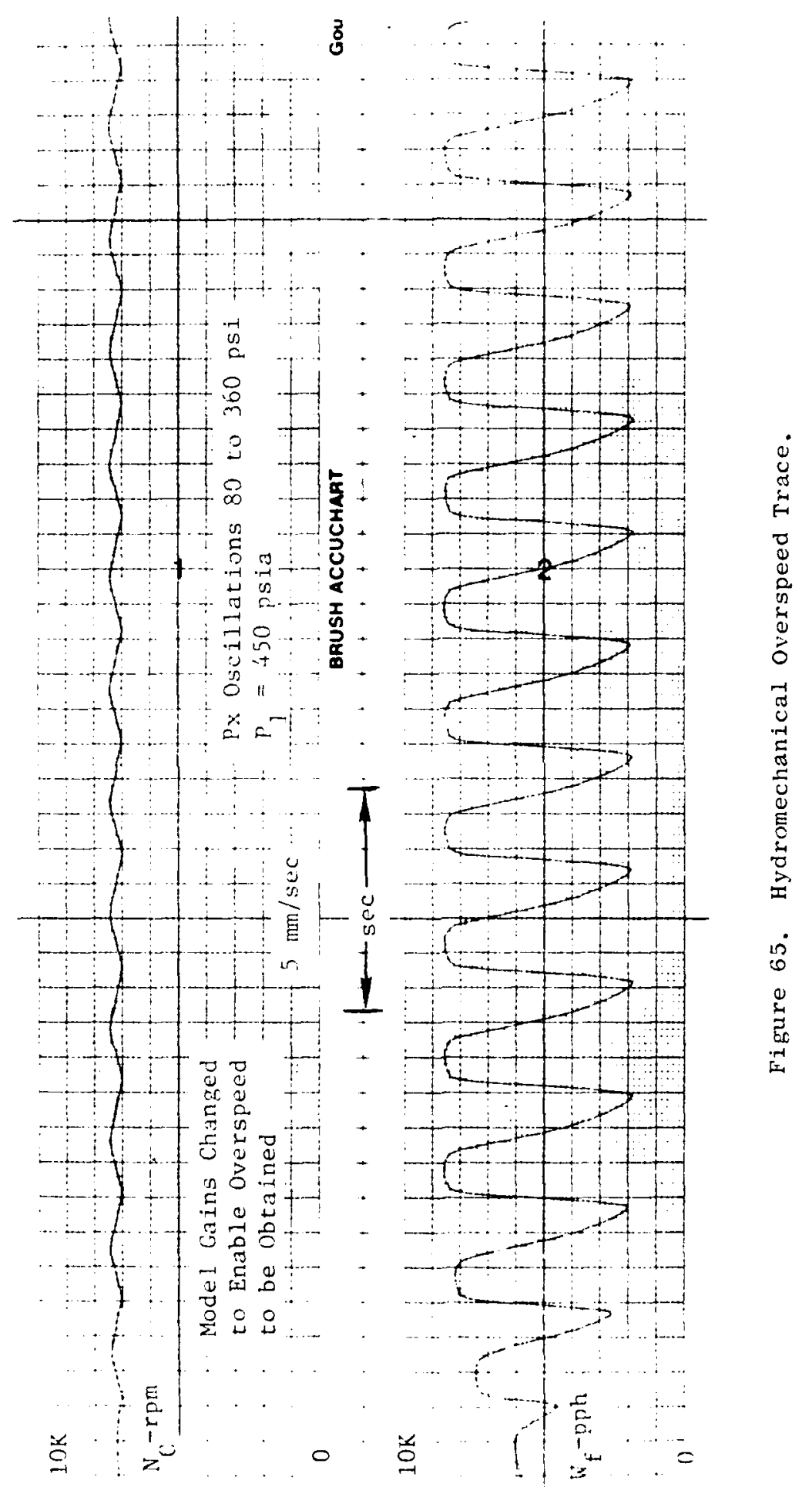




\section{CYCLIC ENDLRANCE}

The planned endurance test consisted of the following steps:

1. Check calibration

2. Run 40 hours of accel/decel cycles

3. Conduct 100 transfers to the backup mode by going overspeed

4. Conduct 10 overspeed transients during which the bydromechanical overspeed valve modulates the throttling valve

\section{Recheck calibration}

Step 2 of this test required operating closed-loop in the backup mode. The power lever was cycled from idle $(70 \% \mathrm{rpm})$ to $\max (100 \% \mathrm{rpm})$ and the engine model plus the test setup caused the drive speed, fuel flow, and $\mathrm{P}_{\mathrm{S} 3}$ to cycle. Temperature $\left(\mathrm{T}_{2.5}\right)$ cycling was not planned.

The calibration check disclosed that accel schedule repeatability was not satisfactory. Lxperimentation indicated that applying current to the primary $h_{f}$ servovalve would change fuel flow a small amount. It was suspected that transfer valve leakage caused a null shift in the flapper servo in the hydromechanical computer. The transfer valve was needed only for Step 3 of the planned endurance test. This portion of the test was conducted first. Speed was ramped successfully 100 tines in the primary mode to the point where the overspeed switch tripped and automatic transfer to the backup mode occurred. The transfer valve was then removed.

The calibration check, with the transfer valve removed, indicated that the repeatability problem was still present. Temperature sensor performance was then checked and the performance was found to be very erratic. As discussed previously, the sensor was installed improperly upon arriving at AEG Evendale. It was now suspected that it had been lamiged during that installation. A suspected cause for the observed action was that the jet pipe was bent, keeping, receiver pressures too low to properly control the sensor servo piston.

The temperature sensor servo pistion was shimmed to the high temperature position. The accel schedule was run twice; the data are shown by Table 2. The repeatability was considered normal. (It should be noted that, for the J85 main fuel control, the fuel flow feedback spring is attached directly to the metering valve. The hackup control has a rack and pinion, a shaft, a cam, and a bell crank between the metering valve and the feedback spring. It is expected that a J85 control would have even better repeatability.) The remainder of the endurance testing was 
TABLE 2.

ACCEL SCHEDULE DATA TAKEN BEFORE

ANI) AFTER THE FNDURANCE TEST

\begin{tabular}{|c|c|c|c|c|c|c|}
\hline $\begin{array}{l}\text { Data } \\
\text { Point }\end{array}$ & $\begin{array}{c}\mathrm{N}_{\mathrm{c}}, \\
\mathrm{rpm}\end{array}$ & $\begin{array}{l}\mathrm{P}_{\text {S3, }} \text {, } \\
\text { psia }\end{array}$ & $\mathrm{P}_{\mathrm{S} 3}^{1}$ & $\begin{array}{c}\text { Before* } \\
W_{f}, \\
\text { pph }\end{array}$ & $\begin{array}{c}\text { Before* } \\
W_{f}, \\
\text { pph }\end{array}$ & $\begin{array}{c}\text { After } \\
w_{f}, \\
p p h\end{array}$ \\
\hline 1 & 6360 & 30.5 & 21.0 & 1404 & 1456 & 1396 \\
\hline 2 & 6360 & 54 & $3<.7$ & 2321 & 2348 & 2302 \\
\hline 3 & 6360 & 67 & 42.7 & 2852 & 2892 & 2857 \\
\hline 4 & 6360 & 90 & 57.1 & 3784 & 3827 & 3798 \\
\hline 5 & 6360 & 104 & 65.9 & 4348 & 4387 & 4341 \\
\hline 6 & 6360 & 114 & 72.2 & 4749 & 4778 & 4736 \\
\hline 7 & 6360 & 144 & 91.2 & 5951 & 5990 & 5913 \\
\hline 8 & 6360 & 176 & 111.3 & 7205 & 7249 & 7177 \\
\hline 9 & 6360 & 222 & 140.8 & 8923 & 8981 & 8942 \\
\hline 10 & 4770 & 54 & 34.7 & 1599 & 1602 & 1567 \\
\hline 11 & 5175 & 67 & 42.7 & 2119 & 2131 & 2096 \\
\hline 12 & 5565 & 90 & 57.2 & 3412 & 3445 & 3440 \\
\hline 13 & 5710 & 104 & 66.0 & 4099 & 4112 & 3972 \\
\hline 14 & 5840 & 114 & 72.3 & 4859 & 4831 & 4805 \\
\hline 15 & 6120 & 1.4 .4 & 91.2 & 5950 & 5971 & 5999 \\
\hline
\end{tabular}

*Second set of calibration data to show repeatability. 
then conducted. This included 1600 accel/decel cycles at 90 seconds per cycle (about 40 hours). The accel data taken after the endurance testing is also shown by Table 2 .

\section{SLMPIRY}

The overall performance of the backup control during the test phase was very satisfactory. A total of 173 bench test hours were accumulated. This testing is a big step in qualifying the backup control for on-engine use.

The test results indicated that some changes should be made to the latching solenoid valve and the transfer valve before the backup control is used on-engine. The latching solenoid valve coils should be replaced with ones capable of withstanding 28 volts continuous duty as originally intendtd. The vendor overlooked a note on the drawing and used coils sulficient for momentary power only. The proper coils would be about 1.5 inches in diameter versus the present 1.0 inch.

The transfer valve leakage affected the backup control $\mathrm{W}_{\mathrm{f}}$ servo. A null shift became evident when current was applied momentarily to the primar: $W_{f}$ servovalve. The transfer valve leakage should be reduced by adding seals to the spool.

The $T_{2} ;$ sensor problem was attributed to damage caused by improper installatioñ. This is a proven component so no changes are recommended. The hysteresis in the speed loop, although higher than desired, is expected to caluse a random but acceptable "wander" during engine test. The expected wander amplitude will be about \pm 55 engine rpm (or $+0.35 \%$ ) at rated engine speed. 
The concept of using gas generator speed demand combined with fuel flow scheduling has provided a practical basis for the variable cycle engine backup control development. Success has been achieved in adapting a control built with hydromechanical iechnology to interface with a primary difital electronic control, thus providing a backup that is free from environmentally induced common failure modes.

Testing of the resulting backup control indicates that satisfactory transient response has been achieved. This backup control has demonstrated the required type of transfer action. It was shown that stall-free transfer can be achieved by having the backup unit continuously compute the controlled variables and thus track the engine operation, in readiness for backup action. These developments have led to a practical and effective backup control.

This techrology places the variable cycle engine one step closer to application reality - especially for the single-engine aircraft application. Finally, this accomplishment makes it reasonable to begin the introduction of full authority digital electronic controls at an earlier stage of weapon system development than would have been practical otherwise. 


\section{SECT LON VII}

\section{RECOMMENDATIONS}

Based on the results achieved by building, testing and evaluating this Backup Control for a variable cycle engine, it is recommended that the activity be continued toward practical engine applications. Cercain design improvements identified during testing could simplify and enhance on-engine usage, and should therefore be incorporated next.

Using the hardware prepared here, the development should proceed directly to on-engine testing using the GE-JTDE, for which the control was designed. Such on-engine measurements should be directed toward obtaining data correlation against a FADEC as the primary control operating a variable cycle engine. 
The subsystem safety (or hazard) analysis identifies the components within the subsystems whose performance degradation or functional failure could result in a hazardous condition. This analysis includes fajlure modes and the effects on safety when failures occur in the subsystem components.

A safety an:lysis has been completed on the backup control subsystem and the results aro given in Table $\mathrm{A}-1$. The hazard levels used herein are as defined in MIL-STD-882 (July 1969):

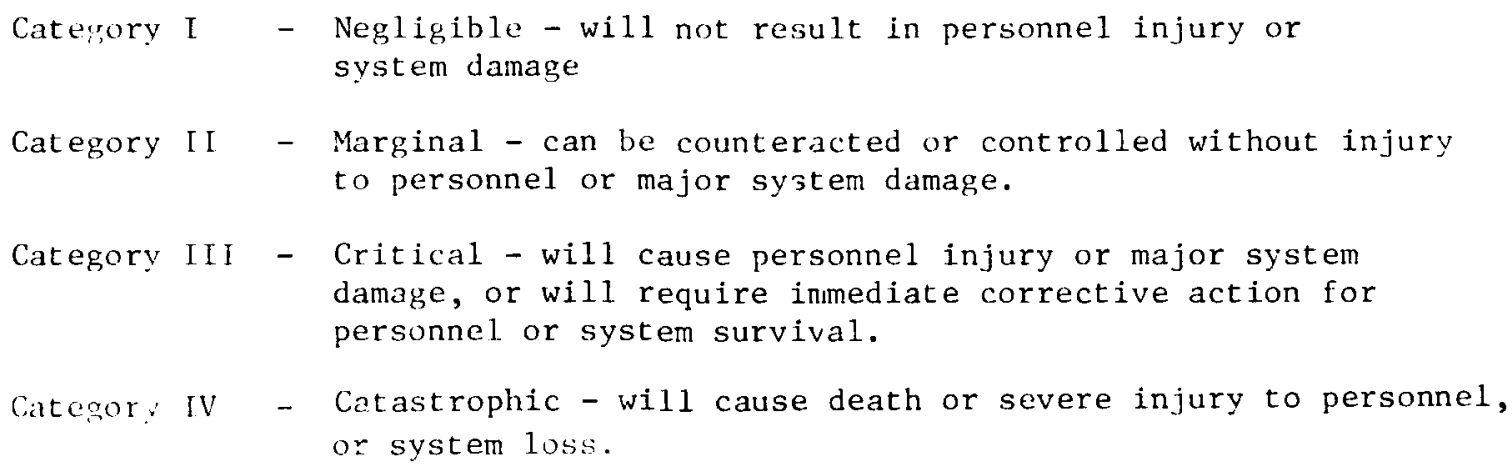




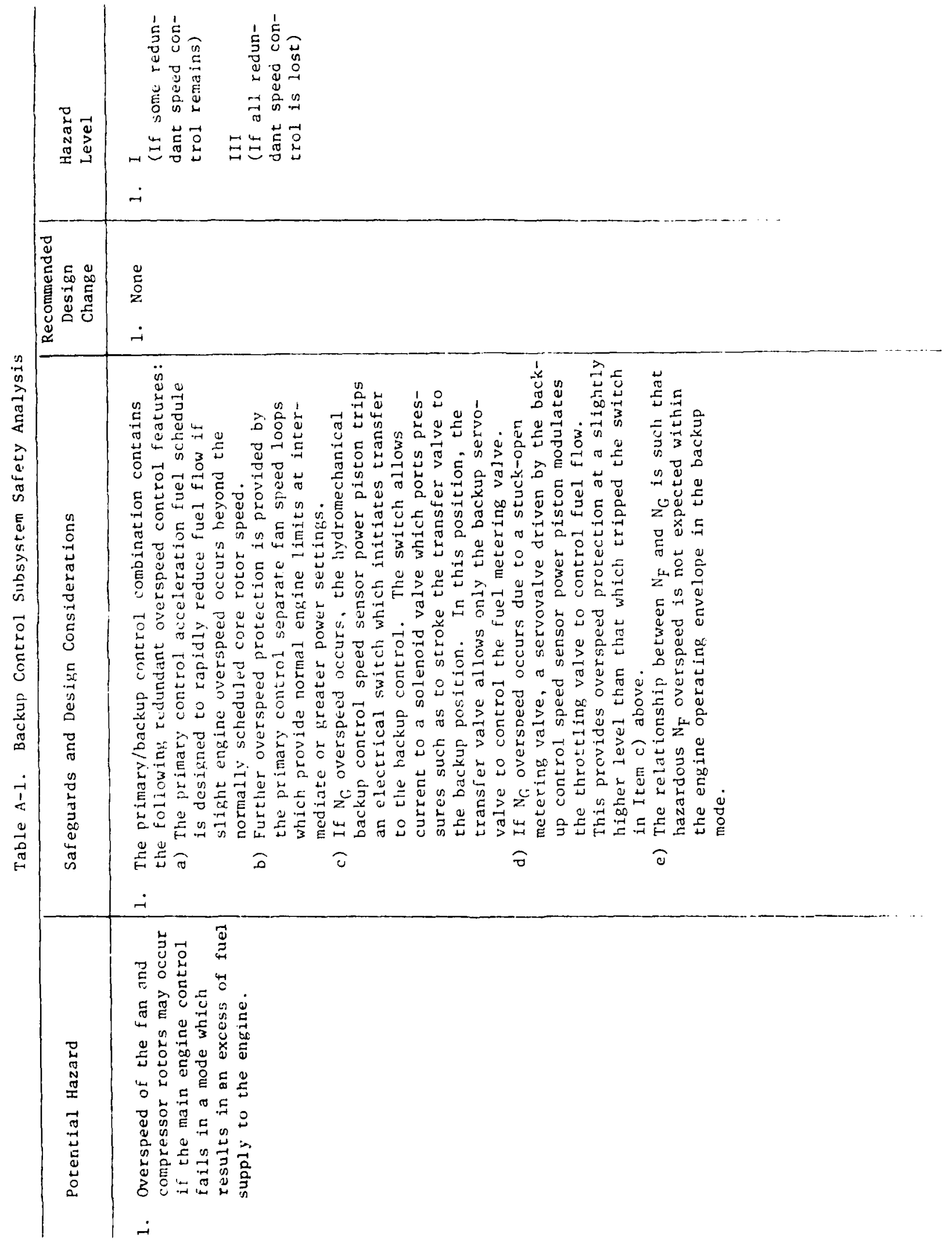




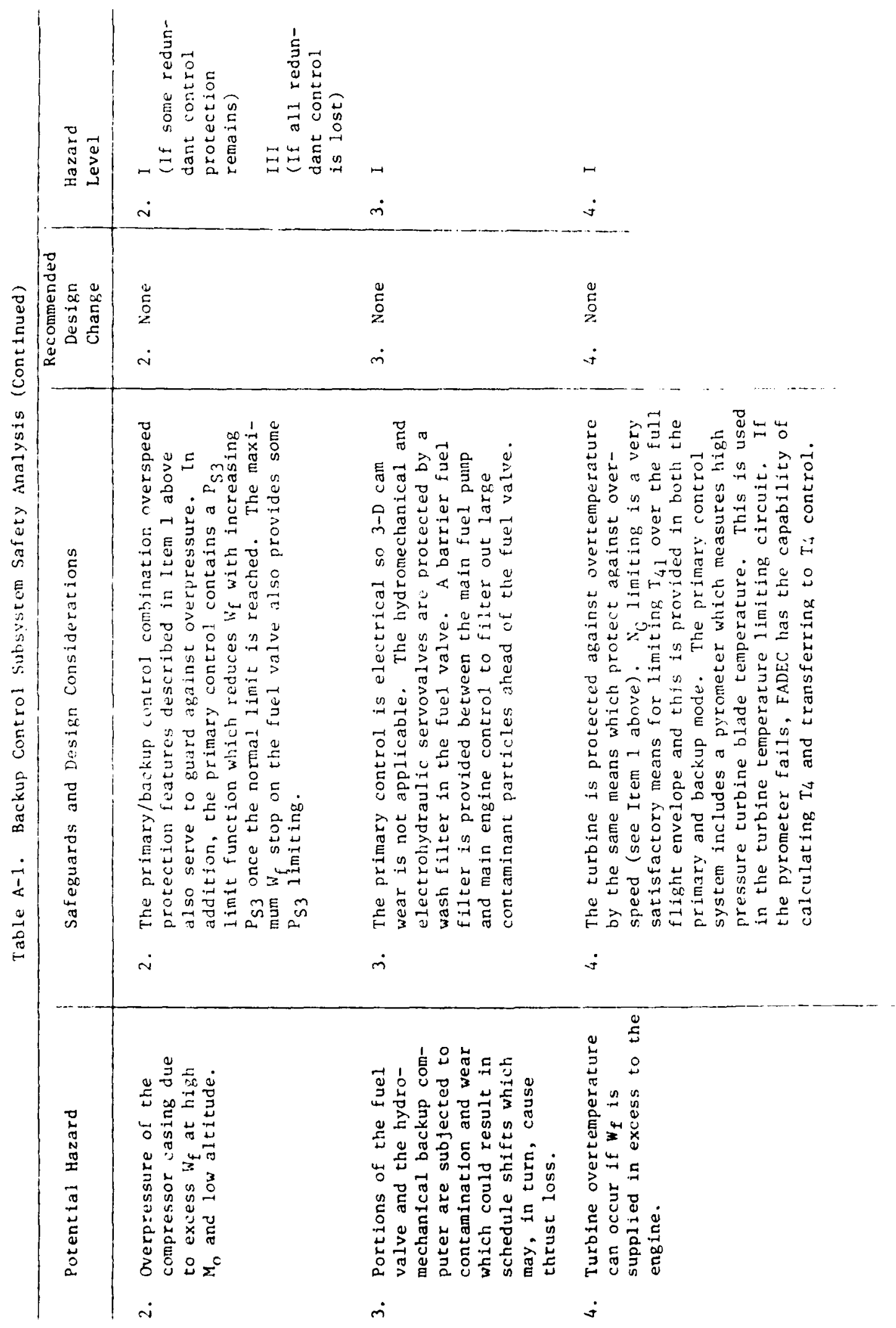




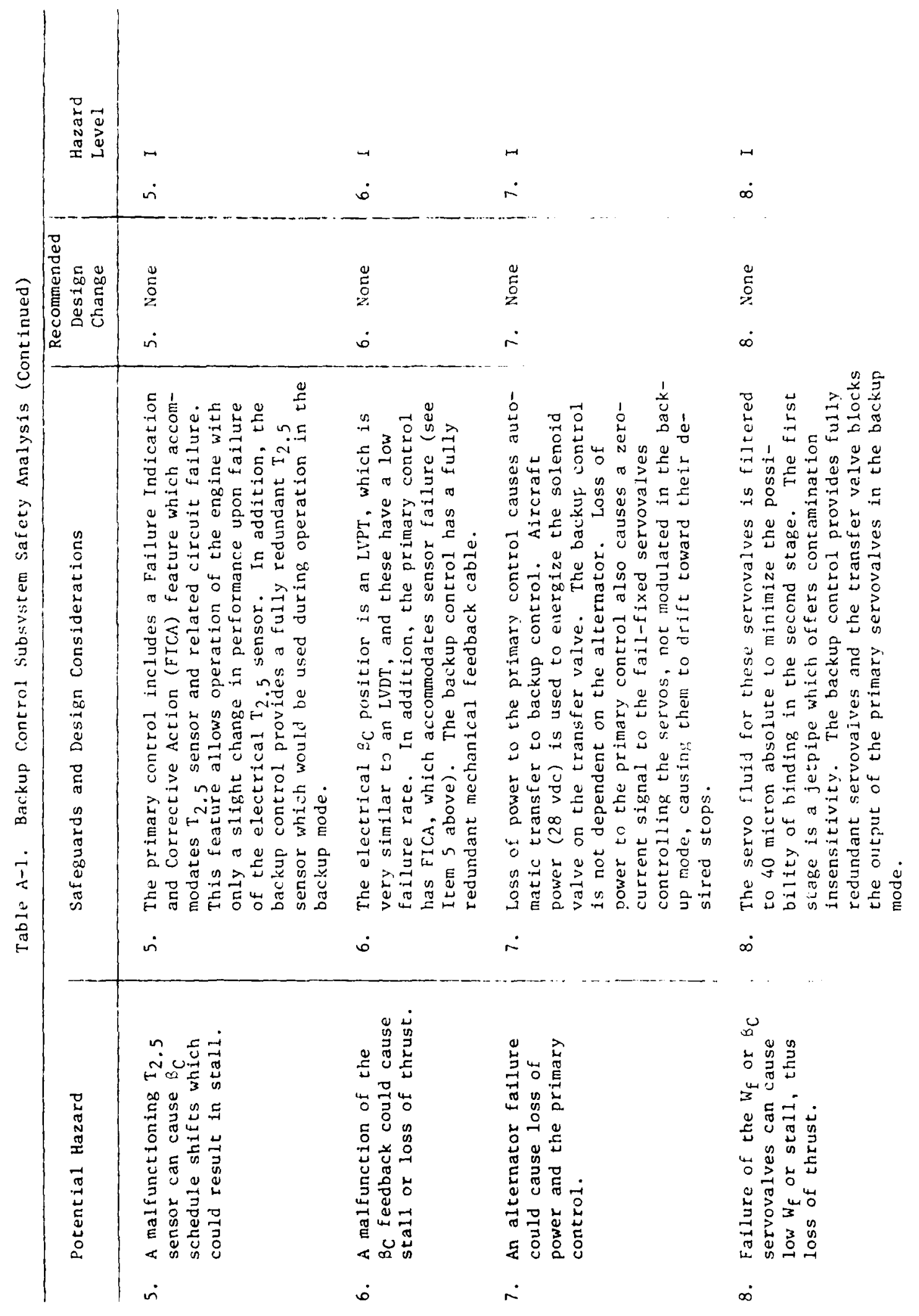




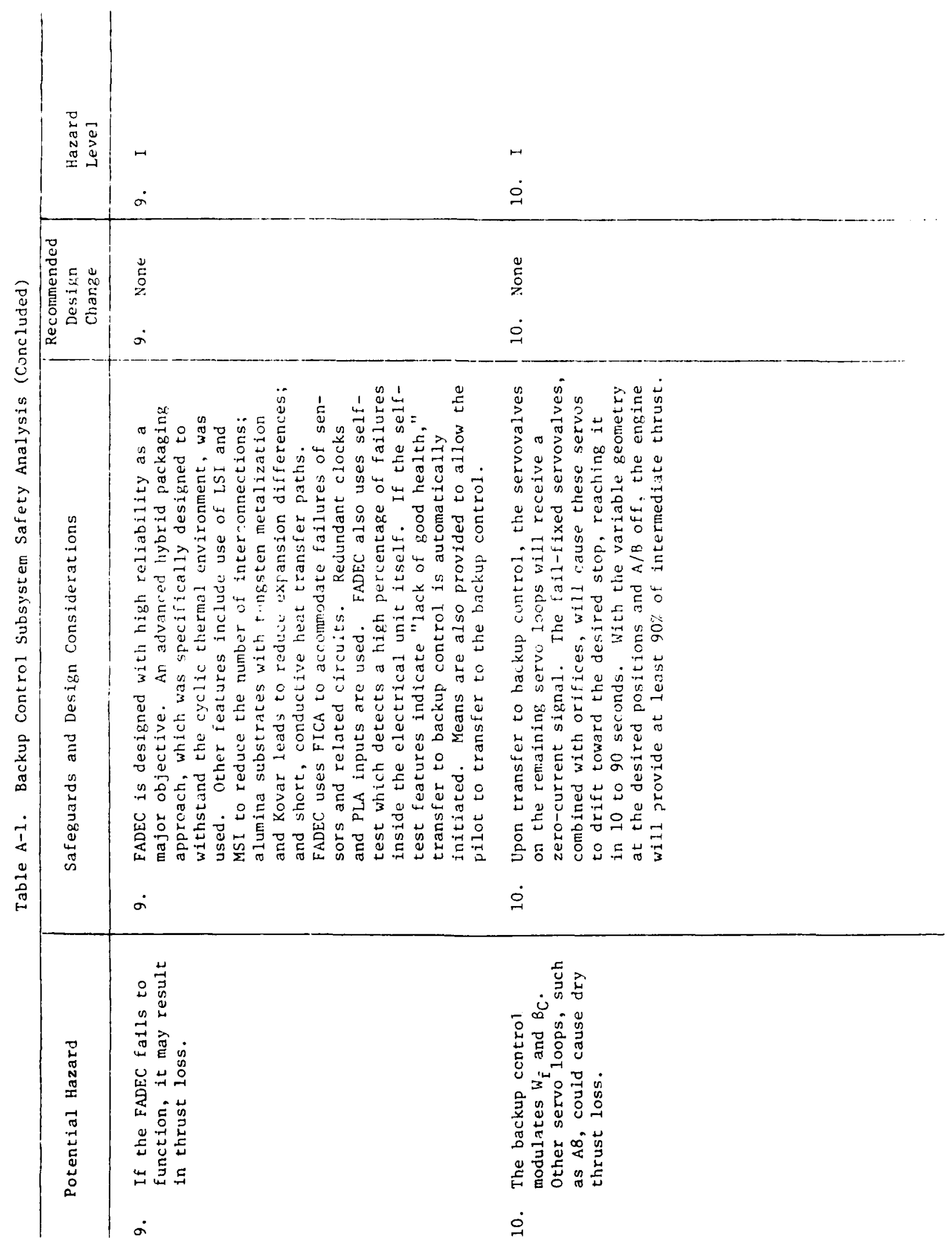


APPENDIX B

CALIBRATION DATA

S/N GAT 06021 
CONTROI. S/N

1. Throttle sitops

a) Set puintor at PLA = 91.5 degreas with 0.0938-inch-diameter pin inserted in cover calibrating hole.

b) Close PLA and check stop location applying $30 \pm 5$ in.-lb of torque. Read PLA $=0$ degrees. Limit: $\quad 0 \pm 0.5$ degrec

c) Open Plat and check max stop location applying $30 \pm 5$ in.-1b of torque. Read $\mathrm{lLA}=115$ degrees. Linit: $115 \pm 0.5$ degree

2. Shutofe Valve

a) Set $P_{1}=350 \pm 5$ psig and shut off lever at 2 degrees.

b) Disconnect outlet fitting and measure leakage.

Leakage* $=275 \mathrm{cc} / \mathrm{min}$.

Limit: $\quad 5 \mathrm{cc} / \mathrm{min}$.

*See Section V, paragraph 2 for an explanation of this observation. 
3. Deceleration sohedule

a) Set PIA = 13 degrees

$$
\begin{aligned}
\Gamma_{2.5} & =224 \pm 5^{\circ} \mathrm{F} \\
\mathrm{N}_{C} & =6130(91 \%) \\
\mathrm{P}_{1} & =800 \pm 20 \text { psig }
\end{aligned}
$$

b) Set $P_{S_{3}}$ and $P_{C}$ as frilows and record $W_{f}$

\begin{tabular}{|c|c|c|c|}
\hline Set $P_{\text {S3 }}$ & Set $P_{c}$ & $W_{f}$ & Limit \\
\hline 93 & 200 & 1290 & $960 / 1440$ \\
80 & 200 & 1190 & $840 / 1260$ \\
60 & 200 & 930 & $620 / 930$ \\
50 & 200 & $800^{* *}$ & $500 / 740$ \\
$* 30$ & 200 & $560^{* *}$ & $300 / 450$ \\
\hline
\end{tabular}

* Check this point by applying 18.9 psia directly to the bellows. The $P_{\text {s }}$ ratio selector takes $63 \%$ of applied pressure accurately down to about 50 psia.

4. Minimum Fuel Flow

a) Set PLA $=13$ degrees, $\mathrm{P}_{\mathrm{S} 3}=15 \pm 1$ psia and $\mathrm{T}_{2.5}$ at
$75+10^{\mathrm{O}} \mathrm{F}$

b) Adjust the minimum flow stop

$$
\begin{aligned}
& \text { Minimum Flow } 280 \text { pph } \\
& \text { Limits - 260/280 pph }
\end{aligned}
$$

${ }^{* *}$ See Section V, paragraph 2, for a discussion of these values. 
5. Maximum and Idle Speed Adjustments

a) Set $\mathrm{T}_{2.5}$ at $224^{\circ} \mathrm{F} \pm 5^{\circ} \mathrm{F}$

b) Set PLA, $P_{S 3}$ absolute, $N_{C}, P_{1}$, and $P_{1}$ as follows and set idle and maximum speed adjustments to get ${ }^{{ }} W_{f}$ within limits. Record measured $W_{f}$.

\begin{tabular}{|c|c|c|c|c|c|c|}
\hline PLA & $P_{\text {S3 }}$ & ${ }^{N_{C}}$ & $P_{1}$ & $P_{c}$ & $W_{f}$ & Instructions \\
\hline 13 & 30 & 3370 & 400 & 200 & 740 & $\begin{array}{l}\text { Set Idle Adjustment } \\
\text { Limits: 600/750 } \\
\text { Set Max Adjustment } \\
\text { Limits: 7700/8500 }\end{array}$ \\
\hline
\end{tabular}




\section{Acceleration Schedule}

Set PLA, $\mathrm{T}_{2} .5, \mathrm{~N}_{\mathrm{C}}, \mathrm{P}_{1}, \mathrm{P}_{\mathrm{c}}$ and $\mathrm{P}_{\mathrm{S} 3}$ absolute as indicated and record resulting $W_{f}$. Barometric Pressure: psia)

\begin{tabular}{|c|c|c|c|c|c|c|c|c|}
\hline $\begin{array}{l}\text { Pt. } \\
\text { No. } \\
1\end{array}$ & $\begin{array}{l}\text { PLA } \\
\text { Deg. } \\
92\end{array}$ & $\begin{array}{l}\mathrm{T}_{2.5} \\
{ }_{\mathrm{F}} \\
224\end{array}$ & $\begin{array}{l}\mathrm{N}_{C} \\
\mathrm{RPM}_{6} \\
6360\end{array}$ & $\begin{array}{l}P_{1} \\
\text { pstg } \\
1000\end{array}$ & $\begin{array}{l}P_{c} \\
\text { psig } \\
200\end{array}$ & $\begin{array}{l}\text { PS3 } \\
\text { psia } \\
* \quad 33\end{array}$ & $\begin{array}{l}\mathrm{w}_{\mathrm{f}} \\
\mathrm{pph} \\
1260\end{array}$ & $\begin{array}{l}W_{f} \\
\text { Limits, pph } \\
1270 / 1430\end{array}$ \\
\hline 2 & 92 & 224 & 6360 & 1000 & 250 & 54 & 2120 & $2080 / 2340$ \\
\hline 3 & 92 & 224 & 6360 & 1000 & 250 & 67 & 2610 & $2575 / 2900$ \\
\hline 4 & 92 & 224 & 6360 & 1000 & 300 & 90 & 3530 & $3460 / 3900$ \\
\hline 5 & 92 & 224 & 6360 & 1000 & 400 & 104 & 4060 & $4000 / 4500$ \\
\hline 6 & 92 & 224 & 6360 & 1000 & 400 & 114 & 4440 & $4380 / 4970$ \\
\hline 7 & 92 & 224 & 6360 & 1000 & 500 & 144 & 5630 & $5540 / 6240$ \\
\hline 8 & 92 & 224 & 6360 & 1000 & 500 & 176 & 6800 & $6770 / 7630$ \\
\hline 9 & 92 & 224 & 6360 & 1000 & 600 & 222 & 8540 & $8540 / 9625$ \\
\hline 10 & 92 & 224 & 4770 & 500 & 200 & 54 & 1740 & $1580 / 2780$ \\
\hline 11 & 92 & 224 & 5175 & 500 & 250 & 67 & 2210 & $2010 / 2270$ \\
\hline 12 & 92 & 224 & 5565 & 750 & 300 & 90 & 3290 & $2930 / 3300$ \\
\hline 13 & 92 & 224 & 5710 & 750 & 400 & 104 & 3950 & $3480 / 3920$ \\
\hline 14 & 92 & 224 & 5840 & 1000 & 700 & 114 & 4620 & $3990 / 4500$ \\
\hline 15 & 92 & 224 & 6120 & 1000 & 500 & 144 & 5620 & $5410 / 6100$ \\
\hline
\end{tabular}

*Apply 21.0 psia direct1y to bellows chamber for this test point. 
7. Core Stator Schedule, $R_{c}$

a) Set PLA $=92$ degrees

$\mathbf{P}_{\text {S3 }}=30$ psia

$P_{\mathrm{c}}=200 \mathrm{psi}$

$P_{1}=500 \mathrm{psi}$

b) Set $T_{2.5}$ and $\mathrm{N}_{C}$ as indicated and measure arm position.

$\begin{array}{ll} & \mathrm{T}_{2.5} \text { Sensor } \\ \text { Point } & \mathrm{S} / \mathrm{N} \text { RPA }-04660\end{array}$

No.

1

2

3

4

5

6

7

8

9

10

11

12

13

14

15

Hys teresis
$\mathrm{T}_{2.5}$

56

84

120

157

224

335

157

84

56

157

157

157

157

157

157
${ }^{N} \mathrm{C}$

6053

6220

6448

6668

6847

6809

6668

6448

6220

5739

6303

5634

4468

4125

6303
Ret. Arm Pos. $=0.847$

Limits: $\quad 0.827 / 0.867$

F/B Cable Pos.

Test

Limits

0.720

$.680 / .720$

0.722

$.680 / .720$

0.723

$.680 / .720$

0.720

$.680 / .720$

0.670

$.625 / .672$

$.465 / .523$

0.707

$.680 / .720$

0.724

$.680 / .720$

0.722

$.580 / .720$

$.698 / .743$

$.563 / .616$

$.362 / .422$

$0 / .080$

0 (max)

$.563 / .616$

$7-4=$

$+0.013$

Limit-

$8-2=$

$+0.002$

$\pm .015$

9-1=

$+0.002$

$15-11=$ 
7. Core Stator Schedule, $B_{C}$

a) Set PLA $=92$ degrees

$$
\begin{aligned}
& \mathbf{P}_{\mathbf{S 3}}=30 \mathrm{psia} \\
& \mathbf{P}_{\mathbf{C}}=200 \mathrm{psi} \\
& \mathbf{P}_{\mathbf{l}}=250 \mathrm{psig}
\end{aligned}
$$

b) Set $T_{2} .5$ and $N_{C}$ as indicated and measure arm position.

\begin{tabular}{|c|c|c|}
\hline $\begin{array}{c}\text { Point } \\
\text { No. }\end{array}$ & $\mathrm{T}_{2.5}$ & psi \\
\hline 1 & 56 & 119 \\
\hline 2 & 84 & 125 \\
\hline 3 & 120 & 132 \\
\hline 4 & 157 & 139 \\
\hline 5 & 224 & 152 \\
\hline 6 & 335 & 175 \\
\hline 7 & 157 & 139 \\
\hline 8 & 84 & 125 \\
\hline 9 & 56 & 119 \\
\hline 10 & 157 & 139 \\
\hline 11 & 157 & 139 \\
\hline 12 & 157 & 139 \\
\hline 13 & 157 & 139 \\
\hline 14 & 157 & 139 \\
\hline 15 & 157 & 139 \\
\hline
\end{tabular}

$\mathrm{T}_{2.5}$ Sensor Simulator

$$
S / N \quad 11-3 A
$$

Hys teresis
Ret. Arm Pos. $=0.847$

Limits: $0.827 / 0.867$

F/B Cable Pos 0.847

${ }^{\mathrm{N}}$

6053

6220

6448

6668

6847

6809

6668

6448

6220

6739

6303

5634

4468

4125

6303

$7-4=$

$8-2=$

9-1 =

$15-11=$

Test

Limits

0.715

$.680 / .720$

0.718

0.720

0.717

0.667

$.625 / .672$

0.488

$.465 / .523$

.0703

$.680 / .720$

0.720

$.680 / .720$

0.718

$.580 / .720$

0.720

$.698 / .743$

0.622

$.563 / .616$

0.402

0.026

$.362 / .422$

$0 / .080$

$-0.075$

0 (max)

0.614

$.563 / .616$

Limi t-

$\pm .015$

$$
\begin{array}{r}
0.014 \\
+0.002
\end{array}
$$

$+0.003$

$-0.008$ 
8. Droop Lines

a) Set $T_{2.5}=75 \pm 10^{\circ} \mathrm{F}$

b) Set PLA, $P_{S 3}, N_{C}$, and $P_{c}$ as indicated and record $w_{f}$.

$\begin{array}{lccccc}\text { PLA } & P_{S 3} & P_{C} & N_{C} & W_{f} & W_{f} \\ 13 & 30 & 200 & 3170 & 860 & \\ 13 & 30 & 200 & 3270 & \mathbf{7 8 0} & \\ 13 & 30 & 200 & 3370 & 690 & \mathbf{6 0 0 / 7 5 0} \\ 13 & 30 & 200 & \mathbf{3 4 7 0} & 610 & \\ 13 & 30 & 200 & 3370 & \mathbf{6 1 0} & \\ 92 & 217 & 500 & 6540 & \mathbf{8 2 8 0} & \\ 92 & 217 & 500 & \mathbf{6 6 4 0} & \mathbf{8 2 9 0} & \\ 92 & 217 & 500 & \mathbf{6 7 3 9} & \mathbf{8 1 5 0} & \mathbf{7 7 0 0 / 8 5 0 0} \\ 92 & 217 & 500 & 6840 & \mathbf{7 7 2 0} & \\ 92 & 217 & 500 & \mathbf{6 7 3 9} & \mathbf{8 0 0 0} & \mathbf{7 7 0 0 / 8 5 0 0}\end{array}$


9. Electrical Overspeed Signal

a) Attach a continulty checker across pins one and two at the overspeed switch connector.

b) Increase $N_{C}$ until continuity occurs.

$$
\begin{aligned}
& \text { Indicated } N_{C} 7020 \mathrm{rpm} \\
& \text { Limits }-6975 / 7040
\end{aligned}
$$

10. Hydromechanical Overspeed Limit

a) Set $P_{1}=1000$ psig

$\mathbf{P}_{\mathrm{c}}=500 \mathrm{psig}$

$\mathbf{P}_{\mathrm{S3}}=217 \mathrm{psia}$

$\mathrm{T}_{2.5}=75 \pm 10^{\circ} \mathrm{F}$

b) Increase $N_{C}$ unt1l $w_{f}$ is $500 \pm 100 \mathrm{pph}$.

$$
\begin{aligned}
& \text { Indicated } N_{C} 7196 \mathrm{rpm} \\
& \text { Limits- } 7175 / 7245
\end{aligned}
$$


1. Kast, Howard B., Hurtle, James E., and Poppel, Gary L., "Backup Control for a Variable Cycle Engine," Phase I Interim Technical Report, Air Force Aero Propulsion Laboratory, AFAPL-TR-77-92, December 1977. 


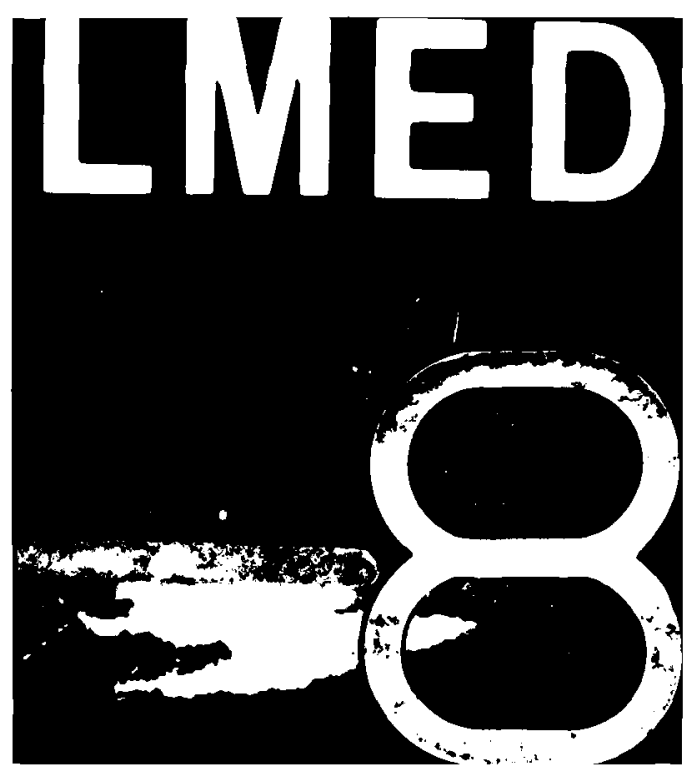

